\title{
Induction of osteogenesis by bone-targeted Notch activation
}

Cong $\mathrm{Xu}^{1, *}$, Van Vuong Dinh ${ }^{1, *}$, Kai Kruse ${ }^{1}$, Hyun-Woo Jeong ${ }^{1}$, Emma C. Watson $^{1}$, Susanne Adams $^{1}$, Frank Berkenfeld ${ }^{1}$, Martin Stehling ${ }^{2}$, Seyed Javad Rasouli ${ }^{1}$, Rui Fan $^{3}$, Rui Chen ${ }^{3}$, Ivan Bedzhov $^{3}$, Qi Chen ${ }^{1}$, Katsuhiro Kato ${ }^{1}$, Mara E. Pitulescu ${ }^{1, \#}$, and Ralf H. Adams ${ }^{1, \#}$

${ }^{1}$ Max Planck Institute for Molecular Biomedicine, Department of Tissue Morphogenesis, and University of Münster, Faculty of Medicine, D-48149 Münster, Germany

${ }^{2}$ Flow Cytometry Unit, Max Planck Institute for Molecular Biomedicine, D-48149 Münster, Germany

${ }^{3}$ Embryonic Self-Organization Research Group, Max Planck Institute for Molecular Biomedicine, D48149 Münster, Germany

"These authors contributed equally.

${ }^{\#}$ Authors for correspondence:

Ralf H. Adams, PhD

Department of Tissue Morphogenesis

Max-Planck-Institute for Molecular Biomedicine, D-48149 Münster, Germany

Phone: +49 25170365 400, E-Mail: ralf.adams@mpi-muenster.mpg.de

Mara E. Pitulescu, PhD

Department of Tissue Morphogenesis

Max-Planck-Institute for Molecular Biomedicine, D-48149 Münster, Germany

5 Phone: +49 25170365 425, E-Mail: mara.pitulescu@ mpi-muenster.mpg.de 
Declining bone mass is associated with aging and osteoporosis, a disease characterized

9 by progressive weakening of the skeleton and increased fracture incidence. Growth and

10 lifelong homeostasis of bone rely on interactions between different cell types including

11 vascular cells and mesenchymal stromal cells (MSCs). As these interactions involve Notch

12 signaling, we have explored whether treatment with secreted Notch ligand proteins can

13 enhance osteogenesis in adult mice. We show that a bone-targeting, high affinity version of

14 the ligand Delta-like 4, termed Dll4 $(\mathrm{E} 12)$, induces bone formation in male mice without causing

15 adverse effects in other organs, which are known to rely on intact Notch signaling. Due to

16 lower bone surface and thereby reduced retention of $\mathrm{Dll}_{(\mathrm{E} 12)}$, the same approach failed to

17 promote osteogenesis in female and ovariectomized mice but strongly enhanced trabecular

18 bone formation in combination with parathyroid hormone. Single cell analysis of stromal cells

19 indicates that $\mathrm{Dll4}_{(\mathrm{E} 12)}$ primarily acts on MSCs and has comparably minor effects on

20 osteoblasts, endothelial cells or chondrocytes. We propose that activation of Notch signaling

21 by bone-targeted fusion proteins might be therapeutically useful and can avoid detrimental

22 effects in Notch-dependent processes in other organs. 


\section{INTRODUCTION}

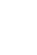

Osteoporosis is the most common disease affecting the skeletal system in humans and characterized by low bone mass, reduced mineral density and disarranged bone microarchitecture. This reduces bone strength and increases the risk of fractures, which leads to secondary health problems and increased mortality ${ }^{1,2}$. The skeletal system is undergoing lifelong remodeling mediated by bone-forming osteoblasts and bone-resorptive osteoclasts ${ }^{3}$. Disbalance between bone formation and resorption can lead to osteopenia, the loss of bone density, and frequently progresses into osteoporosis ${ }^{4}$. Anti-osteoporosis therapies are either anabolic, by enhancing osteoblast activity, or anti-resorptive, involving the inhibition of osteoclast activity. FDA approved osteoclast inhibitors include bisphosphonates, such as Alendronate, Risedronate, Ibandronate and Zoledronic acid ${ }^{5-8}$ but also the peptide hormone calcitonin $^{9}$ and the female sex hormone estrogen ${ }^{10}$, whereas a peptide fragment of parathyroid hormone (PTH1-34) and monoclonal antibodies inhibiting sclerostin are used in the clinic to increase bone formation ${ }^{11-14}$. Apart from specific drawbacks of individual drugs, systemic administration generally facilitates the emergence of adverse side effects, which could be potentially avoided by directing therapeutic agents to bone. Examples include L-Asphexapeptide conjugated-estradiol (E2) $)^{15,16}$ and conjugates of prostaglandin E2 and bisphosphonate ${ }^{17}$. These drugs contain targeting moieties made of either synthetic bisphosphonates or repeats of negatively-charged glutamate (Glu) or aspartate (Asp) amino acid residues, which show high affinity binding to hydroxyapatite, a main component of mineralized bone ${ }^{18}$. Apart from enrichment in the skeletal system, the modified drugs show reduced plasma retention, which limits adverse effects after administration ${ }^{15,16,19}$. However, the efficacy of these drugs still requires clinical validation and there is still high demand for novel and effective anti-osteoporosis drugs. 
Notch signaling is an evolutionary conserved pathway with numerous functional roles including the regulation of osteogenesis. In mammals, there are 4 Notch receptors, namely Notch 1-4, and 5 ligands belonging either to the Jagged/Serrate (Jag1, Jag2) or the Delta-like subfamily (D111, D113 and D114) ${ }^{20}$. As both receptors and ligands are transmembrane proteins, their interaction requires cell-cell contact and triggers ligand internalization, which is necessary for Notch receptor activation ${ }^{21-23}$. Soluble fragments containing the ligand extracellular domain can bind Notch but fail to induce receptor activation and thereby effectively act as antagonists ${ }^{21,22}$. In skeletal development, Notch signaling in limb mesenchyme controls the maintenance and proliferation of mesenchymal progenitor cells and prevents premature osteoblastic differentiation ${ }^{24,25}$. Context-specific Notch signaling also plays important roles in osteoclast differentiation and function ${ }^{26}$. Notch activity in bone marrow (BM) macrophages inhibits commitment to osteoclast differentiation, but it enhances the maturation and function of committed osteoclast precursors ${ }^{27,28}$. Notch is generally a negative regulator of endothelial cell (EC) proliferation and vascular growth, but exerts the opposite function in bone and promotes the formation of type $\mathrm{H}$ vessels. This capillary subtype is associated with osteoblast lineage cells and enhances osteogenesis by providing growth factors and other signals ${ }^{23,29-31}$.

The reports above suggest that Notch activation, e.g. through the administration of exogenous ligand molecules, might have the capacity to enhance bone formation. Given the many functional roles of Notch signaling in different organs and processes, it would be desirable to preferentially direct soluble Notch ligands to bone and thereby limit potentially harmful side effects elsewhere in the body. Here, we report the generation of a soluble, bonetargeted fusion protein, termed Dl14 $(\mathrm{E} 12)$, combining the extracellular domain $(\mathrm{ECD})$ of Deltalike 4 (Dll4), several point mutations to increase affinity for Notch receptors ${ }^{32}$, and a negatively charged poly-aspartate peptide motif $\left(\mathrm{Asp}_{8 \mathrm{x}}\right)$ mediating binding to hydroxyapatite.

74 We show that $\mathrm{Dll4}_{(\mathrm{E} 12)}$ increases bone formation in male adult mice without inducing adverse 
effects in other organs that have been previously linked to compromised Notch function. The same approach fails to enhance osteogenesis in female and ovariectomized mice, which we attribute to the lower bone surface and reduced retention of bone-targeted ligand in these animals. In contrast, bone formation in response to PTH is strongly enhanced by $\mathrm{Dll4}_{(\mathrm{E} 12)}$ in female mice. Based on the histological analysis of Dll4 $(\mathrm{E} 12)$-treated tissue samples as well as immunohistological and single cell RNA sequencing (scRNA-seq) analysis of bone stromal cell populations, we conclude that $\mathrm{D}_{114_{(\mathrm{E} 12)}}$ is safe and can be used to activate Notch signaling in bone mesenchymal stromal cells leading to enhanced osteogenesis.

\section{RESULTS}

\section{Generation and characterization of soluble, bone-binding Dll4}

Notch signaling plays important roles in the maintenance of mesenchymal progenitor cells and the coupling of angiogenesis and osteogenesis in the developing skeletal system ${ }^{23-}$ ${ }^{25,29}$. To explore whether Notch activation might be therapeutically useful to enhance bone formation in the adult organism, we generated a fusion construct comprising the ECD of Dll4, a critical Notch ligand in ECs, a cassette of poly-histidine epitope tags (His $6 \mathrm{x}$ ) enabling protein purification and detection, and a carboxyterminal stretch of 8 aspartic acid residues $\left(\mathrm{Asp}_{8 \mathrm{x}}\right)$ mediating binding to hydroxyapatite (Dll4-Asp $8 \mathrm{x}$ ) (Figure 1A). Expression and molecular weight of the secreted protein was validated by expression in HEK293 cells followed by sodium dodecyl sulfate polyacrylamide gel electrophoresis (SDS-PAGE) of the culture supernatant (Figure 1-figure supplement 1A). Previous work has established that soluble Notch ligands lack the capacity to activate their corresponding receptors and act as inhibitors blocking the interaction between endogenous, membrane-anchored Delta/Jagged ligands and Notch receptors ${ }^{21,22}$. As expected, Dll4-Asp $8 x$ inhibits the expression of established Notch target genes in confluent human umbilical vascular endothelial cells 
101 (HUVECs) in vitro (Figure 1-figure supplement 1B). When culture dishes were pre-coated with poly-L-Lysine enabling the binding of negatively charged molecules, Dll4-Asp 8 acts as an activator and induces the transcription of Notch target genes in sub-confluent HUVECs (Figure 1-figure supplement 1C). These data indicate that Dll4-Asp $\mathrm{px}_{8 \mathrm{x}}$ can interact with Notch receptors and that immobilization via the $\operatorname{Asp}_{8 \mathrm{x}}$ motif enables Notch activation in cultured 106 cells.

For in vivo experiments in mice, a cDNA encoding Dll4-Asp $8 \mathrm{x}$ was cloned into the vector $p L I V E$, which mediates constitutive protein expression in liver after hydrodynamic tail

vein injection ${ }^{27}$. Immunohistological characterization of sectioned $p L I V E-D l l 4-A s p_{8 x}$-treated

110 femurs isolated from male mice at 2 days post-injection (dpi) and 3 weeks post-injection (wpi)

111 shows strong Dll4 signals at trabecular bone, the endosteum lining the inner surface of

112 compact bone, and around distal vessel buds in proximity of the growth plate. In contrast, no 113 comparable signals are seen in samples from male control animals (Figure 1-figure 114 supplement $2 \mathrm{~A}-\mathrm{C}$ and Figure 1-figure supplement 3A). These data confirm the successful 115 expression of recombinant Dll4-Asp $8 \mathrm{x}$ in vivo and binding of the fusion protein to bone.

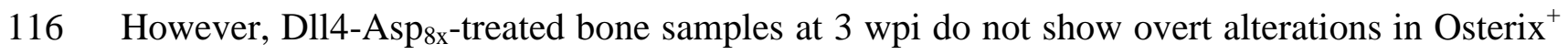
117 osteoblast lineage cells and deposition of the matrix proteins Osteopontin (Opn) and Collagen 118 I alpha 1 chain (Colla1) (Figure 1-figure supplement 3B).

\section{Generation of a high affinity Dll4 fusion protein}

To address the possibility that Dll4-Asp $8 \mathrm{x}$ does not achieve sufficient levels of Notch

122 activation in bone, we also generated a high affinity variant of this protein by introducing multiple point mutations into the Dll4 ECD, which were previously reported to enhance

124 Notch binding and signaling ${ }^{32}$ (Figure 1A and Figure 1-figure supplement 4A). Following 125 expression in HEK293 cells, SDS-PAGE confirmed the correct molecular weight of the 126 resulting Dll4 (E12) $_{\text {version of Dll4-Asp }}$ in in culture supernatants (Figure 1-figure supplement 
4B). Purified and soluble Dl14 ${ }_{(\mathrm{E} 12)}$ inhibits endogenous Notch signaling in cultured HUVECs similar to Dll4-Asp $8 x$, whereas Dll4 $_{(\mathrm{E} 12)}$ in combination with poly-L-Lysine pre-coating induces the upregulation of Notch target genes (Figure 1-figure supplement 4C and D). To overexpress D1l4 (E12) $_{\text {in vivo, a cDNA encoding Dll4 }}(\mathrm{E} 12)$ was cloned into the $p L I V E$ vector and the resulting $p L I V E-D l l 4_{(E 12)}$ construct was administered to male mice via hydrodynamic tail vein injection. Western blot analysis of liver lysates confirmed the expression of Dl14 $4_{(\mathrm{E} 12)}$ at 3 wpi (Figure 1-figure supplement 4E). Consistent with the hydroxyapatite-binding properties of Dll4-Asp 8 , immunohistological analysis of femurs confirm the accumulation of Dll4 ${ }_{(\mathrm{E} 12)}$ at the surface of trabecular and cortical bone (Figure 1B). Notably, histological analysis also reveals a strong increase in the Col1a1-positive area in $p L I V E-D l l 4_{(E 12)}$-injected mice (Figure 1C). Micro-computed tomography $(\mu-\mathrm{CT})$ and histomorphometric analysis show significant increases in bone mass and density (bone volume over total volume; BV/TV), connectivity

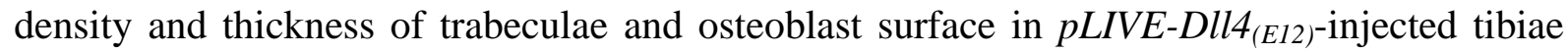
(Figure 1D, E). However, no significant changes are observed in trabecular separation, trabecular number and erosion surface (Figure 1E). In vivo double calcein labeling further argues for enhanced bone formation in mice treated with $\mathrm{Dll4}_{(\mathrm{E} 12)}$ (Figure 1F). Together, these results show that key parameters of bone quality can be enhanced by expression of a soluble, hydroxyapatite-binding version of Dll4 with high affinity for Notch receptors.

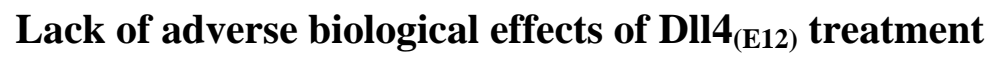

The Notch pathway is involved in a wide range of biological processes and, accordingly, Notch inhibition in vivo can have serious pathological effects. Considering that circulating Dll4 ${ }_{(\mathrm{E} 12)}$ released by liver cells might act as an antagonist of endogenous Notch signaling interactions, we examined several different organs for D114 immunoreactivity and the appearance of pathological alterations. While liver hepatocytes show the expected expression of Dll4 ${ }_{(\mathrm{E} 12)}($ Figure 1-figure supplement 5A), no increase in Dl14 immunoreactivity 
153 indicating binding of Dll4 (E12) was seen in spleen or lung (Figure 1-figure supplement 5B and

154 C). In small intestine, Notch inhibition has been linked to toxicity by impairing the formation 155 and distribution of goblet cells ${ }^{28}$. However, intestinal crypts from $p L I V E-D l l 4_{(E 12)}$-injected

156 mice show no goblet cell metaplasia (Figure 2A). While chronic Dll4 blockade was shown to

157 cause sinusoidal vessel dilation in $\operatorname{liver}^{33}$, histological analysis reveals no differences between

$158 p L I V E-D l l 4_{(E 12)}$ and control livers (Figure 2B). This result is particularly remarkable, as liver

159 is the source of $\mathrm{Dll}_{(\mathrm{E} 12)}$ protein expression after hydrodynamic tail vein injection. Dll4-

160 mediated Notch1 activation is essential for thymic $\mathrm{T}$ cell development ${ }^{28}$, but flow cytometry

161 shows comparable numbers of $\mathrm{CD}^{+}$and $\mathrm{CD} 8^{+}$double positive $\mathrm{T}$ cells in thymi from control

162 and pLIVE-Dll4 $(E 12)$-injected mice (Figure 2C, D). While it has been proposed that Dll4-

163 triggered Notch signaling modulates inflammatory responses ${ }^{34}$, inflammatory cytokines are

164 also not significantly increased in plasma from $p L I V E-D l l 4_{(E 12)}$-injected mice (Figure 2-figure

165 supplement 1). Notch inhibition was also shown to compromise the barrier function of

166 vascular endothelium ${ }^{30}$, but the extravasation of fluorescent, Texas-Red-labeled Dextran is

167 not increased in femurs from $p L I V E-D l l 4_{(E 12)}$-injected mice (Figure 2E, F). Furthermore, there

168 is no significant difference in Texas-Red Dextran extravasation in other organs investigated,

169 namely liver, spleen and lung (Figure 2-figure supplement 2A-C). The sum of these results 170 indicates that $\mathrm{Dll}_{(\mathrm{E} 12)}$ causes no adverse systemic effects that are known to result from Notch 171 inhibition.

173 Effects of recombinant $\mathbf{D l l 4}_{(\mathrm{E} 12)}$ on bone and vasculature

174 Next, we performed a more detailed analysis of the alterations in pLIVE-Dll4 $(E 12)$ 175 femur at 3 wpi. While Osterix ${ }^{+}\left(\mathrm{OSX}^{+}\right)$osteoblasts are strikingly increased relative to control 176 samples, there is a significant reduction in the number of Runx $2^{+}$osteoprogenitors (Figure $3 \mathrm{~A}$, 177 B and Figure 3-figure supplement 1). Dll4 (E12) treatment was also performed on $\mathrm{Tg}(\mathrm{Hey} 1$ $178 E G F P)^{I D 40 G s a t}$ mice, which express enhanced green fluorescent protein (GFP) under the 
control of Heyl, a Notch target gene. Dll4 (E12) strongly increases the number of perivascular

$180 \mathrm{GFP}^{+}$cells in the metaphysis relative to control animals (Figure 3-figure supplement 1).

181 Notably, these cells are located in close proximity to $\mathrm{OSX}^{+}$osteoblasts but lack strong nuclear

182 OSX immunostaining. Vessel-associated Hey1-expressing cells in Dll4 ${ }_{(\mathrm{E} 12)}$-treated mice are

183 also found in the transition zone interconnecting the metaphyseal and diaphyseal vasculature,

184 whereas no $\mathrm{GFP}^{+}$cells are found in BM (Figure 3-figure supplement 1). In addition to the

185 increase in $\mathrm{OSX}^{+}$cells, $\mathrm{Dll4}_{(\mathrm{E} 12)}$ treatment enhances the expression of major non-collagenous

186 proteins involved in bone matrix organization and deposition, namely Osteopontin and

187 Osteocalcin (Figure 3C). Similarly, immunostaining of the receptor tyrosine kinase PDGFR $\beta$

188 and the proteoglycan NG2, both markers of mesenchymal stromal cells, are significantly

189 increased in the pLIVE-Dll4 $(E 12)$ metaphysis (Figure 3-figure supplement 2A, B). Arguing

190 against increased bone turnover involving higher bone resorption, Dll4 (E12) treatment does not

191 lead to significant alterations in the number of V-ATPase ${ }^{+}$osteoclasts (Figure 3D).

192 Furthermore, immunohistological analysis reveals that adipocyte number and the expression

193 of critical chondrocyte markers, such as Aggrecan (Acan) and the transcription factor Sox9,

194 are not significantly altered by recombinant $\mathrm{Dll4}_{(\mathrm{E} 12)}$ (Figure 3E and Figure 3-figure 195 supplement 2C, D).

196 To assess whether blood vessels in long bone are altered by treatment with D114(E12),

197 we examined the expression of some known vascular makers such as Endomucin (Emcn) and

198 VEGFR3 in femoral sections. Low VEGFR3 immunostaining was previously shown to mark

199 type $\mathrm{H}$ vessels columns that are associated with $\mathrm{OSX}^{+}$osteoprogenitors in the metaphysis,

200 whereas vessel buds in direct proximity of growth plate chondrocytes and the sinusoidal (type

201 L) vasculature of the bone marrow show high anti-VEGFR3 signal $^{31}$. Notably, the region with

202 VEGFR $^{\text {low }}$ (type $\mathrm{H}$ ) $\mathrm{Emcn}^{+}$vasculature and $\mathrm{OSX}^{+}$cells is significantly increased in the 203 metaphysis of $p L I V E-D_{l} 4_{(E 12)}$-injected mice relative to control (Figure 4A-C). Notch 204 signaling in bone ECs was previously shown to lead to an expansion of type $\mathrm{H}$ vasculature 
and increased osteogenesis, but it also promotes artery formation ${ }^{23}$. However, the abundance of arteries and small arterioles is not significantly altered by Dll4 (E12) $($ Figure 4D).

\section{Bone formation is not increased by Jag1-Asp $8 \mathrm{x}$ and $\operatorname{Jag1}_{(\mathrm{JV1})}$}

Homotypic signaling interactions between Notch receptors and the ligand Jagged1 in osteochondral progenitors negatively regulate the pool of these progenitors but also promote

211 bone formation ${ }^{35,36}$. Moreover, Delta and Jagged ligands have distinct, sometimes opposite

212 biological functions in certain processes such as retinal angiogenesis or pancreas 213 development ${ }^{37,38}$. To address whether exogenous Jagged1 has the capacity to enhance bone 214 formation, we generated a soluble $\mathrm{Jag} 1-\mathrm{Asp}_{8 \mathrm{x}}$ fusion protein in which, analogous to Dll4215 Asp $_{8 \mathrm{x}}$, the transmembrane and intracellular domain are replaced by His ${ }_{6 \mathrm{x}}$ and $\mathrm{Asp}_{8 \mathrm{x}}$ sequence 216 motifs. In parallel, a high affinity variant of Jag1-Asp $8 \mathrm{x}$, termed Jag $1_{(\mathrm{JV} 1)}$, was generated by 217 replacing several amino acid residues in the ligand ECD, as previously reported ${ }^{39}$ (Figure 5A). Jag1-Asp $8 \mathrm{x}$ and Jag1 $1_{(\mathrm{JV} 1)}$ proteins were purified from HEK293 cell culture supernatants. SDSPAGE and Western blotting confirmed the correct molecular weight of the purified proteins (Figure 5-figure supplement 1A-C). Soluble Jag $1_{(\mathrm{JV} 1)}$ inhibits DLL4, HEY1, HEY2 and EFNB2, known targets of Notch signaling, in cultured HUVECs, whereas immobilized Jag $1_{(\mathrm{JV} 1)}$ induces upregulation of Notch target genes at higher levels compared to Jag1-Asp $\mathrm{p}_{8 \mathrm{x}}$ stimulation (Figure 5-figure supplement 1D and E).

To overexpress these recombinant proteins in vivo, cDNAs of Jagl-Asp $8 x$ and $J a g 1_{(J V I)}$, respectively, were cloned into pLIVE vector. Following hydrodynamic tail vein injection of male mice, both Jag1-Asp ${ }_{8 \mathrm{x}}$ and Jag $1_{(\mathrm{JV} 1)}$ are readily detectable at bone surfaces in sections, but Jag1-Asp $8 \mathrm{x}$ is also more broadly detected throughout the marrow cavity (Figure 5-figure supplement 2A, B). Neither Jag1-Asp $8 x$ nor Jag1 $1_{(\mathrm{JV} 1)}$, however, induce appreciable alterations in Collal deposition (Figure 5B). Micro-computed tomography ( $\mu$-CT) analysis reveals a 230 slight but significant increase in trabecular bone thickness in $p L I V E-J a g 1_{(J V I)}$-injected mice, 
whereas bone volume over total volume (BV/TV), connectivity density, trabecular number

232 and trabecular separation are not altered significantly (Figure 5C). These results argue that 233 only $\mathrm{Dll4}_{(\mathrm{E} 12)}$ is able to stimulate substantial osteogenesis in adult mice, while Dll4-Asp $8 \mathrm{x}$, $234 \quad \operatorname{Jag} 1-\mathrm{Asp}_{8 \mathrm{x}}$ and $\operatorname{Jag} 1_{(\mathrm{JV} 1)}$ lack this capacity.

\section{Sex-specific effects of Dll4 (E12) $_{\text {on }}$ bone formation}

Next, we investigated whether Dl14 $(\mathrm{E} 12)$ treatment provides any beneficial effects in the ovariectomy model of postmenopausal osteoporosis. In comparison to sham controls, ovariectomized female mice show significant reduction of trabecular bone, which is not improved by Dl14 $_{(\mathrm{E} 12)}$ expression (Figure 6A-D). Similarly, Col1a1 and PDGFR $\beta$ 241 immunoreactivity is not significantly altered by $\mathrm{Dll4}_{(\mathrm{E} 12)}($ Figure 6E-F).

Given that bone surface is substantially lower in adult female mice relative to agematched males (Figure 6G and Figure 6-figure supplement 1A, B), we reasoned that D114 $4_{(\mathrm{E} 12)}$

244 binding might depend on the sex of animals. Indeed, endogenous Dll4 immunoreactivity is 245 already significantly lower in control females relative to males and the strong increase in 246 femur sections from Dl14 $(\mathrm{E} 12)$-expressing males is not mirrored by female samples (Figure 6247 figure supplement $1 \mathrm{C}, \mathrm{D})$. Together, these findings indicate that the biological effect of $248 \mathrm{D}_{114_{(\mathrm{E} 12)}}$ depends on the available bone surface, suggesting that this approach might not be 249 beneficial in settings with low bone mass.

Anabolic therapy is a clinical approach for the treatment of osteoporosis, aiming at 251 increase in bone mass. We therefore explored whether $\mathrm{D} 114_{(\mathrm{E} 12)}$ can be beneficial in female 252 mice if used in combination with PTH. Indeed, hydrodynamic tail vein injection of female mice with $p L I V E-D l l 4_{(E 12)}$ followed by daily PTH1-34 administration over a period of 3 weeks leads to a profound increase in Dl14 immunoreactivity in femoral sections (Figure 7and Emcn immunostaining in response to combined Dl14 $(\mathrm{E} 12)$ and PTH1-34 treatment (Figure 
7-figure supplement 1C-E). Furthermore, the combination of Dll4 ${ }_{(\mathrm{E} 12)}$ and PTH1-34 increases

258 the abundance of $\mathrm{OSX}^{+}$osteoprogenitors and the length of the metaphysis in adult females, 259 whereas the Osteopontin ${ }^{+}$area is not significantly enhanced relative to PTH1-34 alone (Figure 260 7-figure supplement 2A, B).

Analysis of $\mathrm{Dll4}_{(\mathrm{E} 12)}$ and PTH1-34 treated femurs by $\mu$-CT shows that the changes above are accompanied by profound increases in trabecular bone and, in particular, connectivity density and bone surface relative to control females or separate administration of either Dll4(E12) or PTH1-34 (Figure 7A-G). In contrast, the beneficial effects of PTH treatment on cortical bone are not enhanced by $\mathrm{Dll}_{(\mathrm{E} 12)}($ Figure $7 \mathrm{H}-\mathrm{K})$. These findings indicate that Dll4 $(\mathrm{E} 12)$ can enhance trabecular bone formation in response to anabolic therapy.

\section{Analysis of $\mathrm{Dll4}_{(\mathrm{E} 12)}$-induced processes at single cell resolution}

Next, we analyzed long bones from $p L I V E-D l l 4_{(E 12)}$ and control-injected males at 3

wpi by scRNA-seq in order to identify the stromal cell populations mediating the response to

Dll4 $_{(\mathrm{E} 12)}$. Following tissue dissociation, hematopoietic cells were depleted from single cell

272 suspensions with magnetic activated cell sorting (MACS) and the remaining stromal single

273 cells were captured and barcoded with the BD Rhapsody Express Single-Cell Analysis

274 System (Figure 8A). We sequenced approximately 20,000 cells from long bones of four pLIVE-Dll4 ${ }_{(E 12)}$ and control-treated mice. The resulting cell libraries were filtered to remove barcode artefacts and low-quality cells using stringent parameters for low library complexity,

277 mitochondrial gene overrepresentation, cell doublet probability and low gene expression to 278 ensure that downstream analysis was not affected by technical artefacts (Figure 8-figure supplement 1A-D). A total of $7750 \mathrm{Dll4}_{(\mathrm{E} 12)}$ cells and 9265 control cells passed filtering and were carried forward for further analysis. To investigate the cell diversity in the $\mathrm{Dll}_{(\mathrm{E} 12)}$ and control group, we performed clustering of cells based on scaled expression profiles (Louvain 282 algorithm), combined with manual clustering annotation using known and de-novo identified 
marker genes. We identified 5 distinct cell populations in both pLIVE-Dll4 ${ }_{(E 12)}$ and control284 injected bone: MSCs, chondrocytes, ECs, osteoblasts and smooth muscle cells (SMCs) (Figure 8B-E). For each population, we then identified all genes that were differentially expressed between the pLIVE-Dll4 ${ }_{(E 12)}$ and control samples (Wilcoxon Rank Sum Test). Due to their small number, SMCs were omitted from this analysis. Data analysis reveals that EC and osteoblast populations show no or only minor alterations in response to $\mathrm{Dll}_{(\mathrm{E} 12)}$. Consistent with this finding, expression of EC markers (Pecam1), regulators of vascular growth (Vegfr2/Kdr), and of venous (Nr2f2, Vegfr3/Flt4) or arterial specification (Sox17, Efnb2) are not altered in the Dll4 $($ E12) group (Figure 8F, I). Expression of Notch pathway ligands, receptors and downstream targets is also only marginally affected in endothelium of the $p L I V E-D l l 4_{(E 12)}$-injected mice (Figure 8-figure supplement 2A, B).

Notably, MSCs and chondrocytes show the strongest response to overexpressed Dll4 $_{(\mathrm{E} 12)}$, although chondrocytes display a comparably smaller number of differentially expressed genes (Figure 8G, H). Dll4 $(\mathrm{E} 12)$ chondrocytes show normal expression of critical transcripts including the transcription factor Sox 9 and the proteoglycan core protein Aggrecan (Acan) (Figure 8J), consistent with the results from the immunostaining of bone sections (Figure 3-figure supplement 2C). In contrast, the alpha1 subunit of type X collagen (Col10a1), which is mainly expressed by hypertrophic chondrocytes in the growth plate, is upregulated after $\mathrm{Dll4}_{(\mathrm{E} 12)}$ treatment $(\mathrm{P}=3.97 \mathrm{e}-32)($ Figure 8J).

In the MSC population, representative markers such as transcripts for the receptor tyrosine kinase PDGFR $\beta$ (Pdgfrb), a critical regulator of MSC proliferation, and Leptin receptor (Lepr), a marker of BM stromal cells, are not altered (Figure 8K). However, known pro-osteogenic genes like Igf2 encoding insulin-like growth factor 2 (ref. 40) are upregulated $(\mathrm{P}=9.52 \mathrm{e}-121)$, whereas transcripts associated with negative regulation of osteogenesis are downregulated. The latter includes the transcript for Insulin-like growth factor-binding protein 
their bioavailability ${ }^{40}$, and matrix Gla ( $\gamma$-carboxyglutamate) protein $(M g p)(\mathrm{P}=1.11 \mathrm{e}-159)$, a

310 negative regulator of calcification ${ }^{41}$ (Figure $8 \mathrm{H}$ and Figure 8-figure supplement 2C). MSCs

311 from $\mathrm{Dll4}_{(\mathrm{E} 12)}$-treated mice showed also increased expression of Angptl4 (P=9.82e-132),

312 which encodes angiopoietin-like 4, a positive regulator of osteogenesis that is highly 313 expressed at bone fracture sites but is also a stimulator of osteoclast-mediated bone

314 resorption $^{42,43}$ (Figure $8 \mathrm{H}$ and Figure 8-figure supplement 2C). Transcripts for the 315 proteoglycan PRG4, a positive regulator of skeletogenesis and parathyroid hormone-mediated 316 bone formation $^{44}$, are also elevated in $\mathrm{Dll4}_{(\mathrm{E} 12)}$ MSCs $(\mathrm{P}=8.39 \mathrm{e}-112)$ (Figure $8 \mathrm{H}$ and Figure 8317 figure supplement 2C).

318 Gene Ontology (GO) analyses (hypergeometric test) of each cell population reveals an 319 enrichment of GO terms for morphogenesis, development, vascular growth, and ossification among differentially expressed genes in the MSC population and, to much smaller extent, in chondrocytes (Figure 8-figure supplement 2D). Analysis of endogenous Notch receptor (Notch1-4) and ligand (Dll1, Dll4 and Jag1, Jag2) expression in Dll4 (E12)-treated stromal cells, however, indicates no alterations except the downregulation of Notch3 in MSCs $(\mathrm{P}=1.10 \mathrm{e}-64)$

324 (Figure 8-figure supplement 2A, B). While Dll4 $(\mathrm{E} 12)$ results in a strong increase of OSX ${ }^{+}$cells 325 in vivo, scRNA-seq analysis reveals very limited gene expression changes in osteoblasts 326 (Figure 8-figure supplement 2E). Together, these data indicate that the pro-osteogenic effects of $\mathrm{Dll}_{(\mathrm{E} 12)}$ are mediated by MSCs.

\section{DII4 $_{(\mathrm{E} 12)}$ effects within the bone MSC subpopulations}

Bone MSCs are highly heterogeneous, found in different locations and can be subdivided based on marker gene expression ${ }^{45-48}$. Sub-clustering (Louvain algorithm) of the

332 MSC population in our scRNA-seq data identifies 3 distinct subpopulations (Figure 9A-C).

333 Diaphyseal MSCs (dpMSCs) show high expression of Lepr and Kitl, the gene encoding stem

334 cell factor, the ligand of c-Kit receptor (Figure 9A-C and E). Metaphyseal MSCs (mpMSCs) 
characterized by expression of markers associated with osteogenesis, namely of the transcription factor Osterix (encoded by the gene $S p 7$ ), the secreted extracellular matrix protein periostin (Postn), and the transcriptional repressor and Notch pathway gene Heyl (Figure 9A-C and E). In addition, we find a small population of fibroblast-like cells, which express the proteoglycan Decorin (Dcn) and the glycosyl phosphatidylinositol-anchored cell

340 surface protein Sca-1 (Ly6a) (Figure 9A-C). Notably, dpMSCs represent $85-86 \%$ of total 341 MSCs in both the Dll4 $(\mathrm{E} 12)$ and control group (Figure 9A, B). Most of genes that are 342 differentially expressed in Dll4 ${ }_{(\mathrm{E} 12)}$-treated samples are also found in the dpMSC 343 subpopulation. This includes the upregulated genes Igf2 $(\mathrm{P}=5.39 \mathrm{e}-88)$ and $\operatorname{Prg} 4(\mathrm{P}=3.05 \mathrm{e}-90)$, 344 which are known to promote osteogenesis, and the downregulated genes Igfbp3 $(\mathrm{P}=1.69 \mathrm{e}-156)$ 345 and $\operatorname{Mgp}(\mathrm{P}=9.76 \mathrm{e}-148)$, which are inhibitors of bone formation (Figure 9D, E). Furthermore, 346 UMAP projections show a significant increase in the fraction of Sp7/Osterix-expressing cells 347 in the dpMSC population (Figure 9F). Consistent with the Heyl-EGFP reporter results 348 (Figure 3-figure supplement 1A), Heyl expression labels mpMSCs and a small fraction of 349 dpMSCs. The latter might, as the $T g(\text { Heyl-EGFP })^{I D 40 G s a t}$ reporter expression suggests (Figure 3503 -figure supplement 1A), represent cells in the transition zone between the metaphysis and 351 diaphysis. The scRNA-seq data show no significant increase in total Heyl ${ }^{+}$MSCs, which is 353 presumably due to the low expression and therefore limited detection of this transcript (Figure 354 9F). Taken together, our results support that $\mathrm{D} 114_{(\mathrm{E} 12)}$ treatment promotes osteogenesis through 355 effects in MSCs and, in particular, the dpMSC population. In contrast, molecular changes are 356 limited in the EC and osteoblast populations, suggesting that these cells are not exposed or 357 unresponsive to $\mathrm{D}_{114_{(\mathrm{E} 12)} \text {. }}$

\section{DISCUSSION}


Notch signaling has multiple important functional roles in the skeletal system, including the maintenance and expansion of the mesenchymal progenitor cell pool and the coupling of angiogenesis and osteogenesis ${ }^{23-25,29,38,49}$. Interactions between Dll4 and Notch receptors, predominantly Notch1 but also Notch4, negatively control EC proliferation and angiogenic growth of the vasculature in most organs. In bone, however, Notch signaling promotes angiogenesis and triggers the expansion of type $\mathrm{H}$ vessels, which, in turn, results in 366 increased osteogenesis ${ }^{23,50}$. To promote bone angiogenesis and osteogenesis, we have designed synthetic Notch ligands containing poly-Asp peptide motifs, which have been previously shown to bind different regions in long bone including the primary spongiosa in 369 proximity of the growth plate ${ }^{51,52}$, a region containing a high amount of angiogenic vessels. It 370 also has been shown that an $\mathrm{Asp}_{6 \mathrm{x}}$ peptide preferentially binds to areas of bone resorption, 371 whereas a different motif, (AspSerSer) $6 \mathrm{x}$, targets bone-forming surfaces ${ }^{53}$. Future work will 372 have to address whether other bone surface-binding moieties will endow Notch ligands with distinct and perhaps even more potent biological properties due to the activation of different 374 target cell populations. Our scRNA-seq analysis shows, for example, that the $\mathrm{Asp}_{8 \mathrm{x}}$ motif in $375 \mathrm{Dll4}_{(\mathrm{E} 12)}$ leads to very limited changes in bone ECs. This might reflect that the spatial distance 376 between the bone surface and ECs precludes sufficient physical contact between 377 hydroxyapatite-bound D114 (E12) and endothelial Notch receptors.

378 Nevertheless, we found that Dll4 $($ E12) can trigger an increase in trabecular bone, 379 whereas similar effects were not seen for Dll4-Asp8x, Jag1-Asp8x or Jag1 $1_{(J V 1)}$. The 380 underlying reasons for this difference are not clear, but it is possible that only Dl14 ${ }_{(\mathrm{E} 12)}$ 381 accomplishes a critical level of Notch activation required for bone formation in adult male 382 mice. This should, however, not lead to conclusions about the functional roles of endogenous 383 Notch ligand expression. In fact, numerous reports have shown that Jagged1 can regulate 384 osteogenic differentiation of bone mesenchymal stromal cells and the ligand is also highly 385 upregulated during fracture repair ${ }^{13,54-56}$. 
Notch signaling was shown to inhibit chondrocyte differentiation by suppressing the expression of the transcription factor Sox9, a known regulator of chondrogenesis ${ }^{57}$. Genetic disruption of Notch signaling in embryonic limb bud mesenchyme using Prxl-Cre transgenic mice led to the accumulation of hypertrophic chondrocytes in the growth plate, whereas chondrocyte proliferation was strongly reduced ${ }^{24}$. Our findings show that Dll4 $(\mathrm{E} 12)$ treatment 391 of adult mice increases the expression of Colloal in chondrocytes, which encodes the alpha 392 chain of type X collagen, a short chain collagen expressed by hypertrophic chondrocytes that 393 is essential for growth plate development and mineralization of trabecular bone ${ }^{58}$. The 394 absence of appreciable accumulation of $\mathrm{Dll}_{(\mathrm{E} 12)}$ inside the growth plate, however, suggests 395 that these alterations might be indirect. It was also shown that conditional activation of Notch 396 signaling in osteocytes increases bone formation and mineralization, which is sufficient for 397 the rescue of both age-associated and ovariectomy-induced bone loss ${ }^{36}$. While our work does 398 not exclude anabolic effects of $\mathrm{Dll4}_{(\mathrm{E} 12)}$ through the activation of Notch signaling in 399 osteocytes, these cells were not recovered in our scRNA-seq data presumably due to the 400 conditions of tissue dissociation.

401 Instead, our results indicate that $\mathrm{Dll4}_{(\mathrm{E} 12)}$ activates Notch signaling primarily in 402 immature MSCs and leads to the expansion of this population and, as shown previously ${ }^{24}$, 403 reduced Runx2 expression. It is also fully consistent with previous findings showing that 404 genetic approaches leading to Notch activation in mesenchymal progenitors suppress 405 differentiation and promote the expansion of these cells ${ }^{24,25,59}$. In this context, it is presumably 406 highly advantageous that Dll4 $4_{(\mathrm{E} 12)}$-mediated Notch activation is, in contrast to irreversible 407 genetic modifications, transient and does not suppress osteoblastic differentiation, presumably 408 because cells are not permanently exposed to the bone surface-bound recombinant protein. 409 This is indicated by the absence of Hey1-GFP signal in $\mathrm{OSX}^{+}$cells but also the absence of 410 major transcriptional alterations in osteoblasts. 
MSCs are a heterogenous population of stromal cells, which includes cells with

412 progenitor properties, colony forming capacity ex vivo, and the potential to generate bone, fat,

413 fibroblasts, and other cell types ${ }^{47,60-62}$. MSCs are likely to include comparably rare

414 mesenchymal stem and progenitor cells characterized by the ability to give rise to multiple

415 differentiated cell types in a clonal fashion ${ }^{60,61,63,64}$. It might appear surprising that our

416 scRNA-seq data show the strongest gene expression changes in diaphyseal MSCs, but

417 previous work has established that vessel-associated mesenchymal stromal cells in the

418 diaphysis can give rise to bone-forming cells $\mathrm{s}^{47,48,65}$. In fact, expansion of the metaphyseal

419 region in response to $\mathrm{Dll4}_{(\mathrm{E} 12)}$ might well involve the incorporation of dpMSCs from the

420 adjacent transition zone and marrow. Taken together, we propose that the pro-osteogenic

421 capacity of $\mathrm{Dll}_{(\mathrm{E} 12)}$ is primarily mediated by Notch-controlled expansion of immature MSCs.

422 It is also feasible that bone formation is enhanced through the release of secreted signaling

423 molecules acting in a paracrine fashion, which might apply to the alterations seen in

424 chondrocytes.

425 Our study not only proves that the administration of exogenous Notch ligand can

426 induce bone formation in adult mice, the results also show that this treatment does not lead to

427 adverse side effects. Circulating Dll4 (E12) might act as an antagonist and therefore disrupt

428 critical endogenous Notch-ligand interactions in multiple organs, which might lead to defects

429 in small intestine, liver or $\mathrm{T}$ cell development that are known to be caused by Notch

430 inhibition ${ }^{33,66,67}$. The absence of such defects might reflect efficient retention of Dll4(E12)

431 fusion protein in bone and thereby low bioavailability in other organs. It is, nevertheless,

432 remarkable that even liver, the site of Dll4 $(\mathrm{E} 12)$ expression, does not show overt morphological

433 alterations.

434 Together, our findings establish that bone-targeting and binding-optimized Dll4 ligand

435 can be used to stimulate osteogenesis in adult mice without adverse side effects. We propose 
that $\mathrm{Dll}_{(\mathrm{E} 12)}$ might serve as a promising example for the design of future anti-osteoporosis

437 drugs.

\section{MATERIALS AND METHODS}

\section{Plasmid Construction}

To generate the Dll4-Asp $\mathrm{p}_{8 \mathrm{x}}$ soluble protein containing the Dll4 ECD fused to 6x His and 8x Asp peptide sequences, a cDNA fragment encoding amino acids 1-530 of murine Dll4

444 (https://www.uniprot.org/uniprot/Q9JI71) was amplified via PCR using the following

primers:

Dll4(ECD)-BamHI-Fwd:

5'-

ACTACATATAGGATCCacctaggatttgctccagg-3' and Dll4(ECD)-PolyD_XhoI-Rev: 5'-

CTTATGATCTCGAGttagtcgtcgtcgtcgtcgtcgtcgtcgtgatggtgatggtgatgatctgttctgtttttcagaggacgc3'.

To generate the plasmid encoding the affinity variant $\mathrm{D} 114_{(\mathrm{E} 12)}$, which contains several 450 point mutations in the $\mathrm{ECD}^{59}$, the plasmid encoding Dll4-Asp $8 \mathrm{x}$ was modified with the 451 QuickChange Lightning Multi Site-Directed Mutagenesis Kit (Cat\#201515, Agilent 452 Technologies) and the following primers: Dll4-g1242a: 5'-gctgcgggctccagcatcttccagc-3', Dll4-t1479c:

$$
\text { 5'-cctctgcagttgcccctcaatttcacctggc-3', }
$$

Dll4-a1513t:

5'ggaaccttctcactcatcatccaagcttggcac-3', Dll4-a1587t: 5'-aaactctctcatcagccaatt catcatccaaggctc-3', Dll4-c1740t: 5'-gcaagaagcgcgatgactacttcggacattatgag-3', Dll4-t1777c: 5'cagatggcagccegtcctgcctgcc-3', Dll4-al803g: 5'-ctggtcacagtactccccagtccagcccg-3'. His and 8x Asp peptide sequences involved a strategy analogous to the construction of Dll4$\mathrm{Asp}_{8 \mathrm{x}}$. A cDNA covering amino acid residues 1-1067 of the murine Jagged1 ECD 460 (https://www.uniprot.org/uniprot/Q9QXX0) was amplified with the following oligonucleotide 461 primers: 
ACTACATATAGGATCCgccgcagcgatgcggtcccacg-3' and Jagged1(ECD)-XhoI-PolyD-Rev: 5'-CTTATGATCTCGAGttagtcgtcgtcgtcgtcgtcgtcgtcgtgatggtgatggtgatgatctgttctgttttcagaggac gc-3'. Site-directed mutagenesis was used to generate Jag $1_{(J V 1)}$, a high affinity version of the Jag1 ECD due to several point mutations ${ }^{39}$, linked to $6 x$ His and $8 x$ Asp peptides with the following primers Jagged1-c260g\&t261g: 5'-gtatcagtcccgcgtcagggccggggga-3', Jagged1-c95t: 5'-ggtgtgcggggccttgggtcagtttg-3', Jagged1-c202g: 5'-cgcaagtgcaccggcgacgagtgt g-3', Jagged1-g214a: 5'-gcaccGgcgacgagtgtaatacgtacttcaaagtg-3', Jagged1-a545g\&g546a: 5'attgccacttcgagtatcgaatccgagtgacctgtgatg-3'.

All PCR reactions were carried out using PrimeSTAR Max DNA Polymerase (R045B, Takara). The resulting PCR fragments were digested by restriction enzymes BamHI and XhoI (New England Biolabs) and the resulting fragments were inserted into the in vivo overexpression vector $p L I V E$ (MIR-5420, Mirus) for in vivo studies and into the expression vector $p c D N A 3.1$ (Invitrogen) for experiments in cultured cells.

\section{HEK293 cell transfection and His-tagged protein purification}

For overexpressing D114 or Jag1 recombinant proteins, 4x $10^{6}$ HEK293 cells were plated per $10 \mathrm{~cm}$ dish. 20 hours later medium was refreshed and after 3 hours cells in each dish were transfected with $18 \mu \mathrm{g}$ plasmid DNA of $p c D N A 3.1-D l l 4-A s p_{8 x}, p c D N A 3.1-D l l 4_{(E 12)}$,

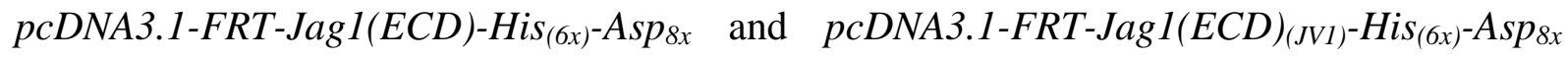
using the Calphos Mammalian Transfection kit (631312, Clontech631312), following the manufacturer's instructions. 16 hours later Opti-MEM culture medium (31985-047, Gibco) was added to the cells.

Culture supernatants were collected at 24 hours post-transfection and clarified by centrifugation at 300x g for $15 \mathrm{~min}$ at $4^{\circ} \mathrm{C}$. For whole cell lysate samples, cells were washed twice with PBS and $1 \mathrm{mM}$ PMSF and incubated with RIPA modified buffer $\left(20 \mathrm{mmol} \cdot \mathrm{L}^{-1}\right.$ Tris $\mathrm{HCl}, \mathrm{pH} 8.0,150 \mathrm{mmol} \cdot \mathrm{L}^{-1} \mathrm{NaCl}, 0.5 \%$ Triton $\mathrm{X}-100,0.1 \%$ SDS, $0.1 \%$ Na-DOC, 2 
mmol $\cdot \mathrm{L}^{-1}$ EDTA, cOmplete ULTRA (05892970001, Roche) and phosphatase inhibitor cocktail set V (524629, EMD Millipore)) for $20 \mathrm{~min}$ at $4^{\circ} \mathrm{C}$. Lysates were further sonicated, spun down at $4^{\circ} \mathrm{C}$ for $10 \mathrm{~min}$ at full speed and protein concentration was quantified using BCA Protein Assay Kit (23225, Pierce).

For the purification of His-tagged recombinant proteins from supernatants, Ni-NTA agarose resin (302010, QIAGEN) packed in disposable polystyrene columns (29922, Thermo Scientific) were used. Binding of recombinant proteins to Ni-NTA resin was done in a buffer containing $20 \mathrm{mmol} \cdot \mathrm{L}^{-1}$ Tris- $\mathrm{HCl}, 150 \mathrm{mmol} \cdot \mathrm{L}^{-1} \mathrm{NaCl}$, and $4 \mathrm{mmol} \cdot \mathrm{L}^{-1}$ imidazole at $\mathrm{pH} 7.4$. After the passage of lysates, beads were washed with wash buffer containing $20 \mathrm{mmol} \cdot \mathrm{L}^{-1}$ Tris- $\mathrm{HCl}, 150 \mathrm{mmol} \cdot \mathrm{L}^{-1} \mathrm{NaCl}$, and $20 \mathrm{mmol} \cdot \mathrm{L}^{-1}$ imidazole at $\mathrm{pH} 7.4$ before His-tagged 498 proteins were eluted into elution buffer containing $20 \mathrm{mmol} \cdot \mathrm{L}^{-1} \mathrm{Tris}-\mathrm{HCl}, 150 \mathrm{mmol} \cdot \mathrm{L}^{-1} \mathrm{NaCl}$, and $500 \mathrm{mmol} \cdot \mathrm{L}^{-1}$ imidazole, $\mathrm{pH}$ 7.4.

To remove imidazole, eluted proteins were dialyzed using Pierce Slide-A-Lyzer 10K MWCO Dialysis Cassettes (66380, Thermo Scientific) in dialysis buffer $\left(20 \mathrm{mmol} \cdot \mathrm{L}^{-1}\right.$ Tris$\mathrm{HCl}, 150 \mathrm{mmol} \cdot \mathrm{L}^{-1} \mathrm{NaCl}$ at $\mathrm{pH}$ 7.4.). To adjust the loading volume, $500 \mu \mathrm{l}$ of supernatant, 503 flow-through and wash solution were concentrated to $30 \mu \mathrm{l}$ using Amicon Ultra- 0.5 504 Centrifugal Filter Unit with 3KDa cutoff (UFC500396, Millipore). After quantitation, whole 505 cell lysates, concentrated protein solutions and eluted recombinant proteins were mixed with SDS loading buffer and boiled for $10 \mathrm{~min}$. Samples were run on $8 \%$ SDS-PAGE gel and visualized by SimplyBlue ${ }^{\mathrm{TM}}$ SafeStain (LC6060, Invitrogen). Target proteins were detected 508 by comparison with protein standard markers.

\section{HUVEC cell culture and Dll4 or Jag1 treatment in vitro}

For D114 experiments, HUVECs (ThermoFisher, C0035C) were cultured in MEM200

512 medium (M200500, ThermoFisher) supplemented with LSGS (S00310, Thermofisher), 2\% 
514 experiments HUVECs (ThermoFisher, C0035C) were cultured in EBM2 medium (33156, 515 Lonza) supplemented with EGM2 bullet kit (CC-4176, Lonza). HUVECs were grown in a 516 humidified atmosphere with $5 \% \mathrm{CO}_{2}$ at $37^{\circ} \mathrm{C}$. Cells were not tested for mycoplasma 517 contamination. For Notch activation assays with immobilized Dll4 or Jag1 recombinant 518 proteins, poly-L-lysine (P6282, SIGMA) coating was used in combination with Dll4-Asp 8 , $519 \mathrm{Dll4}_{(\mathrm{E} 12),}$ Jag1-Asp $8 \mathrm{x}$ or $\mathrm{Jag} 1_{(\mathrm{JV} 1)}$. Corning $60 \mathrm{~mm} \times 15 \mathrm{~mm}$ culture dishes $(430196$, Corning) were pre-incubated with $0.2 \mathrm{mg}$ of poly-L-lysine in $0.1 \mathrm{M}$ sodium borate buffer $(\mathrm{pH}=8.5)$ overnight at $37^{\circ} \mathrm{C}$ in the cell culture incubator (Heracell ${ }^{\mathrm{TM}} 240 \mathrm{i}$, Thermo Fisher). Dishes were washed 4 times with $\mathrm{H}_{2} \mathrm{O}$ followed by 4 times additional washes with PBS. Following incubation with $4 \mu \mathrm{g}$ of D1l4, Jag1 recombinant proteins or BSA in $2 \mathrm{ml}$ PBS for 12 hours at $4^{\circ} \mathrm{C}$ and 4 washes with PBS, each culture dish was seeded with $2.2 \times 10^{5}$ cells $4 \mathrm{ml}$ complete medium and cultured for $16 \mathrm{~h}$.

For Notch inhibition assays, $4.5 \times 10^{5}$ cells per well were cultured in Corning 6-well plates pre-coated with $0.1 \%$ Gelatin. The final volume of M200 + LSGS or EGM2 medium was adjusted to $2 \mathrm{ml}$ and $20 \mu \mathrm{g}$ of Dll4 recombinant, $35 \mu \mathrm{g}$ of Jag1 recombinant proteins or BSA protein was added to confluent HUVECs for $8 \mathrm{~h}$ at $37^{\circ} \mathrm{C}$.

\section{Quantitative RT-PCR}

For the analysis of gene expression, total RNA from HUVECs was collected directly from the culture dish with $350 \mu 1$ RLT plus lysis buffer (1053393, Qiagen) followed by

534 immediate RNA extraction using RNeasy Plus Micro Kit (Qiagen, 74034). Complementary

535 DNA was generated with 500ng RNA per reaction iScript cDNA Synthesis Kit (170-8890, BIO-RAD). Quantitative PCR (qPCR) was performed on a CFX96 Touch Real-Time PCR Detection System (BIO-RAD). The following FAM-conjugated TaqMan gene expression probes (ThermoFisher) were used in combination with SsoAdvanced Universal Probes

539 Supermix (BIO-RAD): DLL4 (Hs00184092_m1), HEY1 (Hs00232618_m1), HEY2 
541 (Hs01104102_s1). VIC-conjugated ACTB (4352935) or VIC-conjugated GAPDH

542 (44326317E) were used to normalize gene expression. HUVECs with at least 3 independent

543 stimulation experiments for each gene were analyzed to obtain the relative expression

544 differences using the $2^{-\Delta \Delta C t}$ method.

Mice and in vivo experiments

$\mathrm{C} 57 \mathrm{BL} / 6 \mathrm{~J}$ and $T g(\text { Heyl-EGFP })^{I D 40 G s a t}$ males or C57BL/6J at the age of 8 weeks were

used for hydrodynamic tail vein injection. Animals were anesthetized with $3.75 \%$ isoflurane and injected with $5 \mu \mathrm{g} / \mathrm{g}$ (plasmid/body weight) plasmid suspended in TransIT-EE hydrodynamic delivery solution (MIR5340, Mirus) according to the manufacturer's instruction. The appropriate amount of plasmid was suspended in an injection volume of $10 \%$ of the body weight and injected into each individual mouse via the tail vein in $5-7 \mathrm{~s}$ as 553 previously reported ${ }^{68}$.

For the ovariectomy (OVX) osteoporosis model, 8-week-old C57BL/6J female mice were anesthetized by intraperitoneally injection of ketamine hydrochloride (Ketavet; 100 $556 \mathrm{mg} / \mathrm{kg}$ body weight) and Xylazine (Rompun; $16 \mathrm{mg} / \mathrm{kg}$ body weight) in sterile PBS. Once animals had entered the tolerance phase without foot reflexes, a small incision was made along the dorsal midline, the abdominopelvic cavity was opened and ovaries were removed bilaterally. The skin was closed by metal clips. After that, analgesic Carprofen (Rimadyl; 4 $560 \mathrm{mg} / \mathrm{kg}$ body weight) was applied subcutaneously. Mice in the sham group underwent the 561 same procedure without removal of ovaries. 4 weeks after the surgery, mice received $p L I V E-$ $562 D l l 4(E 12)$ or vehicle by hydrodynamic tail vein injection. 3 weeks later, mice were analyzed 563 and the successful ovariectomy was confirmed by the reduction of uterus size. 
pLIVE-Dll4(E12). Following pLIVE-Dll4(E12) injection at day 0, PTH (1-34) (human)

567 acetate salt (Bachem) was injected subcutaneously every day from day 1 to day 20 at a dose $568100 \mathrm{mg} / \mathrm{kg}$ body weight, diluted in sterilized PBS. Mice were analyzed at day 21.

All animals were housed at the Max Planck Institute for Molecular Biomedicine and protocols were approved by animal ethics committees with permissions (Az 8102.04.2019.A114 and Az 81-02.04.2020.A416) granted by the Landesamt für Natur, Umwelt und Verbraucherschutz (LANUV) of North Rhine-Westphalia.

\section{Bone sample preparation and immunohistochemistry}

Freshly isolated femurs were collected from plasmid and vehicle-injected mice and immediately fixed in $4 \%$ ice-cold paraformaldehyde solution for $24 \mathrm{~h}$. Decalcification was carried out with $0.5 \mathrm{M}$ EDTA $(\mathrm{pH} 8.0)$ at $4{ }^{\circ} \mathrm{C}$ with constant shaking on a horizontal shaker for 48h. Next, decalcified bones were immersed into $20 \%$ sucrose and $2 \%$ polyvinylpyrrolidone (PVP) for $24 \mathrm{~h}$. Finally, tissues were embedded and frozen in embedding solution containing $8 \%$ porcine gelatin together with $20 \%$ sucrose and $2 \%$ PVP. Cryosections of $80-100 \mu \mathrm{m}$ thickness were generated with low-profile disposable blades 819 (LEICA) on a Leica CM2050 cryostat.

For immunostaining, bone sections were air-dried, rehydrated in PBS, permeabilized for 30 min with $0.3 \%$ Triton X-100 PBS and blocked in PBS containing 5\% donkey serum at room temperature for $30 \mathrm{~min}$. Blocked sections were incubated with primary antibodies diluted in $5 \%$ donkey serum in PBS overnight at $4{ }^{\circ} \mathrm{C}$. After primary antibody incubation, sections were washed with PBS for three times and incubated with appropriate Alexa-Fluorconjugated secondary antibodies $(1: 400)$ diluted in PBS for overnight at $4{ }^{\circ} \mathrm{C}$. Nuclei were counterstained with DAPI after secondary antibody incubation. Sections were washed four

590 times with PBS before mounting with FluoroMount-G (0100-01, Southern Biotech). Finally, 591 the slides were air-dried and sealed with nail polish. 
593 Cruz, 1:100), rat anti-PECAM-1 (553370, Pharmingen), rabbit anti-Osterix (Abcam, ab22552,

594 1:1000), rat anti-Runx2 (MAB2006, R\&D, 1:50), rabbit anti-Collagen type I (AB675P, 595 Millipore, 1:200), goat anti-Osteopontin (AF808, R\&D Systems, 1:100), rabbit anti596 Osteocalcin (LS-C17044, LifeSpan BioSciences, 1:100), goat anti-Dl14 (AF1389, R\&D 597 Systems, 1:100), goat anti-Jag1 (J4127, Sigma, 1:100), goat anti-PDGFR $\beta$ (AF1042, R\&D, 598 1:100), rabbit anti-NG2 (AB5320, Millipore), goat anti-BCAM (AF8299, R\&D Systems, 599 1:50), rabbit anti-ATP6V1B1 + ATP6V1B2 (ab200839, Abcam), rabbit anti-Aggrecan 600 (AB1031, Millipore), goat anti-Sox9 (AF3075, R\&D Systems), rabbit anti-Perilipin (9349, 601 Cell Signaling).

602 Secondary antibodies were: donkey anti-rat IgG conjugated to AF594 (A21209, 603 Invitrogen), donkey anti-goat IgG conjugated to AF647 (A21447, Invitrogen), donkey anti604 rabbit IgG conjugated to AF488 (A21206, Invitrogen), donkey anti-rabbit IgG conjugated to 605 594 (A21207, Invitrogen), donkey anti-rat IgG conjugated to 647 (712-605-153, Jackson 606 ImmunoResearch), donkey anti-goat IgG conjugated to AF488 (A11055, Invitrogen), donkey 607 anti-rabbit IgG conjugated to AF647 (A31573, Invitrogen), donkey anti-rat IgG conjugated to 608 AF488 (A21208, Invitrogen), and donkey anti-goat IgG conjugated to AF647 (A32849, 609 ThermoScientific).

Histology of liver and intestine

The dissected intestinal tract was flushed gently with cold PBS followed by a flush

613 with $4 \%$ PFA. The intestine was fixed at $4{ }^{\circ} \mathrm{C}$ for $16 \mathrm{~h}$. The Median lobe of liver was dissected 614 and fixed at $4^{\circ} \mathrm{C}$ for $16 \mathrm{~h}$. Formalin-fixed and paraffin-embedded tissues were sectioned at $6157 \mu \mathrm{m}$ thickness. Histochemical identification of intestinal cell types was performed with 616 Alcian blue and Nuclear Fast Red double staining. Liver sections were stained with 617 Hematoxylin and Eosin. Images were taken with Zeiss Axio Imager M1 microscope. 


\section{Immunohistochemistry of lung}

Lung sample preparation and immunohistochemistry were performed as previously

621 described $^{69}$. To expose the heart and lungs, the chest cavity of anesthetized mice was opened.

622 Through the right ventricle with manual pressure, a warm $\left(37^{\circ} \mathrm{C}\right)$ solution of $6 \%$ gelatin/PBS

623 (G1890, Sigma) was gently perfused. After 15 minutes exposure to ice-cold paper tissue, the

624 ventral trachea was cannulated with an intravenous catheter tube that was secured by tying a

625 suture around the trachea. The lungs were inflated to full capacity by gently injecting warm

$626\left(37^{\circ} \mathrm{C}\right) 1 \%$ low gelling agarose/PBS (A4018, Sigma). After 20 minutes exposure to ice-cold 627 paper tissue, the lungs were placed in $2 \%$ paraformaldehyde solution (PFA/PBS, $4{ }^{\circ} \mathrm{C}, \mathrm{P} 6148$, 628 Sigma) for $30 \mathrm{~min}$. After washing with cold PBS for $30 \mathrm{~min}$, the lung lobes were sliced $629(150 \mu \mathrm{m})$ using vibrating blade microtome (VT1200, Leica). Lung slices were fixed in $6304 \% \mathrm{PFA} / \mathrm{PBS}$ at $4{ }^{\circ} \mathrm{C}$ for $1 \mathrm{~h}$, washed thoroughly in PBS and incubated twice in PBS for $63130 \mathrm{~min}$ at room temperature. Lung slices were blocked (5\% donkey serum, $0.5 \%$ Triton X-100 632 in PBS) overnight at $4{ }^{\circ} \mathrm{C}$. Next, sections were treated with primary antibodies (goat anti633 CD31 (FAB3628, R\&D Systems, 1:100), rat anti-CD31 (553370, Pharmingen, 1:100), goat 634 anti-DLL4 (R\&D Systems; AF1389, 1:100)) in blocking solution over night at $4{ }^{\circ} \mathrm{C}$. 635 Following four washes with PBST (10 min each), sections were incubated with secondary 636 antibodies (donkey anti-goat IgG AF488 (A11055, Invitrogen, 1:500), donkey anti-goat IgG 637 AF647 (A21447, Thermo Fisher, 1:500), donkey anti-rat IgG AF647 (A21247, Invitrogen, 638 1:500)) in blocking solution over night at $4{ }^{\circ} \mathrm{C}$. Nuclei were counterstained with DAPI 639 (D9542, Sigma, $2 \mu \mathrm{g} / \mathrm{ml}$ ). After four wash steps with PBS, sections were mounted using 640 FluoroMount-G (Southern Biotech) under cover slips.

641

642 Analysis of inflammatory cytokines and thymic T cells 
644 Sarstedt) for blood collection. Cells were removed from plasma by centrifugation for $15 \mathrm{~min}$ 645 at 2,000x g using an ice-cold refrigerated centrifuge. Cytokines levels were measured from 646 the resulting supernatant with LEGENDplex ${ }^{\mathrm{TM}}$ Mouse Inflammation Panel (13-plex) with V647 bottom plates (740446, Biolegend). Analysis and quantification were performed according to 648 the manufacturer's protocol. Data analysis was performed using software provided by 649 Biolegend. Manual gating was used to define beads A and B, while an automatic gating strategy was used to gate individual cytokine in APC-PE plot. suspensions of thymocytes, individual thymi were placed in pre-wet $70 \mu \mathrm{m}$ cell strainers immersed in ice-cold 2\%FCS/PBS in petri dishes for gentle disruption with the end of a $5 \mathrm{ml}$ syringe plunger. Thymocytes were stained with rat-anti-CD45-FITC (11-0451, eBioscience), rat-anti-CD8-Biotin (13-0081, eBioscience) and rat-anti-CD4-APC (17-0042-82, eBioscience) followed by staining with Streptavidin PE/Cy7 (SA1012, Thermo Scientific). Flow cytometry was performed using a FACSAria Fusion with FACSDiva (BD Biosciences).

\section{Analysis of vascular leakage}

Adult mice were injected with $1 \mathrm{mg}$ of $70 \mathrm{kDa}$ Dextran, Texas Red ${ }^{\mathrm{TM}}$ (Lysine fixable, D1864, Molecular Probes) dissolved in $200 \mu$ l of PBS via tail vein injection. Femur, liver, kidney and lung were harvested from Dextran and PBS-injected mice after 15min and subjected to sample preparation and staining as describe above for bone samples.

\section{Micro-CT analysis and histomorphometry}

Tibiae were collected and attached soft tissue was removed thoroughly prior to

667 fixation in $4 \%$ paraformaldehyde overnight at $4^{\circ} \mathrm{C}$. Fixed samples were analyzed with micro 668 computed tomography ( $\mu$ CT 50) by Scanco Medical AG, Switzerland. A voxel size of $6 \mu \mathrm{m}$ 
669 was chosen in all three spatial dimensions. For each sample, 500 slices were evaluated 670 covering a total of $3 \mathrm{~mm}$, X-ray voltage was $70 \mathrm{kVp}$, intensity $86 \mu \mathrm{A}$, and integration time $671 \quad 1000 \mathrm{~ms}$, frame averaging 1.

672 Calcein double labelling was performed as reported previously ${ }^{70}$ with minor 673 modifications to calculate bone formation rate (BFR) and mineral apposition rate (MAR). 674 Briefly, mice were intraperitoneally injected with $10 \mathrm{mg} \mathrm{kg}^{-1}$ calcein (Sigma, C0875) 675 dissolved in $2 \%$ sodium bicarbonate solution at the tenth day and third day before euthanasia. 676 Bones were fixed in 4\% PFA for $2 \mathrm{~d}$ at room temperature followed by transfer to $70 \%$ ethanol. 677 Fixed bones were incubated with $5 \%$ potassium hydroxide for $96 \mathrm{~h}$ at room temperature. 678 Processed bones were embedded in bone embedding solution (8\% porcine gelatin in the 679 presence of $20 \%$ sucrose and $2 \%$ PVP). Cryosections were taken at $20 \mu \mathrm{m}$ using low-profile 680 blades on a Leica CM2050 cryostat. Single plane images were acquired from the sections 681 using an LSM 880 confocal microscope (Carl Zeiss). Representative images show trabecular 682 bone. Mineral apposition rate and bone formation rate were calculated from trabecular bone in 683 the metaphysis.

\section{Single cell sequencing of bone marrow stromal cells}

Femurs and tibiae were harvested 3 weeks post-injection from adult mice at the age of 11 weeks. Bones were crushed by pestle and mortar with ice-cold 2\% FCS/PBS and followed by 30 min digestion at $37{ }^{\circ} \mathrm{C}$ with collagenase cocktail by mixing with $2 \mathrm{mg} / \mathrm{ml}$ of 689 collagenase IV (17104-019, Gibco), 2 mg/ml collagenase I (17100-017, Gibco), and 10 U/ml 690 of Dispase (17105-041) in a 1:1:1 ratio. The resulting single cell suspension was subjected to 691 depletion of lineage-positive hematopoietic cells with following reagents from Miltenyi 692 Biotec: Lineage Cell Depletion Kit (130-090-858), CD45 Microbeads (130-052-301), CD117 693 Microbeads (130-091-224), Ter-119 Microbeads (130-049-901), and CD71-biotin (Biolegend, 694 113803) in combination with Anti-Biotin UltraPure MicroBeads (Miltenyi Biotec, 130-105- 
637). Lineage-depleted stromal cells were loaded into a BD Rhapsody ${ }^{\mathrm{TM}}$ Cartridge for capturing single cells for whole transcriptome according to the manufacturer's instructions. scRNA libraries were prepared with The BD Rhapsody Whole Transcriptome Analysis (WTA) Amplification kit. DNA sequencing was performed on a NextSeq500 (Illumina).

\section{scRNA-seq bioinformatics and data access}

FASTQ files from BD Rhapsody WTA and sequencing were first trimmed for adapters and Phred score (>20) using TrimGalore! (0.6.4), discarding reads shorter than 66bp after trimming. The first mate was then split into barcode and UMI using the pattern described in the BD Rhapsody Bioinformatics Handbook (revision 6.0, Figure 3), allowing up to 2 mismatches in each of the fixed sequences L1 and L2. A barcode whitelist was created by counting the occurrences of each of the three CLS sequences, choosing those that occur at least 1000 times, and forming every possible combination of CLS1-CLS2-CLS3. Reads were mapped using Salmon alevin (1.1.0) with the vM22 Gencode transcripts and genomic decoy sequences, including the above whitelist for barcode correction. Automatic filtering by Salmon alevin was disabled; and Alevin count matrices were used for downstream analyses. Count matrices were loaded into R using tximport (1.1.14). Empty wells were identified using DropletUtils (1.6.1) with an FDR cutoff of 0.001. Cells classified as empty wells or with less than 500 expressed genes, and genes with signal in less than 10 cells were removed from the analysis. Doublets were identified using scDblFinder (1.0.0) with default parameters and subsequently removed. Filtered count matrices were imported into Seurat (3.1.3). Mitochondrial gene contribution was estimated using Seurat's PercentageFeatureSet, and cells with more than $20 \%$ mitochondrial reads were removed. Expression counts were normalized using scran normalize (1.14.6). Control and treatment samples were analyzed together as an integrated Seurat dataset. The data was scaled using Seurat's ScaleData 
function and variable features were selected by FindVariableFeatures (nFeatures=2000, selection.method='vst'). parameter of 0.05 , using the top 50 principal components (PCs). Marker genes were identified using Seurat's FindAllMarkers function with default settings, and cells identified as hematopoietic were removed as contaminants. Marker expression was plotted using DoHeatmap on the top 10 marker genes in each cluster. Dimensionality reduction plots are based on UMAP projections using Seurat's RunUMAP function.

For the MSC population subclustering, we first applied stricter empty droplet filtering $(\mathrm{FDR}=0)$ to remove low complexity subpopulations. The expression values were re-scaled and variable feature selection was repeated. We then used the top 6 PCs for Louvain clustering at a resolution of 0.05 , and UMAP projection. Marker genes were identified using Seurat's FindAllMarkers function with default settings, and marker expression was plotted using DoHeatmap on the top 5 marker genes in each cluster.

Differentially expressed genes were identified separately for each cluster, using Seurat's FindMarkers function with default settings (Wilcoxon Rank Sum Test) on the

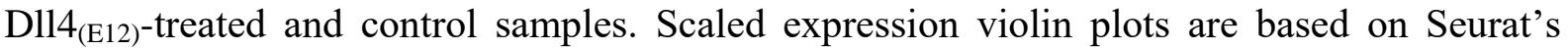
RNA assay and the "data" slot. Each violin is scaled to the width of the plotting window. testing. P-values were multiple testing corrected using the Bonferroni method. scRNA-seq data have been deposited in the GEO functional genomics data repository

741 under the accession number GSE152285. Data can be accessed via https://www.ncbi.nlm.nih.gov/geo/query/acc.cgi?acc=GSE152285 with the token 743 mzcbwwqgptidxmh. 
Half of the median liver lobe was dissected from plasmid and vehicle injected mice and snap frozen in liquid nitrogen. Liver samples were homogenized in lysis buffer $(50 \mathrm{mM}$ Tris- $\mathrm{HCl} \mathrm{pH}$ 7.4, $1 \mathrm{mM}$ EDTA, 1\% Triton X-100, 0.2\% Na-DOC, 0.2\% SDS, cOmplete ULTRA Proteinase inhibitor 1x (Roche, 05892970001), Phosphatase Inhibitor Cocktail Set V (524632-1SET, Merck), $1 \mathrm{mM}$ PMSF) with Tissuelyser LT (QIAGEN) and clarified by centrifugation by $20000 \mathrm{x} \mathrm{g}$ for $20 \mathrm{~min}$ at $4^{\circ} \mathrm{C}$. Protein concentration in lysates was measured using Pierce ${ }^{\mathrm{TM}} \mathrm{BCA}^{\mathrm{TM}}$ Protein-Assay kit (23225, Pierce). Soluble supernatants were prepared in SDS-PAGE sample buffer and analyzed by SDS-polyacrylamide gel electrophoresis and immunoblotting after loading $40 \mu \mathrm{g}$ of total liver lysate. Signal was detected using horseradish peroxidase-conjugated secondary antibodies followed by ECL Prime Western Blotting Detection Reagents (RPN2232, GE Healthcare). Primary antibodies: goat anti-Dll4 (AF1389, R\&D, 1:200), rabbit anti-GAPDH (AM4300, Ambion, 1:1000). Secondary antibodies: goat anti-rabbit IgG, HRP-linked whole Ab (7074, Cell Signaling, 1: 15000), donkey anti-goat IgG, HRP-linked whole Ab (ABIN1536502, antibody online, 1:15000). buffer and analyzed by SDS-polyacrylamide gel electrophoresis, followed by immunoblotting.

762 Primary antibodies used are mouse anti-His tag (Zymed; 372900 1:200) and goat anti-Jag1 763 (Sigma; J4127 1:500). Secondary antibodies used are sheep anti-mouse IgG 656G, HRP764 linked whole Ab (HG-Healthcare, NA931, 1:40000) and Peroxidase AffiniPure bovine anti 765 goat IgG (H+L) (Jackson Immuno Research, 805-035-180, 1:15000).

\section{Image acquisition, processing and statistical analysis}

Confocal image acquisition was performed using confocal microscope LSM880

769 (Zeiss). Z-stacks of images were processed and 3D reconstructed with Imaris software 770 (version 9.50, Bitplane). Image J (NIH) and Illustrator (Adobe) software were used for image 
processing. Quantifications of vascular and bone related parameters were performed with Fiji software on high resolution images.

For quantification of Osterix ${ }^{+}$and Runx $2^{+}$cells, a region of $400 \mu \mathrm{m}$ from growth plate towards the caudal region was selected in images of the metaphysis. Osteoclast surface/bone surface (Oc. S/BS; \%) and osteoclast number/bone perimeter (No. Oc./B. Pm) were calculated based on ATP6V1B1 + ATP6V1B2 staining of bone sections. VEGFR3 ${ }^{\text {low }}$ area was calculated based on VEGFR3 staining and normalized to the total selected area. Adipocyte cell number was calculated based on Perilipin staining of bone sections. Artery number was calculated based on BCAM staining

Col1a1, PDGFRb, Dll4, Endomucin, OPN areas were calculated based on the corresponding stainings and were normalized to DAPI area. The length of metaphysis was calculated as the mean of three values: length of left, right and middle regions of metaphysis.

All images shown are representative for the respective staining in several experiments. Within one experiment laser excitation and confocal scanner detection were the same. All images shown in the figures are maximum intensity projections and are representative of at least three mice analyzed for each condition unless stated otherwise.

Statistical analysis was performed with Graphpad Prism software. All data are presented as mean \pm s.e.m or mean \pm SD. Unpaired two tailed Student's t-test, Mann-Whitney U test, one-way and two-way ANOVA were used to determine statistical significance, as indicated in the legends. All experiments were performed independently at least three times and respective data were used for statistical analysis. Sample sizes for each experiment are described in the respective figure legends. No randomization or blinding was used and no animals were excluded from analysis. Several independent experiments were performed to guarantee reproducibility of findings. 
was supported by the Alexander von Humboldt Foundation.

\section{References}

8021 NIH Consensus Development Panel on Osteoporosis Prevention, Diagnosis, and

803 Therapy, March 7-29, 2000: highlights of the conference. South Med J 94, 569-573,

$804 \quad$ (2001).

8052 Cosman, F. et al. Clinician's Guide to Prevention and Treatment of Osteoporosis.

$806 \quad$ Osteoporos Int 25, 2359-2381, (2014).

8073 Walsh, M. C. et al. Osteoimmunology: interplay between the immune system and

808 bone metabolism. Annu Rev Immunol 24, 33-63, (2006).

8094 Feng, X. \& McDonald, J. M. Disorders of bone remodeling. Annu Rev Pathol 6, 121-

$810 \quad 145,(2011)$.

8115 Saag, K. G. et al. Alendronate for the prevention and treatment of glucocorticoid-

812 induced osteoporosis. Glucocorticoid-Induced Osteoporosis Intervention Study Group.

$813 \quad$ N Engl J Med 339, 292-299, (1998).

8146 Eastell, R. et al. Prevention of bone loss with risedronate in glucocorticoid-treated

815 rheumatoid arthritis patients. Osteoporos Int 11, 331-337, (2000).

8167 Chesnut, C. H., 3rd et al. Effects of oral ibandronate administered daily or

817 intermittently on fracture risk in postmenopausal osteoporosis. J Bone Miner Res 19,

818 1241-1249, (2004).

8198 Lyles, K. W. et al. Zoledronic acid and clinical fractures and mortality after hip

$820 \quad$ fracture. N Engl J Med 357, 1799-1809, (2007).

8219 Chesnut, C. H., 3rd et al. A randomized trial of nasal spray salmon calcitonin in 822 postmenopausal women with established osteoporosis: the prevent recurrence of 823 osteoporotic fractures study. PROOF Study Group. Am J Med 109, 267-276, (2000).

82410 Rossouw, J. E. et al. Risks and benefits of estrogen plus progestin in healthy

825

826

827

828

829

830 postmenopausal women: principal results From the Women's Health Initiative randomized controlled trial. JAMA 288, 321-333, (2002).

11 Neer, R. M. et al. Effect of parathyroid hormone (1-34) on fractures and bone mineral density in postmenopausal women with osteoporosis. N Engl J Med 344, 1434-1441, (2001).

831

832

833

834

835

12 Clarke, B. L. Anti-sclerostin antibodies: utility in treatment of osteoporosis. Maturitas 78, 199-204, (2014).

$13 \mathrm{Li}, \mathrm{X}$. et al. Sclerostin antibody treatment increases bone formation, bone mass, and bone strength in a rat model of postmenopausal osteoporosis. J Bone Miner Res 24, 578-588, (2009).

14 Ross, R. D. et al. Bone matrix quality after sclerostin antibody treatment. $J$ Bone

$836 \quad$ Miner Res 29, 1597-1607, (2014). 
15 Sekido, T. et al. Novel Drug Delivery System to Bone Using Acidic Oligopeptide: Pharmacokinetic Characteristics and Pharmacological Potential. Journal of Drug Targeting 9, 111-121, (2001).

16 Yokogawa, K. et al. Selective delivery of estradiol to bone by aspartic acid oligopeptide and its effects on ovariectomized mice. Endocrinology 142, 1228-1233, (2001).

17 Gil, L. et al. Prostaglandin E2-bisphosphonate conjugates: potential agents for treatment of osteoporosis. Bioorg Med Chem 7, 901-919, (1999).

18 Stapleton, M. et al. Development of Bone Targeting Drugs. Int J Mol Sci 18, (2017).

19 Katsumi, H. et al. Molecular Design of Bisphosphonate-Modified Proteins for Efficient Bone Targeting In Vivo. PLoS One 10, e0135966, (2015).

20 Zanotti, S. \& Canalis, E. Notch Signaling and the Skeleton. Endocr Rev 37, 223-253, (2016).

21 Hicks, C. et al. A secreted Delta1-Fc fusion protein functions both as an activator and inhibitor of Notch1 signaling. J Neurosci Res 68, 655-667, (2002).

22 Noguera-Troise, I. et al. Blockade of Dll4 inhibits tumour growth by promoting nonproductive angiogenesis. Nature 444, 1032-1037, (2006).

23 Ramasamy, S. K., Kusumbe, A. P., Wang, L. \& Adams, R. H. Endothelial Notch activity promotes angiogenesis and osteogenesis in bone. Nature 507, 376-380, (2014).

24 Hilton, M. J. et al. Notch signaling maintains bone marrow mesenchymal progenitors by suppressing osteoblast differentiation. Nat Med 14, 306-314, (2008).

25 Engin, F. et al. Dimorphic effects of Notch signaling in bone homeostasis. Nat Med 14, 299-305, (2008).

26 Yu, J. \& Canalis, E. Notch and the regulation of osteoclast differentiation and function. Bone 138, 115474, (2020).

27 Jiménez-Alcázar, M. et al. Host DNases prevent vascular occlusion by neutrophil extracellular traps. Science 358, 1202-1206, (2017).

$28 \mathrm{Wu}$, Y. et al. Therapeutic antibody targeting of individual Notch receptors. Nature 464, 1052-1057, (2010).

29 Kusumbe, A. P., Ramasamy, S. K. \& Adams, R. H. Coupling of angiogenesis and osteogenesis by a specific vessel subtype in bone. Nature 507, 323-328, (2014).

30 Polacheck, W. J. et al. A non-canonical Notch complex regulates adherens junctions and vascular barrier function. Nature 552, 258-262, (2017).

31 Langen, U. H. et al. Cell-matrix signals specify bone endothelial cells during developmental osteogenesis. Nat Cell Biol 19, 189-201, (2017).

32 Luca, V. C. et al. Structural biology. Structural basis for Notch1 engagement of Deltalike 4. Science 347, 847-853, (2015).

33 Yan, M. et al. Chronic DLL4 blockade induces vascular neoplasms. Nature 463, E6E7, (2010).

34 Fung, E. et al. Delta-like 4 induces notch signaling in macrophages: implications for inflammation. Circulation 115, 2948-2956, (2007).

35 Youngstrom, D. W. et al. Jagged1 expression by osteoblast-lineage cells regulates trabecular bone mass and periosteal expansion in mice. Bone 91, 64-74, (2016).

36 Liu, P. et al. Anabolic actions of Notch on mature bone. Proc Natl Acad Sci U S A 113, E2152-2161, (2016).

37 Benedito, R. et al. The notch ligands Dll4 and Jagged1 have opposing effects on angiogenesis. Cell 137, 1124-1135, (2009).

38 Golson, M. L. et al. Jagged1 is a competitive inhibitor of Notch signaling in the embryonic pancreas. Mech Dev 126, 687-699, (2009).

39 Luca, V. C. et al. Notch-Jagged complex structure implicates a catch bond in tuning ligand sensitivity. Science 355, 1320-1324, (2017). 
40 Chen, L. et al. Insulin-like growth factor 2 (IGF-2) potentiates BMP-9-induced osteogenic differentiation and bone formation. J Bone Miner Res 25, 2447-2459, (2010).

41 Yagami, K. et al. Matrix GLA protein is a developmental regulator of chondrocyte mineralization and, when constitutively expressed, blocks endochondral and intramembranous ossification in the limb. J Cell Biol 147, 1097-1108, (1999).

42 Wilson, S. S., Wong, A., Toupadakis, C. A. \& Yellowley, C. E. Expression of angiopoietin-like protein 4 at the fracture site: Regulation by hypoxia and osteoblastic differentiation. J Orthop Res 33, 1364-1373, (2015).

43 Knowles, H. J., Cleton-Jansen, A. M., Korsching, E. \& Athanasou, N. A. Hypoxiainducible factor regulates osteoclast-mediated bone resorption: role of angiopoietinlike 4. Faseb j 24, 4648-4659, (2010).

44 Novince, C. M. et al. Proteoglycan 4: a dynamic regulator of skeletogenesis and parathyroid hormone skeletal anabolism. J Bone Miner Res 27, 11-25, (2012).

45 Baryawno, N. et al. A Cellular Taxonomy of the Bone Marrow Stroma in Homeostasis and Leukemia. Cell 177, 1915-1932.e1916, (2019).

46 Pinho, S. \& Frenette, P. S. Haematopoietic stem cell activity and interactions with the niche. Nat Rev Mol Cell Biol 20, 303-320, (2019).

47 Zhou, B. O., Yue, R., Murphy, M. M., Peyer, J. G. \& Morrison, S. J. Leptin-receptorexpressing mesenchymal stromal cells represent the main source of bone formed by adult bone marrow. Cell Stem Cell 15, 154-168, (2014).

48 Mizoguchi, T. et al. Osterix marks distinct waves of primitive and definitive stromal progenitors during bone marrow development. Dev Cell 29, 340-349, (2014).

49 Limbourg, F. P. et al. Essential role of endothelial Notch1 in angiogenesis. Circulation 111, 1826-1832, (2005).

50 Ramasamy, S. K. et al. Blood flow controls bone vascular function and osteogenesis. Nat Commun 7, 13601, (2016).

51 Kasugai, S., Fujisawa, R., Waki, Y., Miyamoto, K. \& Ohya, K. Selective drug delivery system to bone: small peptide (Asp)6 conjugation. J Bone Miner Res 15, 936943, (2000).

52 Miller, S. C. et al. Feasibility of using a bone-targeted, macromolecular delivery system coupled with prostaglandin $\mathrm{E}(1)$ to promote bone formation in aged, estrogendeficient rats. Pharm Res 25, 2889-2895, (2008).

53 Zhang, G. et al. A delivery system targeting bone formation surfaces to facilitate RNAi-based anabolic therapy. Nat Med 18, 307-314, (2012).

54 Hill, C. R., Yuasa, M., Schoenecker, J. \& Goudy, S. L. Jagged1 is essential for osteoblast development during maxillary ossification. Bone 62, 10-21, (2014).

55 Dishowitz, M. I. et al. Jagged1 immobilization to an osteoconductive polymer activates the Notch signaling pathway and induces osteogenesis. J Biomed Mater Res A 102, 1558-1567, (2014).

56 Osathanon, T. et al. Surface-bound orientated Jagged-1 enhances osteogenic differentiation of human periodontal ligament-derived mesenchymal stem cells. $J$ Biomed Mater Res A 101, 358-367, (2013).

57 Chen, S. et al. Notch gain of function inhibits chondrocyte differentiation via Rbpjdependent suppression of Sox9. J Bone Miner Res 28, 649-659, (2013).

58 Kwan, K. M. et al. Abnormal compartmentalization of cartilage matrix components in mice lacking collagen X: implications for function. J Cell Biol 136, 459-471, (1997).

59 Canalis, E., Parker, K., Feng, J. Q. \& Zanotti, S. Osteoblast lineage-specific effects of notch activation in the skeleton. Endocrinology 154, 623-634, (2013).

60 Bianco, P. \& Gehron Robey, P. Marrow stromal stem cells. J Clin Invest 105, 16631668, (2000). 
61 Nombela-Arrieta, C., Ritz, J. \& Silberstein, L. E. The elusive nature and function of mesenchymal stem cells. Nat Rev Mol Cell Biol 12, 126-131, (2011).

62 Ortinau, L. C. et al. Identification of Functionally Distinct Mx1+aSMA+ Periosteal Skeletal Stem Cells. Cell Stem Cell 25, 784-796.e785, (2019).

63 Ono, N., Ono, W., Nagasawa, T. \& Kronenberg, H. M. A subset of chondrogenic cells provides early mesenchymal progenitors in growing bones. Nat Cell Biol 16, 11571167, (2014).

64 Uccelli, A., Moretta, L. \& Pistoia, V. Mesenchymal stem cells in health and disease. Nat Rev Immunol 8, 726-736, (2008).

65 Sivaraj, K. K. et al. Regional specialization and fate specification of bone stromal cells in skeletal development. Cell Rep 36, 109352, (2021).

66 Radtke, F. et al. Deficient T cell fate specification in mice with an induced inactivation of Notch1. Immunity 10, 547-558, (1999).

67 van Es, J. H. et al. Notch/gamma-secretase inhibition turns proliferative cells in intestinal crypts and adenomas into goblet cells. Nature 435, 959-963, (2005).

68 Liu, F., Song, Y. \& Liu, D. Hydrodynamics-based transfection in animals by systemic administration of plasmid DNA. Gene Ther 6, 1258-1266, (1999).

69 Kato, K. et al. Pulmonary pericytes regulate lung morphogenesis. Nat Commun 9 , 2448, (2018).

70 Porter, A. et al. Quick and inexpensive paraffin-embedding method for dynamic bone formation analyses. Scientific Reports 7, 42505, (2017).

\section{Figure Legends}

Figure 1. Recombinant $\mathrm{Dll4}_{(\mathrm{E} 12)}$ increases bone formation in vivo

(A) Schematic diagram showing the domain organization of murine Dll4 full length protein and recombinant Dll4-Asp $8 \mathrm{x}$ and $\mathrm{Dll}_{(\mathrm{E} 12)}$ fusion proteins. The latter contain 6x His epitope tags (green boxes) and negatively charged peptides consisting of 8 Asp residues (8x Asp; blue boxes) instead of the transmembrane (TM) domain and cytoplasmic region (CR) of Dll4. Missense mutations were introduced in the MNNL (modulus at the N-terminus of Notch ligands) and DSL (Delta-Serrate-Lin) domains to generate Dll4 $($ E12) with increased Notch 
974 binding affinity. The resulting amino acid replacements are highlighted in red. SP, signal 975 peptide.

976 (B) Representative overview and high-magnification confocal images of D1l4 staining (green) 977 on the femurs of $p L I V E-D l l 4_{(E 12)}$ and control-injected mice at the age of 11 weeks. Nuclei, 978 DAPI (blue). Images on the right show higher magnifications of insets in metaphysis (1), 979 bone marrow (2) and cortical bone (3).

980 (C) Tile scan confocal images showing Collal staining (green) in sections from pLIVE$981 \operatorname{Dll}_{(E 12)}$ and control femur. Nuclei, DAPI (blue).

982 (D) Representative 3D reconstruction of $\mu \mathrm{CT}$ measurements for tibial metaphysis of 11-week983 old pLIVE-Dll4 ${ }_{(E 12)}$ - and control-injected mice.

984 (E) Bone parameters measured by $\mu \mathrm{CT}$ analyses: bone volume/total volume (BV/TV) in 985 percentage, trabecular thickness in millimeters, connectivity density in 1 per cubic millimeter, 986 trabeculae number in 1 per millimeter, trabecular separation in millimeters and trabecular 987 number in 1 per millimeter. Data represent mean \pm s.e.m. ( $n=5$ mice, except for trabecular 988 number with $\mathrm{n}=4$ mice), ( $\mathrm{p}$-values determined by unpaired $\mathrm{t}$ test with Welch's correction).

989 Graphs at the bottom represent quantitation of eroded surface over bone surface (ES/BS) in 990 percentage and osteoblast surface overs total bone surface (Ob.S/BS) in percentage, 991 calculated from histological HE-stained bone sections. Data represent mean \pm s.e.m. $(n=5$ 992 mice), (p-values determined by Mann Whitney U test).

993 (F) Representative images of calcein double labeling (7-day time interval) in mineralized 994 sections of the distal femur confirm increased bone formation after $p L I V E-D l l 4_{(E 12)}$ injection. 995 Quantification of mineral apposition rate (MAR) and bone formation rate (BFR) (right 996 panels). Data represent mean \pm s.e.m. ( $\mathrm{n}=5$ mice), ( $\mathrm{p}$-values determined by unpaired $\mathrm{t}$ test 997 with Welch's correction).

999 Figure 1-source data 1. Source data for Figure 1E and F. 
1001 Figure 1-figure supplement 1. Generation of Dll4-Asp 8 recombinant proteins

1002 (A) SDS-PAGE analysis of purified Dll4-Asp $8 x$ recombinant proteins. From left to right, 1003 protein molecular mass marker (Marker), extract of untransfected HEK293 cells (Cells (-)) 1004 OR pcDNA3.1-Dll4-Asp $8 x$ transfected cells (Cells (+)), supernatant after culture of 1005 untransfected (Supernatant (-)) OR pcDNA3.1-Dll4-Asp 8 transfected cells (Supernatant (+)), 1006 flow through after loading of Supernatant (+) on His-tag protein purification column (Flow1007 through), wash buffer (Wash), elute (Elute), elute after dialysis (Elute (AD)) and Opti-MEM 1008 culture medium (Medium) were loaded.

1009 (B, C) RT-qPCR analysis of DLL4, HEY1, HEY2, HES1, EFNB2, and NRARP transcripts in 1010 confluent HUVECs stimulated with soluble (B) or in sub-confluent HUVECs stimulated with 1011 immobilized Dll4-Asp $\mathrm{px}_{8 \mathrm{x}}$ or BSA with poly-L-lysine coating $(\mathbf{C})$. Data represent mean \pm s.e.m. $1012(\mathrm{n}=4$ for $(\mathbf{B})$ and $\mathrm{n}=6$ for $(\mathbf{C}))$, (p-values determined by multiple unpaired t test with Welch's 1013 correction).

1014

Figure 1-supplement 1-source data 1. Source data for Figure 1-figure supplement 1B, C.

1016

Figure 1-supplement 1-source data 2. Images of uncropped blots and gels with the relevant bands labeled for Figure 1-figure supplement 1, Figure 1-figure supplement 4, and Figure 5figure supplement 1 .

Figure 1-supplement 1-source data 3. ZIP file containing the full raw unedited blots and gels for Figure 1-figure supplement 1, Figure 1-figure supplement 4, and Figure 5-figure supplement 1 . 
1026 (A, B) Confocal images showing Dll4 (cyan) and Emcn (red) staining in femoral metaphysis

1027 (A) and endosteum and cortical bone (B) of $p L I V E-D l l 4-A s p_{8 x}$ and control-injected 11-week1028 old mice. Nuclei, DAPI (blue).

1029 (C) Higher magnification images showing pronounced Dll4 signal (cyan, arrows) in 1030 proximity of Emcn+ (red) distal vessels in the $p L I V E-D l l 4-A s p_{8 x}$ metaphysis. Nuclei, DAPI 1031 (blue).

1032

Figure 1-figure supplement 3. Bone formation is not increased by Dll4-Asp8x

1034 (A) Tile scan images of Dll4 (cyan) staining in sections of $p L I V E-D l l 4-$ Asp $_{8 x}$ and control 1035 femur. Nuclei, DAPI (blue). Images on the right show higher magnifications of insets in 1036 metaphysis (1), bone marrow (2) and cortical bone (3).

1037 (B) OSX, Osteopontin and Col1a1 (green) immunostaining, as indicated, in $p L I V E-D l l 4-A s p_{8 x}$ 1038 and control femur. Nuclei, DAPI (blue).

1039

1040 Figure 1-figure supplement 4. Generation of Dll4

1041 (A) Diagram showing the amino acid sequence of mouse and rat Dll4 ECD. Amino acid 1042 replacements shown in red were introduced into the murine sequence for the generation of 1043 Dll4 (E12) with increased Notch binding affinity.

1044 (B) SDS-PAGE analysis of purified Dll4 $(\mathrm{E} 12)$ recombinant protein. From left to right, protein 1045 molecular mass marker (Marker), supernatant after culture of untransfected (Supernatant (-))

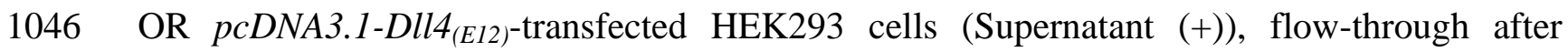
1047 loading of Supernatant (+) on His-tag protein purification column (Flow-through), wash 1048 buffer (Wash), elute (Elute), elute after dialysis (Elute (AD)), and Opti-MEM culture medium 1049 (Medium) were loaded.

1050 (C, D) RT-qPCR analysis of DLL4, HEY1, HEY2, HES1, EFNB2, and NRARP transcripts in 1051 confluent HUVECs stimulated with soluble (C) or in sub-confluent HUVECs stimulated with 
1052 immobilized Dll4 ${ }_{(\mathrm{E} 12)}$, Dll4-Asp $8 \mathrm{x}$ and BSA by poly-L-lysine coating (D). Data represent 1053 mean \pm s.e.m. ( $\mathrm{n}=3$ for $(\mathbf{C})$ and $\mathrm{n}=4$ for $(\mathbf{D})$ ), ( $\mathrm{p}$-values determined by ordinary one-way 1054 ANOVA with Tukey's multiple comparison test).

1055 (E) Western blot analysis of Dll4 $_{(\mathrm{E} 12)}$ protein expression in liver lysate of $p L I V E-D l l 4_{(E 12)}$ and 1056 control-injected mice. GAPDH is used as loading control.

1057

1058 Figure 1-supplement 4-source data 1. Source data for Figure 1-figure supplement 1C, D.

1059

1060 Figure 1-figure supplement 5. Dll4 $(\mathrm{E12})$ immunoreactivity in vivo

1061 (A-C) Representative confocal images showing Dll4 $(\mathrm{E} 12)$ immunoreactivity after $p L I V E$ $1062 \operatorname{Dll}_{(E 12)}$ or control injection in liver (A), spleen $(\mathbf{B})$ and lung $(\mathbf{C})$. Dll4 (E12) signal (green) is 1063 prominent in liver hepatocytes but undetectable in spleen and lung. Note absence of overt 1064 changes in the vasculature (red) of all three organs. Nuclei (DAPI, blue).

1065

1066 Figure 2. Notch-dependent processes are not blocked by $\mathrm{Dll}_{(\mathrm{E} 12)}$ in vivo

1067 (A) Alcian blue and Nuclear fast red double staining of small intestine. Secretory goblet cells 1068 are labeled by Alcian blue.

1069 (B) Hematoxylin and eosin staining of liver sections of 11-week-old pLIVE-Dll4(E12) and 1070 control-injected mice.

1071 (C, D) Analysis of $\mathrm{CD}^{+} / \mathrm{CD}^{+}$cells from $p L I V E-D l l 4_{(E 12)}$ and control thymi by flow

1072 cytometry $(\mathbf{C})$ and corresponding quantification $(\mathbf{D})$. Data represent mean \pm s.e.m. $(\mathrm{n}=3$ mice $)$, 1073 (p-values determined by unpaired t test with Welch's correction).

1074 (E) Confocal images showing comparable extravasation of fluorescent Dextran (70kD) in 1075 femur of pLIVE-Dll4 (E12) and control-injected mice.

1076 (F) Quantitation of Texas-Red-labeled Dextran extravasation in femoral metaphysis and 1077 diaphysis of $p L I V E-D_{l l 4_{(E 12)}}$ and control-injected mice. Data represent mean \pm s.e.m. (n=5 
mice), (adjusted p-values determined by two-way ANOVA with Tukey's multiple comparison test).

Figure 2-source data 1. Source data for Figure 2D, F

Figure 2-figure supplement 1. Inflammatory cytokines are not induced by Dll4(E12)

Quantification of inflammatory cytokines in the plasma of pLIVE-Dll4 (E12)- and controlinjected mice. Data represent mean \pm s.e.m. ( $n=3$ mice), ( $p$-values determined by multiple unpaired t test with Welch correction).

Figure 2-supplement 1-source data 1. Source data for Figure 2-figure supplement 1

\section{Figure 2-figure supplement 2. Dll4 $(\mathrm{E12})$ does not induce vascular leakage}

(A-C) Representative confocal images and corresponding quantitation showing comparable extravasation of Texas-red-coupled fluorescent Dextran (purple) in liver (A), spleen (B) and lung $(\mathbf{C})$ of $p L I V E-D l l 4_{(E 12)}$ and control-injected mice. Vasculature in liver and spleen $(\mathbf{A}, \mathbf{B})$ has been immunostained for Emcn (green) and in lung (C) for CD31 (green). Data represent mean \pm s.e.m. ( $\mathrm{n}=5$ mice), ( $\mathrm{p}$-values determined by unpaired $\mathrm{t}$ test with Welch's correction).

Figure 2-supplement 2-source data 1. Source data for Figure 2-figure supplement 2A-C

Figure 3. Recombinant $\mathrm{Dll4}_{(\mathrm{E} 12)}$ increases osteogenesis

(A) Tile scan confocal images of OSX staining (green) in femurs from $p L I V E-D l l 4_{(E 12)}$ and control-injected mice. Nuclei, DAPI (blue). Graph shows quantitation of $\mathrm{OSX}^{+}$cells. Data represent mean \pm s.e.m. ( $n=4$ mice), ( $p$-values determined by two-tailed unpaired $t$ test). 
1103 (B) Runx2 staining (green) of $p L I V E-D l l 4_{(E 12)}$ and control femurs. Nuclei, DAPI (blue).

1104 Graph shows quantitation of Runx $2^{+}$cells. Data represent mean \pm s.e.m. $(n=4$ mice), (p-values 1105 determined by two-tailed unpaired $t$ test).

1106 (C) Representative images showing Osteopontin (Opn) and Osteocalcin staining (green) in $1107 p_{\text {LIVE-Dll4 }}^{(E 12)}$ and control femur. Nuclei, DAPI (blue). Data represent mean \pm s.e.m. $(\mathrm{n}=3$ 1108 mice), (p-values determined by unpaired t test with Welch's correction).

1109 (D) Tile scan images of ATP6V1B1 + ATP6V1B2 (V-ATPase) staining (green) in pLIVE$1110 \operatorname{Dll}_{(E 12)}$ and control femur. Nuclei, DAPI (blue). Graphs show quantification of osteoclast 1111 surface/bone surface (Os. S/B S) and osteoclast number/bone perimeter (No. Oc./B. Pm). 1112 Data represent mean \pm s.e.m. ( $\mathrm{n}=4$ mice), ( $\mathrm{p}$-values determined by unpaired $\mathrm{t}$ test with 1113 Welch's correction).

1114 (E) Tile scan images of Perilipin staining (green) in pLIVE-Dll4 $(E 12)$ and control femurs. 1115 Nuclei, DAPI (blue). Graph shows quantitation of Perilipin ${ }^{+}$adipocytes. Data represent mean $1116 \pm$ s.e.m. ( $\mathrm{n}=3$ mice), (p-values determined by unpaired t test with Welch's correction).

1118 Figure 3-source data 1. Source data for Figure 3A-E

Figure 3-figure supplement 1. Activation of the Hey1-EGFP reporter by Dll4 $(\mathrm{E} 12)$

1121 Expression of the Tg(Heyl-EGFP) $)^{\text {ID40Gsat }}$ reporter (GFP, green) in 11-week-old pLIVE$1122 \operatorname{Dll}_{(E 12)}$ and control femur. Note that Dll4 (E12) increases the number of $\mathrm{OSX}^{+}$cells (cyan) and 1123 leads to induction of GFP expression in the metaphysis but also in the adjacent transition zone.

1124 GFP+ cells show no or weak nuclear OSX signals (arrows). Vessels, Emcn (red). Nuclei, 1125 DAPI (blue). 
1128 (A, B) Tile scan confocal images showing that PDGFR $\beta(\mathbf{A})$ and NG2 (B) immunostaining in

1129 the adult metaphysis is increased by recombinant Dll4 $(\mathrm{E} 12)$. Nuclei, DAPI (blue).

1130 Graph shows quantitation of PDGFR $\beta$ area/DAPI area (A) and NG2 area/DAPI area in

1131 percentage. Data represent mean \pm s.e.m. $(n=3$ mice), ( $p$-values determined by unpaired $t$ test

1132 with Welch's correction).

1133 (C, D) Representative confocal images of chondrocyte staining in adult metaphysis showing that $\operatorname{ACAN}^{+}(\mathbf{C})$ and $\mathrm{SOX}^{+}(\mathbf{D})$ chondrocytes are not affected by $p L I V E-D l l 4_{(E 12)}$ injection.

1135 Nuclei, DAPI (blue). Graphs shows quantitation of $\mathrm{ACAN}^{+}$cells number $(\mathbf{C})$ and $\mathrm{SOX}^{+}$cells

1136 number (D). Data represent mean \pm s.e.m. $(\mathrm{n}=3$ mice), ( $\mathrm{p}$-values determined by unpaired $\mathrm{t}$ test 1137 with Welch's correction).

Figure 3-supplement 2-source data 1. Source data for Figure 3-figure supplement 2A-D

\section{Figure 4. Effect of $\mathrm{Dll}_{(\mathrm{E} 12)}$ on bone vasculature}

1142 (A) Tile scan images of Emcn (red), VEGRR3 (green) and OSX (cyan) stained sections of $1143 p^{p L I V E-D l l 4_{(E 12)}}$ and control femur at 11 weeks of age. Dashed line indicates the border of 1144 VEGFR $3^{\text {high }}$ and VEGFR $3^{\text {low }}$ area.

1145 (B) Higher magnifications of insets in (A) showing the metaphysis close to growth plate (1' 1146 and 2') and bone marrow close to transition zone (1', and 2'). Stainings show VEGFR3 1147 (green) and OSX (cyan). Note increase in $\mathrm{OSX}^{+}$cells and presence of OSX-stained nuclei 1148 close to VEGFR3 ${ }^{\text {high }}$ vessels after D114 ${ }_{(\mathrm{E} 12)}$ treatment.

1149 (C) Quantification of VEGFR3 ${ }^{\text {low }}$ area per region of interest (ROI) in the metaphysis. Data 1150 represent mean \pm s.e.m. $(n=5$ mice), ( $p$-values determined by unpaired $t$ test with Welch's 1151 correction).

1152 (D) Tile scan images of BCAM (green) stained sections of $p L I V E-D l l 4_{(E 12)}$ and control femur. 1153 Graph shows quantification of the number of $\mathrm{BCAM}^{+}$arteries per region of interest (ROI) in 
1154 the metaphysis. Data represent mean \pm s.e.m. $(n=3$ mice), ( $p$-values determined by unpaired $t$

1155 test with Welch's correction).

1157 Figure 4-source data 1. Source data for Figure 4C, D

1159 Figure 5. Bone formation is not changed by recombinant Jag1-Asp $\mathbf{8 x}_{\mathbf{x}}$ and Jag1(JV1).

1160 (A) Schematic diagram showing the domain organization of murine Jag1 full length protein 1161 and recombinant Jag1-Asp $8 \mathrm{x}$ and $\mathrm{Jag} 1_{(\mathrm{JV} 1)}$ fusion proteins. Fusion proteins contain 6x His

1162 epitope tag (green boxes) and $\mathrm{Asp}_{8 \mathrm{x}}$ negatively charged peptide motif (blue boxes) instead of 1163 the transmembrane (TM) domain and cytoplasmic region (CR) of Jag1. Missense mutations 1164 were introduced in the calcium-binding C2 and DSL (Delta-Serrate-Lin) domains to generate $1165 \mathrm{Jag} 1_{(\mathrm{JV} 1)}$ with increased Notch binding affinity. The resulting amino acid replacements are 1166 highlighted in red. SP, signal peptide.

1167 (B) Tile scan images of Colla1 (green) staining on the femur sections of control, pLIVE$1168 J a g 1-A s p_{8 x}$ and $p L I V E-J a g 1_{(J V I)}$-injected mice at the age of 11 weeks. Nuclei, DAPI (blue).

1169 (C) Representative 3D reconstruction from $\mu$ CT measurements of tibial metaphysis of $p L I V E-$ $1170 \operatorname{Jagl}_{(J V 1)}$ and control-injected mice. Diagrams show bone parameters measured in $\mu \mathrm{CT}$ 1171 analyses: bone volume/total volume (BV/TV) in percentage, trabecular thickness in

1172 millimeters, connectivity density in 1 per cubic millimeter, trabeculae number in 1 per 1173 millimeter and trabecular separation in millimeters. Data represent mean \pm s.e.m. $(n=5$ mice $)$, 1174 p-values determined by unpaired t test with Welch's correction).

1176 Figure 5-source data 1. Source data for Figure 5C

1178 Figure 5-figure supplement 1. Generation of Jag1-Asp 8x $_{\mathbf{x}}$ and Jag1 $\mathbf{J}_{(J V 1)}$ recombinant 1179 proteins 
1180 (A) SDS-PAGE analysis of purified Jag1-Asp $\mathrm{p}_{8 \mathrm{x}}$ recombinant protein. From left to right, 1181 protein molecular mass marker (Marker), extract of untransfected HEK293 cells (Cells (-)) 1182 OR pcDNA3.1-Jag1-Asp $8 x$ transfected cells (Cells (+)), supernatant after culture of 1183 untransfected (Supernatant (-)) OR pcDNA3.1-Jag1-Asp $8 x$ transfected cells (Supernatant (+)),

1184 flow through after loading of Supernatant (+) on His-tag protein purification column (Flow1185 through), wash buffer (Wash), elution of Jag1-Asp 8 (Elute) and Opti-MEM culture medium 1186 (Medium) were loaded.

1187 (A, B) SDS-PAGE analysis of purified Jag1-Asp ${ }_{8 x}(\mathbf{A})$ and Jag1 $1_{(\mathrm{JV} 1)}(\mathbf{B})$ recombinant proteins.

1188 From left to right, protein molecular mass marker (Marker), extract of untransfected (Cells (-)) 1189 or transfected HEK293 cells (Cells (+)), supernatant after culture of untransfected 1190 (Supernatant (-)) or transfected cells (Supernatant (+)), flow through after loading of 1191 Supernatant (+) on His-tag protein purification column (Flow-through), wash buffer (Wash), 1192 elution of recombinant Jag1 (Elute) and Opti-MEM culture medium (Medium) were loaded.

1193 (C) Western blot analysis of eluted Jag1-Asp $\mathrm{Px}_{\mathrm{x}}$ and Jag1 $1_{(\mathrm{JV} 1)}$ recombinant proteins used for in 1194 vitro stimulation experiments (D, E). Proteins detected at the expected molecular weight with 1195 anti-Jag1 and anti-His1 antibodies.

1196 (D, E) RT-qPCR analysis of human (HS) DLLA, HEY1, HEY2, HES1, EFNB2, and NRARP 1197 transcripts in confluent HUVECs after stimulation with soluble (D) or immobilized (poly-L1198 lysine coating) Jag1-Asp $8 x, \operatorname{Jag} 1_{(\mathrm{JV} 1)}$ and BSA (E). Data represent mean \pm s.e.m. (n=3), (p1199 values determined by ordinary one-way ANOVA with Tukey's multiple comparison test).

1201 Figure 5-supplement 1-source data 1. Source data for Figure 5-figure supplement 1D, E

Figure 5-figure supplement 2. Detection of Jag1-Asp ${ }_{8 x}$ and $\operatorname{Jag1}_{(J V 1)}$ in the bone

1204 (A) Tile scan confocal images of Jag1 (cyan) immunostaining in sections from control, 1205 pLIVE-Jagl-Asp $p_{8 x}$ and $p L I V E-J a g 1_{(J V I)}$ femur. Nuclei, DAPI (blue). 
1206 (B) Representative higher magnification images of CD31 (green) and Jag1 (cyan) staining in 1207 the metaphysis of control, pLIVE-Jag1-Asp $8 x$ and pLIVE-Jag1 $1_{(J V I)}$-injected mice. Nuclei, 1208 DAPI (blue).

1210 Figure 6. Bone formation is not increased by Dll4 $_{(\mathrm{E} 12)}$ in ovariectomized female mice

1211 (A, B) Representative 3D $\mu$-CT images of trabecular bone in the distal tibial metaphysis (A) 1212 and cortical bone in the mid-tibial diaphysis $(\mathbf{B})$ of sham or ovariectomized mice treated with 1213 vehicle or $p L I V E-D l l 4_{(E 12) .}$

1214 (C) Bone parameters measured by $\mu$-CT analysis of trabecular bone volume/total volume, 1215 trabecular connectivity density, trabecular thickness, trabecular separation, bone surface, and 1216 trabecular number in the distal tibial metaphysis. Data represent mean \pm SD. ( $n=5$ mice), (p1217 values determined by two-way ANOVA with Tukey’s multiple comparisons test).

1218 (D) Quantitation of $\mu$-CT analysis of cortical bone consistency and cortical thickness in the 1219 mid-tibial diaphysis. Data represent mean \pm SD. ( $n=5$ mice), (p-values determined by two1220 way ANOVA with Tukey’s multiple comparisons test).

1221 (E, F) Tile scan confocal images showing Colla1 staining (green; E) and PDGFR $\beta$ staining 1222 (green; F) in femoral sections from ovariectomized female mice treated with vehicle or $1223 p L I V E-D l l 4_{(E 12)}$. Nuclei, DAPI (blue). Graphs show relative ratio (percentage) of Col1a 1224 area/DAPI area and PDGFR $\beta$ area/DAPI area. Data represent mean \pm SD. $(\mathrm{n}=5$ mice), $(\mathrm{p}$ 1225 values determined by two-tailed unpaired t test $(\mathrm{E})$ with Welch's correction $(\mathrm{F}))$.

1226 (G) Representative $\mu$-CT images of trabecular bone in the distal tibial metaphysis of male, 1227 female sham, and ovariectomized mice. Graphs show quantitation of the trabecular bone 1228 volume/total volume, trabecular number, and bone surface. Data represent mean $\pm \mathrm{SD}$. $(\mathrm{n}=5$ 1229 mice), (p-values determined by one-way ANOVA followed by Sidak's multiple comparisons 1230 test. 
1232 Figure 6-source data 1. Source data for Figure 6C-G

1233

1234 Figure 6 - figure supplement 1. Reduced $\mathrm{DII4}_{(\mathrm{E} 12)}$ immunoreactivity and trabecular bone 1235 in female mice compared to male mice.

1236 (A, B) Representative overview confocal images of Col1a1 staining (green) in the femurs of 1237 wild-type male and female mice treated with vehicle $(\mathbf{A})$ or $p L I V E-D l l 4_{(E 12)}(\mathbf{B})$. Nuclei, DAPI 1238 (blue). Data represent mean \pm SD. ( $\mathrm{n}=5-7$ mice), (p-values determined by two-tailed unpaired $1239 t$-test (control) or unpaired t test).

1240 (C, D) Representative overview confocal images of Dll4 staining (green) in the femurs of 1241 wild-type male and female mice treated with vehicle (C) or pLIVE-Dll4(E12) (D). Nuclei, 1242 DAPI (blue).

1243 Diagrams represent percentage of Dll4 area/DAPI area. Data represent mean \pm SD. $(n=5-7$ 1244 mice), (p-values determined by two-tailed unpaired $t$-test (control) or unpaired t test with 1245 Welch's correction $\left.\left(D_{l l 4}(E 12)\right)\right)$.

1247 Figure 6-supplement 1-source data 1. Source data for Figure 6-figure supplement 1A-D

1249 Figure 7. Synergistic action of recombinant Dll4 ${ }_{(\mathrm{E12})}$ and PTH.

1250 (A) Representative $\mu$-CT images of trabecular bone in the distal femoral metaphysis of female 1251 wild-type mice treated with vehicle, pLIVE-DIl4(E12), PTH or the combination of both for 3 1252 weeks.

1253 (B-G) Quantitative analysis of $\mu-C T$ data on trabecular bone volume/total volume (B), 1254 trabecular connectivity density $(\mathbf{C})$, trabecular number $(\mathbf{D})$, bone surface $(\mathbf{E})$, trabecular 1255 thickness $(\mathbf{F})$, trabecular separation $(\mathbf{G})$ in the distal femoral metaphysis. Data represent mean $1256 \pm$ SD. (n=5 mice), (p-values determined by one-way ANOVAs $(\mathbf{F}, \mathbf{G})$ followed by Sidak's 
1257 multiple comparisons test or Brown-Forsythe and Welch ANOVAs (B, C, D, E) followed by

1258 Dunnett's T3 multiple comparisons test).

1259 (H) Representative $\mu$-CT images of cortical bone in the female midfemoral diaphysis.

1260 (I - K) Graphs from $\mu$-CT analysis of the cortical bone volume/total volume (I), cortical 1261 thickness $(\mathbf{J})$, and cortical porosity $(\mathbf{K})$ in the midfemoral diaphysis. Data represent mean \pm 1262 SD. ( $\mathrm{n}=5$ mice), (p-values determined using one-way ANOVAs followed by Sidak's multiple 1263 comparisons test).

1264

Figure 7-source data 1. Source data for Figure 7B-G, I-K

Figure 7 - figure supplement 1. Effects of combined PTH and Dll4(E12) administration

(A) Time course of pLIVE-Dll4(E12) and PTH administration to adult wild-type female mice. (B-E) Representative overview confocal images and corresponding quantification of immunostainings for Dll4 (B, green), Col1a1 (C, green), PDGFR $\beta$ (D, green), Endomucin (E, red) in the femurs treated with vehicle, pLIVE-Dll4(E12), PTH or the combination of both. Nuclei, DAPI (blue). Data represent mean \pm SD. ( $n=4-5$ mice), Statistical significance was assessed using one-way ANOVAs (B, C, D) followed by Sidak's multiple comparisons test or Brown-Forsythe and Welch ANOVA (E) followed by Dunnett's T3 multiple comparisons test.

Figure 7-supplement 1-source data 1. Source data for Figure 7-figure supplement 1B-E Figure 7 - figure supplement 2. Synergistic effects of Dll4 (E12) $_{2}$ and PTH on osteogenesis Representative overview confocal images and corresponding quantifications for OSX (A, 1280 white) and OPN (B, green) immunostaining in wild-type female femur after treatment with 1281 vehicle, pLIVE-Dll4(E12), PTH or the combination of both. Nuclei, DAPI (blue). Data 
represent mean $\pm \mathrm{SD}$. ( $\mathrm{n}=5$ mice), (p-values determined using one-way ANOVA followed by

1283 Sidak's multiple comparisons test).

1284

1285

Figure 7-supplement 1-source data 1. Source data for Figure 7-figure supplement 2A, B

1286

1287 Figure 8. scRNA-seq analysis of control and Dll4 ${ }_{(\mathrm{E} 12)}$-treated bone

1288 (A) Overview of the sample processing and scRNA-seq procedure.

1289

(B) UMAP projection of all cells in pLIVE-Dll4 ${ }_{(E 12)}$ and control, colored by Louvain clusters.

1290

ECs, MSCs, SMCs, chondrocytes, and osteoblasts are indicated.

1291

(C) UMAP projection of all cells colored by experimental condition (green=control, purple=

$\left.1292 \operatorname{Dll}_{(\mathrm{E} 12)}\right)$

1293

(D, E) Barplot showing absolute numbers of cells (D) and scaled expression heatmap of the

1294

top 10 marker genes $(\mathbf{E})$ for each of the clusters shown in (B).

1295

(F-H) Differential expression volcano plots showing -log10(adjusted P-value) against average log-fold change of pLIVE-Dll4 $(E 12)$ vs. control in ECs $(\mathbf{F})$, chondrocytes $(\mathbf{G})$ and MSCs $(\mathbf{H})$.

1297 Genes with an adjusted P-values smaller than 1e-10 are colored in red.

1298 (I-K) Selected cell-population relevant gene expression shown as violin (density) plots for EC (I), chondrocyte (J) and MSC (K) subpopulations.

1300

Figure 8-source data 1. Source data for Figure 8F-H

1302

Figure 8-figure supplement 1. scRNA quality control statistics

1304

(A-D) Quality control plots. In each panel, the top plot shows distribution of count depths, middle plot shows knee plot, and the bottom plot shows cumulative count depth plotted as a function of cell barcodes sorted by count depth. Plot show control sample before filtering (A), 
control sample after filtering (B), pLIVE-Dll4 $(E 12)$ sample before filtering $(\mathbf{C})$, and $p L I V E$ -

$1308 \operatorname{Dll}_{(E 12)}$ sample after filtering (D).

Figure 8-figure supplement 2. Extended analysis of differentially expressed genes

1311 (A) Differential expression volcano plots showing -log10(adjusted P-value) against average 1312 log-fold change of $p L I V E-D_{l l 4_{(E 12)}}$ vs. control for Notch pathway related genes (parent GO 1313 term "Notch signaling pathway" GO:0007219) for EC, chondrocyte, osteoblast, and MSC 1314 populations.

1315 (B) Heatmap of the average expression log fold-change of selected Notch pathway genes with 1316 a P-value $<1 \mathrm{e}-10$ and log fold-change $>0.2$ across the four major cell populations.

1317 (C) Heatmap of the average expression log fold-change of genes with a P-value $<1 \mathrm{e}-10$ and $1318 \log$ fold-change $>0.2$ across the four major cell populations.

1319 (D) Dot plot of Gene Ontology (GO) analysis results showing all enriched GO terms with a P-

1320 value below 1e-5 across all four major cell populations. Color encodes hypergeometric test P1321 value, size of each dot is proportional to the Odds-Ratio (OR).

1322 (E) Differential expression volcano plot for the osteoblast population showing $1323 \log 10$ (adjusted P-value) against average log-fold change of $p L I V E-D l l 4_{(E 12)}$ vs. control. Genes 1324 with an adjusted P-value less than 1e-10 are colored in red.

1326 Figure 8-figure supplement 2-source data 1. Source data for Figure 8-figure supplement 1327 2A-E Figure 9. scRNA-seq analysis of MSC subclusters

1330 (A) UMAP projection of MSCs in both control and pLIVE-Dll4(E12) samples colored by 1331 Louvain clusters. Metaphyseal mpMSCs, diaphyseal dpMSCs and fibroblasts are indicated. 
1332 (B) Barplot showing absolute numbers of cells per sample (left), and scaled expression

1333 heatmap of the top 10 marker genes (right) in each of the clusters shown in (A).

1334 (C) UMAP projection of all cells colored by experimental condition green=control, purple= $1335 \mathrm{Dll4}_{(\mathrm{E} 12)}$.

1336 (D) Differential expression volcano plots showing -log10(adjusted P-value) against average 1337 log-fold change of treatment/control for dp MSCs (left) and mp MSCs (right). Genes with an 1338 adjusted P-value less than 1e-10 are colored in red.

1339 (E) Violin plots showing selected differentially expressed genes in the three MSC 1340 subpopulations. Each violin is split along the vertical axis into control and pLIVE-Dll4 ${ }_{(E 12)}$.

1341 (F) UMAP projections of control and Dll4 ${ }_{(\mathrm{E} 12)}$-treated cells colored for the expression of $S p 7$ 1342 and Heyl.

1343 (G) Heatmap of the average expression log fold-change of selected Notch pathway genes with 1344 a P-value $<1 \mathrm{e}-10$ and log fold-change $>0.2$ in dpMSCs and mpMSCs.

1346 Figure 9-source data 1. Source data for Figure 9D-G

1349 Key Resources Table

\begin{tabular}{|l|l|l|l|l|}
\hline $\begin{array}{l}\text { Reagent } \\
\text { type } \\
\text { (species) or } \\
\text { resource }\end{array}$ & Designation & $\begin{array}{l}\text { Source or } \\
\text { reference }\end{array}$ & Identifiers & Additional information \\
\hline $\begin{array}{l}\text { strain, strain } \\
\text { background } \\
\left(\begin{array}{l}\text { Mus } \\
\text { musculus, } \\
\text { C57BL/6JRj })\end{array}\right.\end{array}$ & WT & Janvier Labs & & \\
\hline $\begin{array}{l}\text { genetic } \\
\text { reagent }(\text { Mus } \\
\text { musculus })\end{array}$ & $\begin{array}{l}\text { Tg(Heyl- } \\
\text { EGFP) }\end{array}$ & GENGGat & MGI:4847129 & \\
\hline
\end{tabular}




\begin{tabular}{|c|c|c|c|c|}
\hline $\begin{array}{l}\text { recombinant } \\
\text { DNA } \\
\text { reagent }\end{array}$ & $\begin{array}{l}\text { pcDNA3.1- } \\
\text { Dl14(ECD)- } \\
\text { His(6x)-Asp(8x) } \\
\text { (plasmid) }\end{array}$ & This paper & & $\operatorname{Dlll}_{-1} \operatorname{Asp}_{(8 x)}$ \\
\hline $\begin{array}{l}\text { recombinant } \\
\text { DNA } \\
\text { reagent }\end{array}$ & $\begin{array}{l}\text { pcDNA3.1- } \\
\text { Dll4(ECD)- } \\
\text { Variant- His(6x)- } \\
\text { Asp(8x) (plasmid) }\end{array}$ & This paper & & $\mathrm{Dll4}_{(\mathrm{E} 12)}$ \\
\hline $\begin{array}{l}\text { recombinant } \\
\text { DNA } \\
\text { reagent }\end{array}$ & $\begin{array}{l}\text { pLIVE-D1l4(ECD)- } \\
\text { His(6x)-Asp(8x) } \\
\text { (plasmid) }\end{array}$ & This paper & & pLIVE-DIl4-Asp(8x) \\
\hline $\begin{array}{l}\text { recombinant } \\
\text { DNA } \\
\text { reagent }\end{array}$ & $\begin{array}{l}\text { pLIVE-Dll4(ECD) } \\
\text { Variant- His(6x)- } \\
\text { Asp(8x) (plasmid) }\end{array}$ & This paper & & pLIVE-Dll4(E12) \\
\hline $\begin{array}{l}\text { recombinant } \\
\text { DNA } \\
\text { reagent }\end{array}$ & $\begin{array}{l}\text { pcDNA3.1- Jag1 } \\
\text { (ECD)- His(6x)- } \\
\text { Asp(8x) } \\
\text { (plasmid) }\end{array}$ & This paper & & Jag1- $\operatorname{Asp}_{(8 x)}$ \\
\hline $\begin{array}{l}\text { recombinant } \\
\text { DNA } \\
\text { reagent }\end{array}$ & $\begin{array}{l}\text { pcDNA3.1- Jag1 } \\
\text { (ECD)- JV1- } \\
\text { His(6x)-Asp(8x) } \\
\text { (plasmid) }\end{array}$ & This paper & & $\operatorname{Jag} 1_{(\mathrm{JV} 1)}$ \\
\hline $\begin{array}{l}\text { recombinant } \\
\text { DNA } \\
\text { reagent }\end{array}$ & $\begin{array}{l}\text { pLIVE- Jag1 } \\
\text { (ECD)- His(6x)- } \\
\text { Asp(8x) (plasmid) }\end{array}$ & This paper & & pLIVE-Jag1-Asp $(8 x)$ \\
\hline $\begin{array}{l}\text { recombinant } \\
\text { DNA } \\
\text { reagent }\end{array}$ & $\begin{array}{l}\text { pLIVE- Jag1 } \\
\text { (ECD)- JV1- } \\
\text { His(6x)-Asp(8x) } \\
\text { (plasmid) }\end{array}$ & This paper & & pLIVE-Jagl(JV1) \\
\hline $\begin{array}{l}\text { cell line } \\
\text { (Homo- } \\
\text { sapiens) }\end{array}$ & $\begin{array}{l}\text { Human Umbilical } \\
\text { Vein Endothelial } \\
\text { Cells (HUVEC) }\end{array}$ & ThermoFisher & Cat\# C0035C & $\begin{array}{l}\text { Cell identity and absence of } \\
\text { mycoplasma contamination } \\
\text { or human pathogens were } \\
\text { certified by the supplier }\end{array}$ \\
\hline $\begin{array}{l}\text { cell line } \\
\text { (Homo- } \\
\text { sapiens) }\end{array}$ & $\begin{array}{l}\text { Human Embryonal } \\
\text { kidney -293 } \\
\text { (HEK293) }\end{array}$ & DSMZ & Cat\# ACC 305 & $\begin{array}{l}\text { Cell identity and absence of } \\
\text { mycoplasma contamination } \\
\text { were certified by the } \\
\text { supplier }\end{array}$ \\
\hline
\end{tabular}




\begin{tabular}{|c|c|c|c|c|}
\hline antibody & $\begin{array}{l}\text { anti-Endomucin } \\
\text { (Rat, monoclonal) }\end{array}$ & Santa Cruz & $\begin{array}{l}\text { Cat\# SC- } \\
65495\end{array}$ & $\operatorname{IF}(1: 100)$ \\
\hline antibody & $\begin{array}{l}\text { anti-PECAM-1 } \\
\text { (Rat, monoclonal) }\end{array}$ & Pharmigen & Cat\# 553370 & $\operatorname{IF}(1: 100)$ \\
\hline antibody & $\begin{array}{l}\text { anti-CD31 } \\
\text { (Goat, polyclonal) }\end{array}$ & R\&D Systems & $\begin{array}{l}\text { Cat\# } \\
\text { FAB3628 }\end{array}$ & IF (1:100) \\
\hline antibody & $\begin{array}{l}\text { anti-Pdgfr } \beta \text { (Goat, } \\
\text { polyclonal) }\end{array}$ & R\&D Systems & Cat\# AF1042 & $\operatorname{IF}(1: 100)$ \\
\hline antibody & $\begin{array}{l}\text { anti-NG2 (Rabbit, } \\
\text { polyclonal) }\end{array}$ & Millipore & Cat\# AB5320 & $\operatorname{IF}(1: 100)$ \\
\hline antibody & $\begin{array}{l}\text { anti-BCAM (Goat, } \\
\text { polyclonal) }\end{array}$ & R\&D Systems & Cat\# AF8299 & $\operatorname{IF}(1: 50)$ \\
\hline antibody & $\begin{array}{l}\text { anti-ATP6V1B1 + } \\
\text { ATP6V1B2 (Rabbit, } \\
\text { polyclonal) }\end{array}$ & Abcam & $\begin{array}{l}\text { Cat\# } \\
\text { ab200839 }\end{array}$ & $\operatorname{IF}(1: 100)$ \\
\hline antibody & $\begin{array}{l}\text { anti-Aggrecan } \\
\text { (Rabbit, polyclonal) }\end{array}$ & Millipore & Cat\# AB1031 & IF (1:100) \\
\hline antibody & $\begin{array}{l}\text { anti-Sox9 (Goat, } \\
\text { polyclonal) }\end{array}$ & R\&D Systems & Cat\# AF3075 & $\operatorname{IF}(1: 100)$ \\
\hline antibody & $\begin{array}{l}\text { anti-Perilipin } \\
\text { (Rabbit, polyclonal) }\end{array}$ & Cell Signaling & Cat\# 9349 & IF (1:100) \\
\hline antibody & $\begin{array}{l}\text { anti-Osterix (Rabbit, } \\
\text { polyclonal) }\end{array}$ & Abcam & Cat\# ab22552 & IF $(1: 1000)$ \\
\hline
\end{tabular}




\begin{tabular}{|c|c|c|c|c|}
\hline antibody & $\begin{array}{l}\text { anti-Collagen Type I } \\
\text { (Rabbit, polyclonal) }\end{array}$ & Millipore & Cat\# AB765P & $\operatorname{IF}(1: 200)$ \\
\hline antibody & $\begin{array}{l}\text { anti-Osteopontin } \\
\text { (Goat, polyclonal) }\end{array}$ & R\&D Systems & Cat\# AF808 & $\operatorname{IF}(1: 100)$ \\
\hline antibody & $\begin{array}{l}\text { anti-Osteocalcin } \\
\text { (Rabbit, polyclonal) }\end{array}$ & $\begin{array}{l}\text { LifeSpan } \\
\text { BioSciences }\end{array}$ & $\begin{array}{l}\text { Cat\# LS- } \\
\text { C17044 }\end{array}$ & IF $(1: 100)$ \\
\hline antibody & $\begin{array}{l}\text { anti-Runx2 (Rabbit, } \\
\text { monoclonal) }\end{array}$ & R\&D Systems & $\begin{array}{l}\text { Cat\# } \\
\text { MAB2006 }\end{array}$ & $\operatorname{IF}(1: 50)$ \\
\hline antibody & $\begin{array}{l}\text { anti-Dll4 (Goat, } \\
\text { polyclonal) }\end{array}$ & R\&D Systems & Cat\# AF1389 & $\begin{array}{l}\text { IF }(1: 100) \\
\text { WB }(1: 200)\end{array}$ \\
\hline antibody & $\begin{array}{l}\text { anti-Jag1 (Goat, } \\
\text { polyclonal) }\end{array}$ & Sigma & Cat\# J4127 & $\begin{array}{l}\text { IF }(1: 100) \\
\text { WB }(1: 500)\end{array}$ \\
\hline antibody & $\begin{array}{l}\text { anti-GAPDH (Rabbit, } \\
\text { monoclonal) }\end{array}$ & Ambion & Cat\# AM4300 & WB $(1: 1000)$ \\
\hline antibody & $\begin{array}{l}\text { anti-CD45-FITC } \\
\text { (Rat, monoclonal) }\end{array}$ & eBioscience & Cat\# 11-0451 & \\
\hline antibody & $\begin{array}{l}\text { anti-CD8-Biotin } \\
\text { (Rat, monoclonal) }\end{array}$ & eBioscience & Cat\# 13-0081 & \\
\hline antibody & $\begin{array}{l}\text { anti-CD4-APC (Rat, } \\
\text { monoclonal) }\end{array}$ & eBioscience & $\begin{array}{l}\text { Cat\# 17-0042- } \\
82\end{array}$ & \\
\hline antibody & Streptavidin PE/Cy7 & $\begin{array}{l}\text { Thermo } \\
\text { Scientific }\end{array}$ & Cat\# SA1012 & \\
\hline
\end{tabular}




\begin{tabular}{|c|c|c|c|c|}
\hline antibody & $\begin{array}{l}\text { Lineage Cell } \\
\text { Depletion Kit }\end{array}$ & Miltenyi Biotec & $\begin{array}{l}\text { Cat\# 130-090- } \\
858\end{array}$ & \\
\hline antibody & CD45 Microbeads & Miltenyi Biotec & $\begin{array}{l}\text { Cat\# 130-052- } \\
301\end{array}$ & \\
\hline antibody & CD117 Microbeads & Miltenyi Biotec & $\begin{array}{l}\text { Cat\# 130-091- } \\
224\end{array}$ & \\
\hline antibody & Ter-119 Microbeads & Miltenyi Biotec & $\begin{array}{l}\text { Cat\# 130-049- } \\
901\end{array}$ & \\
\hline antibody & $\begin{array}{l}\text { anti-rabbit Alexa } \\
\text { Fluor-488 (Donkey, } \\
\text { polyclonal) }\end{array}$ & Invitrogen & Cat\# A21206 & IF $(1: 500)$ \\
\hline antibody & $\begin{array}{l}\text { anti-rabbit Alexa } \\
\text { Fluor-594 (Donkey, } \\
\text { polyclonal) }\end{array}$ & Invitrogen & Cat\# A21207 & $\operatorname{IF}(1: 500)$ \\
\hline antibody & $\begin{array}{l}\text { anti-rabbit Alexa } \\
\text { Fluor-647 (Donkey, } \\
\text { polyclonal) }\end{array}$ & Invitrogen & Cat\# A31573 & $\operatorname{IF}(1: 500)$ \\
\hline antibody & $\begin{array}{l}\text { anti-rat Alexa Fluor- } \\
488 \text { (Donkey, } \\
\text { polyclonal) }\end{array}$ & Invitrogen & Cat\# A21208 & $\operatorname{IF}(1: 500)$ \\
\hline antibody & $\begin{array}{l}\text { anti-rat Alexa Fluor- } \\
594 \text { (Donkey, } \\
\text { polyclonal) }\end{array}$ & Invitrogen & Cat\# A21209 & $\operatorname{IF}(1: 500)$ \\
\hline antibody & $\begin{array}{l}\text { anti-rat Alexa Fluor- } \\
647 \text { (Donkey, } \\
\text { polyclonal) }\end{array}$ & $\begin{array}{l}\text { Jackson Immuno } \\
\text { Research }\end{array}$ & $\begin{array}{l}\text { Cat\# 712-605- } \\
153\end{array}$ & $\operatorname{IF}(1: 500)$ \\
\hline antibody & $\begin{array}{l}\text { anti-rat Alexa Fluor- } \\
647 \text { (Donkey, } \\
\text { polyclonal) }\end{array}$ & Invitrogen & Cat\# A21247 & $\operatorname{IF}(1: 500)$ \\
\hline
\end{tabular}




\begin{tabular}{|c|c|c|c|c|}
\hline antibody & $\begin{array}{l}\text { anti-goat Alexa } \\
\text { Fluor-488 (Donkey, } \\
\text { polyclonal) }\end{array}$ & Invitrogen & Cat\# A11055 & $\operatorname{IF}(1: 500)$ \\
\hline antibody & $\begin{array}{l}\text { anti-goat Alexa } \\
\text { Fluor-647 (Donkey, } \\
\text { polyclonal) }\end{array}$ & Invitrogen & Cat\# A21447 & IF (1:500) \\
\hline antibody & $\begin{array}{l}\text { anti-goat Alexa } \\
\text { Fluor-647 (Donkey, } \\
\text { polyclonal) }\end{array}$ & ThermoScientific & Cat\# A32849 & IF (1:500) \\
\hline antibody & $\begin{array}{l}\text { anti-rabbit IgG HRP- } \\
\text { linked (Goat) }\end{array}$ & Cell Signaling & Cat\# 7074 & WB $(1: 15000)$ \\
\hline antibody & $\begin{array}{l}\text { anti-goat IgG HRP- } \\
\text { linked (Donkey) }\end{array}$ & Antibody online & $\begin{array}{l}\text { Cat\# } \\
\text { ABIN1536502 }\end{array}$ & WB $(1: 15000)$ \\
\hline antibody & $\begin{array}{l}\text { anti-mouse IgG } \\
\text { 656G HRP-linked } \\
\text { (Sheep) }\end{array}$ & GE-Healtcare & Cat\# NA931 & WB $(1: 40000)$ \\
\hline antibody & $\begin{array}{l}\text { anti-goat } \mathrm{IgG}(\mathrm{H}+\mathrm{L}) \\
\text { Peroxidase } \\
\text { AffiniPure Bovine }\end{array}$ & $\begin{array}{l}\text { Jackson Immuno } \\
\text { Research }\end{array}$ & $\begin{array}{l}\text { Cat\# 805-035- } \\
180\end{array}$ & WB $(1: 15000)$ \\
\hline $\begin{array}{l}\text { sequence- } \\
\text { based } \\
\text { reagent }\end{array}$ & $\begin{array}{l}\text { Human GAPDH } \\
\text { Endogenous Control } \\
\text { (VICTM/MGB probe, } \\
\text { primer limited) }\end{array}$ & $\begin{array}{l}\text { Applied } \\
\text { Biosystems }\end{array}$ & $\begin{array}{l}\text { Cat\# } \\
4326317 \mathrm{E}\end{array}$ & $\begin{array}{l}\text { TaqMan probe } \\
\text { Hs99999905_m1 }\end{array}$ \\
\hline $\begin{array}{l}\text { sequence- } \\
\text { based } \\
\text { reagent }\end{array}$ & $\begin{array}{l}\text { Human } A C T B \\
\text { Endogenous Control } \\
\text { (VICTM/MGB probe, } \\
\text { primer limited) }\end{array}$ & $\begin{array}{l}\text { Applied } \\
\text { Biosystems }\end{array}$ & $\begin{array}{l}\text { Cat\# } \\
4326315 \mathrm{E}\end{array}$ & $\begin{array}{l}\text { TaqMan probe } \\
\text { Hs99999903_m1 }\end{array}$ \\
\hline $\begin{array}{l}\text { sequence- } \\
\text { based } \\
\text { reagent }\end{array}$ & $\begin{array}{l}\text { Human } H E Y 1 \\
\text { TaqMan }^{\mathrm{TM}} \text { Gene } \\
\text { Expression Assay } \\
\text { (FAM) }\end{array}$ & $\begin{array}{l}\text { Applied } \\
\text { Biosystems }\end{array}$ & Cat\# 4331182 & $\begin{array}{l}\text { TaqMan probe } \\
\text { Hs00232618_m1 }\end{array}$ \\
\hline $\begin{array}{l}\text { sequence- } \\
\text { based } \\
\text { reagent }\end{array}$ & $\begin{array}{l}\text { Human DLLA } \\
\text { TaqMan }^{\text {TM }} \text { Gene } \\
\text { Expression Assay } \\
\text { (FAM) }\end{array}$ & $\begin{array}{l}\text { Applied } \\
\text { Biosystems }\end{array}$ & Cat\# 4331182 & $\begin{array}{l}\text { TaqMan probe } \\
\text { Hs00184092_m1 }\end{array}$ \\
\hline
\end{tabular}




\begin{tabular}{|c|c|c|c|c|}
\hline $\begin{array}{l}\text { sequence- } \\
\text { based } \\
\text { reagent }\end{array}$ & $\begin{array}{l}\text { Human } H E Y 2 \\
\text { TaqMan }^{\mathrm{TM}} \text { Gene } \\
\text { Expression Assay } \\
\text { (FAM) }\end{array}$ & $\begin{array}{l}\text { Applied } \\
\text { Biosystems }\end{array}$ & Cat\# 4331182 & $\begin{array}{l}\text { TaqMan probe } \\
\text { Hs00232622_m1 }\end{array}$ \\
\hline $\begin{array}{l}\text { sequence- } \\
\text { based } \\
\text { reagent }\end{array}$ & $\begin{array}{l}\text { Human HES1 } \\
\text { TaqMan }^{\mathrm{TM}} \text { Gene } \\
\text { Expression Assay } \\
\text { (FAM) }\end{array}$ & $\begin{array}{l}\text { Applied } \\
\text { Biosystems }\end{array}$ & Cat\# 4331182 & $\begin{array}{l}\text { TaqMan probe } \\
\text { Hs00172878_m1 }\end{array}$ \\
\hline $\begin{array}{l}\text { sequence- } \\
\text { based } \\
\text { reagent }\end{array}$ & $\begin{array}{l}\text { Human EFNB2 } \\
\text { TaqMan }^{\text {TM }} \text { Gene } \\
\text { Expression Assay } \\
\text { (FAM) }\end{array}$ & $\begin{array}{l}\text { Applied } \\
\text { Biosystems }\end{array}$ & Cat\# 4331182 & $\begin{array}{l}\text { TaqMan probe } \\
\text { Hs00187950_m1 }\end{array}$ \\
\hline $\begin{array}{l}\text { sequence- } \\
\text { based } \\
\text { reagent }\end{array}$ & $\begin{array}{l}\text { Human NRARP } \\
\text { TaqMan }^{\mathrm{TM}} \text { Gene } \\
\text { Expression Assay } \\
\text { (FAM) }\end{array}$ & $\begin{array}{l}\text { Applied } \\
\text { Biosystems }\end{array}$ & Cat\# 4331182 & $\begin{array}{l}\text { TaqMan probe } \\
\text { Hs01104102_s1 }\end{array}$ \\
\hline $\begin{array}{l}\text { peptide, } \\
\text { recombinant } \\
\text { protein }\end{array}$ & $\begin{array}{l}\text { Recombinant Human } \\
\text { PTH (1-34) }\end{array}$ & BACHEM & $\begin{array}{l}\text { Cat\# H-4835- } \\
\text { GMP, } 4033364\end{array}$ & \\
\hline $\begin{array}{l}\text { commercial } \\
\text { assay or kit }\end{array}$ & $\begin{array}{l}\text { BCA Protein Assay } \\
\text { Kit }\end{array}$ & Pierce & Cat\# 23225 & \\
\hline $\begin{array}{l}\text { commercial } \\
\text { assay or kit }\end{array}$ & $\begin{array}{l}\text { RNeasy Plus Micro } \\
\text { Kit }\end{array}$ & QIAGEN & Cat\# 74034 & \\
\hline $\begin{array}{l}\text { commercial } \\
\text { assay or kit }\end{array}$ & $\begin{array}{l}\text { iScript cDNA } \\
\text { Synthesis Kit }\end{array}$ & BIO-RAD & $\begin{array}{l}\text { Cat\# 170- } \\
8891\end{array}$ & \\
\hline $\begin{array}{l}\text { commercial } \\
\text { assay or kit }\end{array}$ & $\begin{array}{l}\text { SsoAdvanced } \\
\text { Universal Probes } \\
\text { Supermix }\end{array}$ & BIO-RAD & $\begin{array}{l}\text { Cat\# 172- } \\
5284\end{array}$ & \\
\hline $\begin{array}{l}\text { commercial } \\
\text { assay or kit }\end{array}$ & $\begin{array}{l}\text { LEGENDplex } \\
\text { Mouse Inflammation } \\
\text { Panel (13-plex) with } \\
\text { V-bottom plates }\end{array}$ & BioLegend & Cat\# 740446 & \\
\hline $\begin{array}{l}\text { commercial } \\
\text { assay or kit }\end{array}$ & $\begin{array}{l}\text { Anticoagulant } \\
\text { EDTA-treated } \\
\text { Microvettes }\end{array}$ & Sarstedt & Cat\# 20.1341 & \\
\hline $\begin{array}{l}\text { commercial } \\
\text { assay or kit }\end{array}$ & $\begin{array}{l}\text { BD Rhapsody Whole } \\
\text { Transcriptome } \\
\text { Analysis (WTA) } \\
\text { Amplification kit }\end{array}$ & BD Biosciences & Cat\# 633801 & \\
\hline
\end{tabular}




\begin{tabular}{|c|c|c|c|c|}
\hline $\begin{array}{l}\text { commercial } \\
\text { assay or kit }\end{array}$ & $\begin{array}{l}\text { Agencourt AMPure } \\
\text { XP magnetic beads }\end{array}$ & $\begin{array}{l}\text { Beckman } \\
\text { Coulter Life } \\
\text { Sciences }\end{array}$ & Cat\# A638880 & \\
\hline $\begin{array}{l}\text { commercial } \\
\text { assay or kit }\end{array}$ & $\begin{array}{l}\text { Disposable } \\
\text { polystyrene columns }\end{array}$ & $\begin{array}{l}\text { Thermo } \\
\text { Scientific }\end{array}$ & Cat\# 29922 & \\
\hline $\begin{array}{l}\text { commercial } \\
\text { assay or kit }\end{array}$ & $\begin{array}{l}\text { Amicon Ultra- } 0.5 \\
\text { Centrifugal Filter }\end{array}$ & Millipore & $\begin{array}{l}\text { Cat\# } \\
\text { UFC500396 }\end{array}$ & \\
\hline $\begin{array}{l}\text { commercial } \\
\text { assay or kit }\end{array}$ & $\begin{array}{l}\text { Pierce Slide-A-Lyzer } \\
10 \mathrm{~K} \text { MWCO } \\
\text { Dialysis Cassettes }\end{array}$ & $\begin{array}{l}\text { Thermo } \\
\text { Scientific }\end{array}$ & Cat\# 66380 & \\
\hline $\begin{array}{l}\text { chemical } \\
\text { compound, } \\
\text { drug }\end{array}$ & $\begin{array}{l}\text { Ni-NTA agarose } \\
\text { resin }\end{array}$ & Qiagen & Cat\# 302010 & \\
\hline $\begin{array}{l}\text { chemical } \\
\text { compound, } \\
\text { drug }\end{array}$ & Sucrose & Sigma & Cat\# S0389 & \\
\hline $\begin{array}{l}\text { chemical } \\
\text { compound, } \\
\text { drug }\end{array}$ & $\begin{array}{l}\text { cOmplete ULTRA } \\
\text { Tablets Protease } \\
\text { Inhibitor Cocktail }\end{array}$ & Roche & $\begin{array}{l}\text { Cat\# } \\
05892970001\end{array}$ & \\
\hline $\begin{array}{l}\text { chemical } \\
\text { compound, } \\
\text { drug }\end{array}$ & $\begin{array}{l}\text { phosphatase } \\
\text { inhibitor cocktail set } \\
\text { V }\end{array}$ & EMD Millipore & Cat\# 524629 & \\
\hline $\begin{array}{l}\text { chemical } \\
\text { compound, } \\
\text { drug }\end{array}$ & $\begin{array}{l}\text { SimplyBlue } \\
\text { SafeStain }\end{array}$ & Invitrogen & Cat\# LC6060 & \\
\hline $\begin{array}{l}\text { chemical } \\
\text { compound, } \\
\text { drug }\end{array}$ & Gelatine & Sigma & Cat\# G1890 & \\
\hline $\begin{array}{l}\text { chemical } \\
\text { compound, } \\
\text { drug }\end{array}$ & Polyvinylpyrrolidone & Sigma & Cat\# P5288 & \\
\hline $\begin{array}{l}\text { chemical } \\
\text { compound, } \\
\text { drug }\end{array}$ & $\begin{array}{l}\text { Trypsin-EDTA } \\
\text { solution }\end{array}$ & Sigma & Cat\# T3924 & \\
\hline
\end{tabular}




\begin{tabular}{|c|c|c|c|c|}
\hline $\begin{array}{l}\text { chemical } \\
\text { compound, } \\
\text { drug }\end{array}$ & Paraformaldehyde & Sigma & Cat\# P6148 & \\
\hline $\begin{array}{l}\text { chemical } \\
\text { compound, } \\
\text { drug }\end{array}$ & $\begin{array}{l}70 \mathrm{kDa} \text { Dextran, } \\
\text { Texas Red }{ }^{\mathrm{TM}} \text { Lysine } \\
\text { fixable }\end{array}$ & $\begin{array}{l}\text { Molecular } \\
\text { Probes }\end{array}$ & Cat\# D1864 & \\
\hline $\begin{array}{l}\text { chemical } \\
\text { compound, } \\
\text { drug }\end{array}$ & Calcein & Sigma & Cat\# C0875 & \\
\hline $\begin{array}{l}\text { chemical } \\
\text { compound, } \\
\text { drug }\end{array}$ & Fluoromount-G & Southern Biotech & Cat\# 0100-01 & \\
\hline $\begin{array}{l}\text { chemical } \\
\text { compound, } \\
\text { drug }\end{array}$ & $\begin{array}{l}\text { ECL }{ }^{\text {тм }} \text { Prime } \\
\text { Western Blotting } \\
\text { Detection Reagent }\end{array}$ & GE-Healthcare & $\begin{array}{l}\text { Cat\# } \\
\text { RPN2236 }\end{array}$ & \\
\hline $\begin{array}{l}\text { chemical } \\
\text { compound, } \\
\text { drug }\end{array}$ & 4-hydroxy tamoxifen & Sigma & Cat\# H7904 & \\
\hline $\begin{array}{l}\text { chemical } \\
\text { compound, } \\
\text { drug }\end{array}$ & Hematoxilin & Sigma & Cat\# MHS16 & \\
\hline $\begin{array}{l}\text { chemical } \\
\text { compound, } \\
\text { drug }\end{array}$ & Dimethyl sulfoxide & Sigma & Cat\# D8418 & \\
\hline $\begin{array}{l}\text { chemical } \\
\text { compound, } \\
\text { drug }\end{array}$ & $\begin{array}{l}\text { MEM200 } \\
\text { endothelial cells } \\
\text { medium }\end{array}$ & ThermoFisher & $\begin{array}{l}\text { Cat\# } \\
\text { M200500 }\end{array}$ & \\
\hline $\begin{array}{l}\text { chemical } \\
\text { compound, } \\
\text { drug }\end{array}$ & LSGS & ThermoFisher & Cat\# S00310 & \\
\hline $\begin{array}{l}\text { chemical } \\
\text { compound, } \\
\text { drug }\end{array}$ & $\begin{array}{l}\text { EBM-2 endothelial } \\
\text { cells medium }\end{array}$ & Lonza & Cat\# CC-3156 & \\
\hline
\end{tabular}




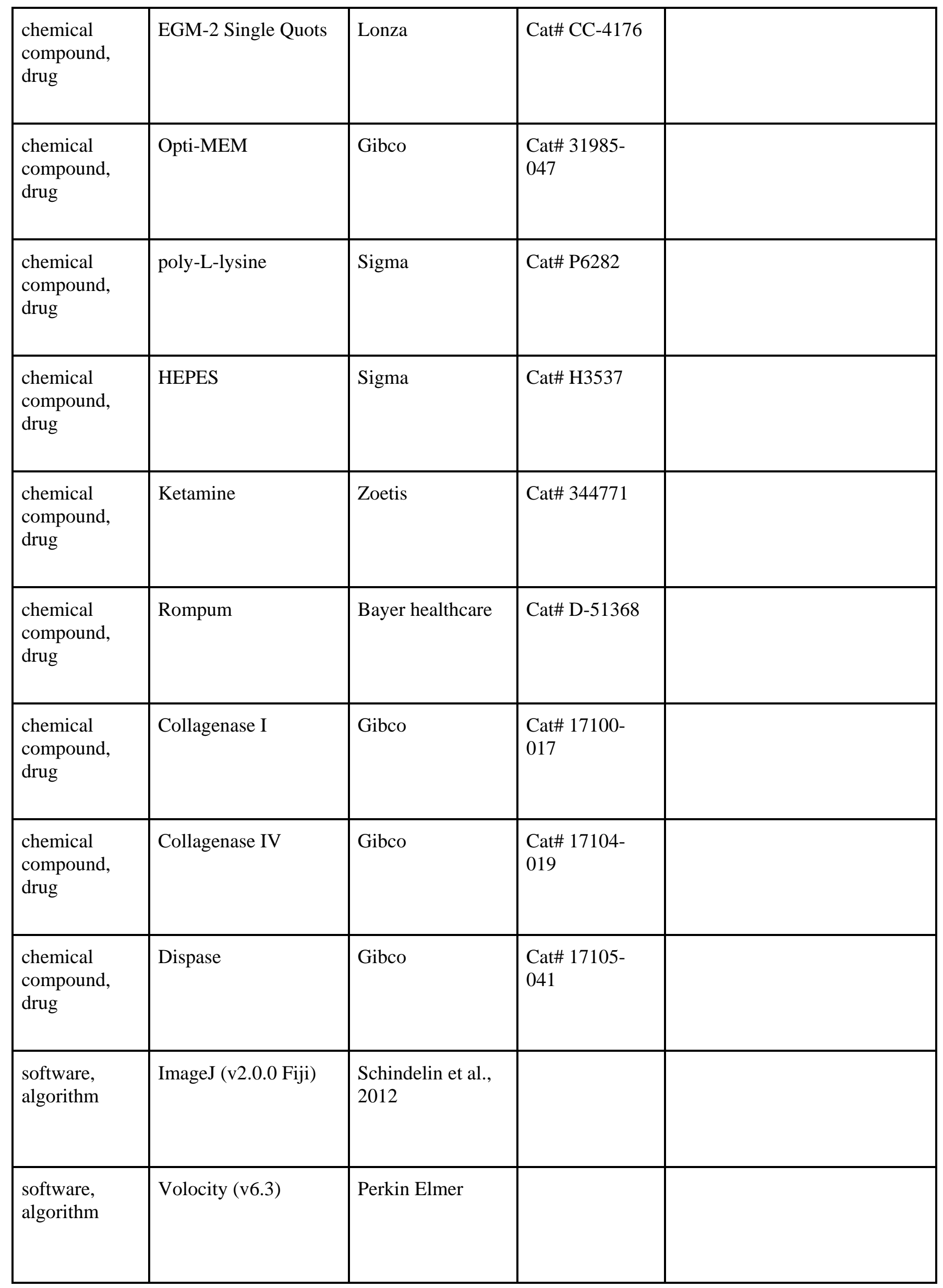




\begin{tabular}{|c|c|c|c|c|}
\hline $\begin{array}{l}\text { software, } \\
\text { algorithm }\end{array}$ & $\begin{array}{l}\text { Illustrator } \\
\text { (vCC2018) }\end{array}$ & Adobe & & \\
\hline $\begin{array}{l}\text { software, } \\
\text { algorithm }\end{array}$ & GraphPad Prism7 & $\begin{array}{l}\text { GraphPad } \\
\text { Software }\end{array}$ & & \\
\hline $\begin{array}{l}\text { software, } \\
\text { algorithm }\end{array}$ & FlowJo (v10.3) & $\begin{array}{l}\text { BD Life } \\
\text { Sciences }\end{array}$ & & \\
\hline other & DAPI stain & Sigma & Cat\# D9542 & $(1 \mathrm{mg} / \mathrm{ml})$ \\
\hline
\end{tabular}




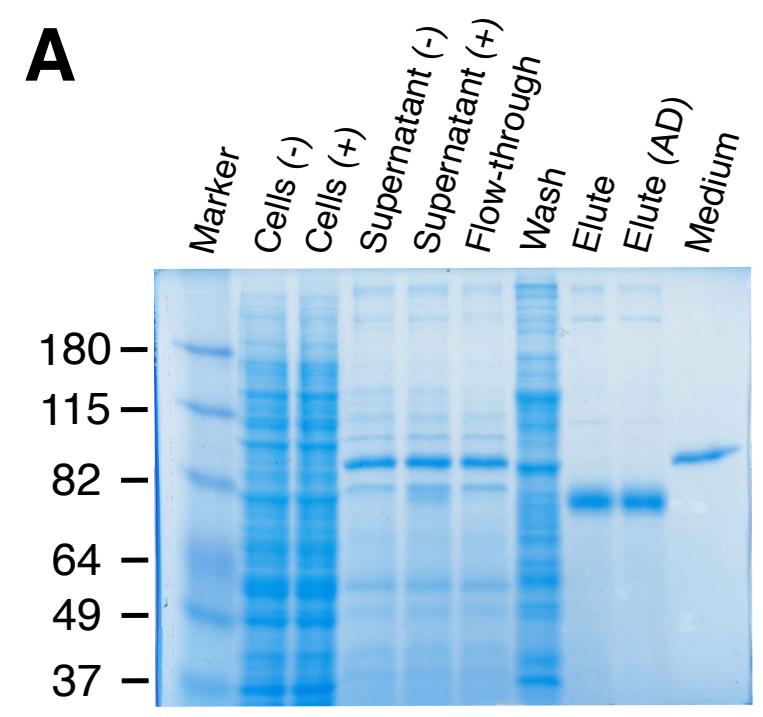

B

Soluble DII4-ECD on confluent HUVEC

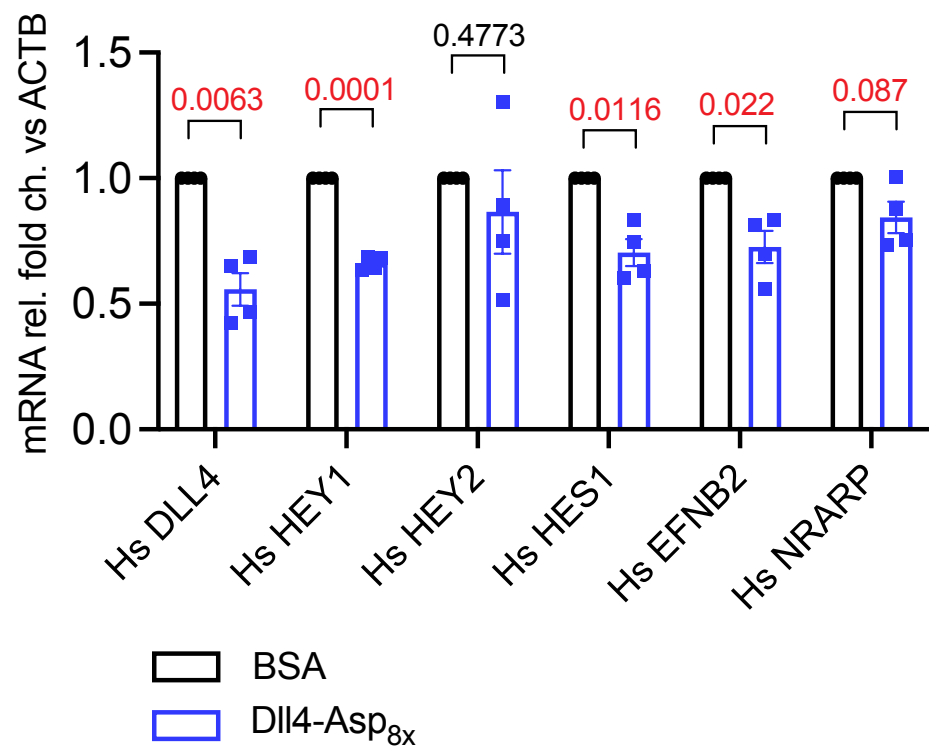

C Immobilized DII4-ECD on HUVEC

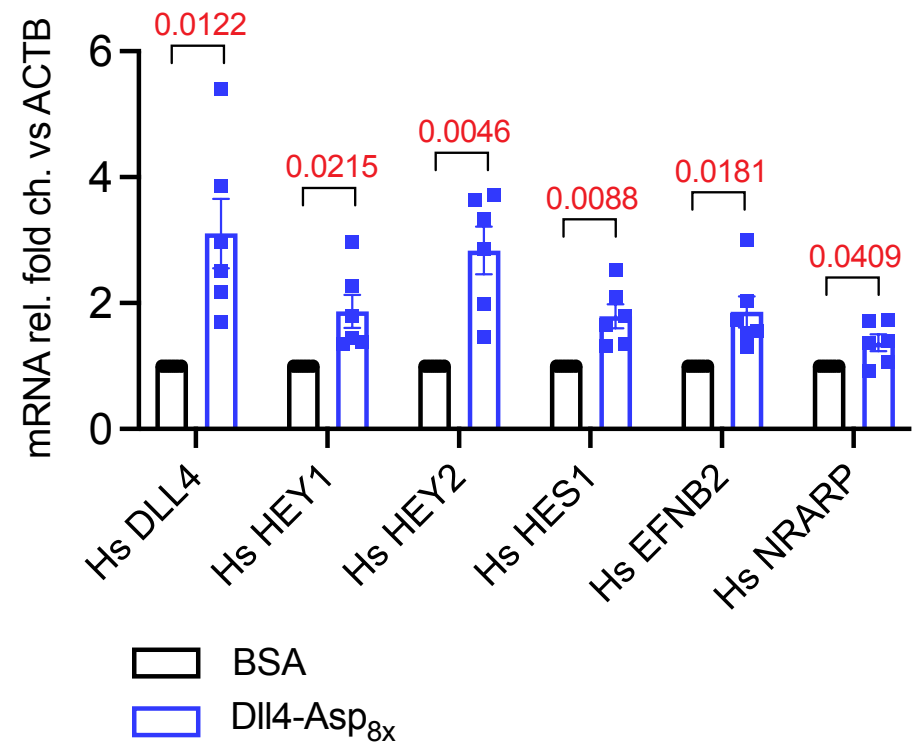

Xu, Dinh et al., Figure 1-figure supplement 1_R1 
A

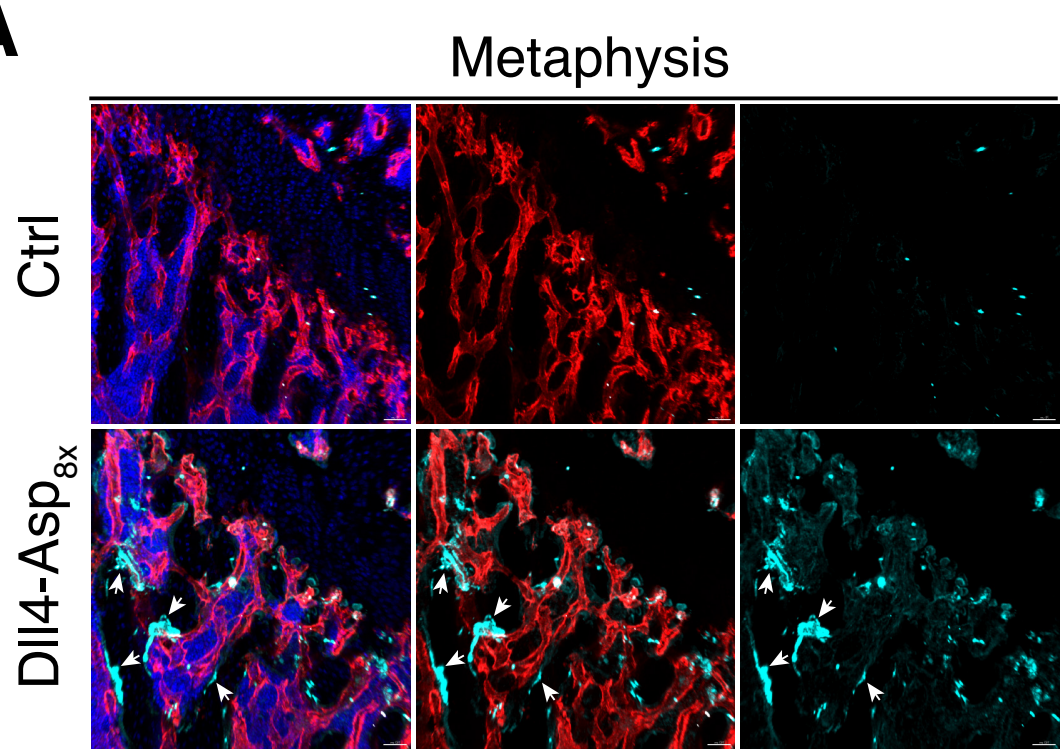

DAPI Emcn DII4
B

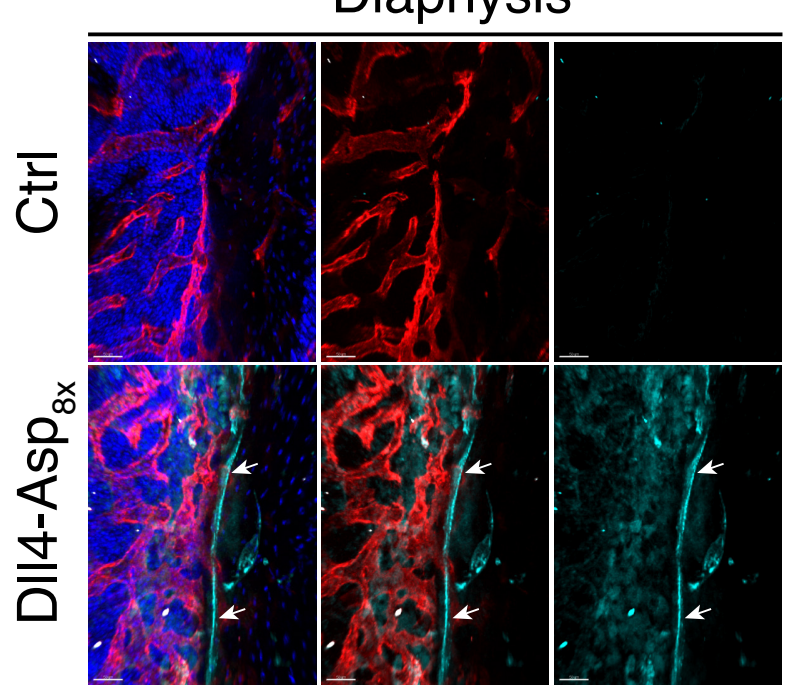

DAPI Emcn DII4

C

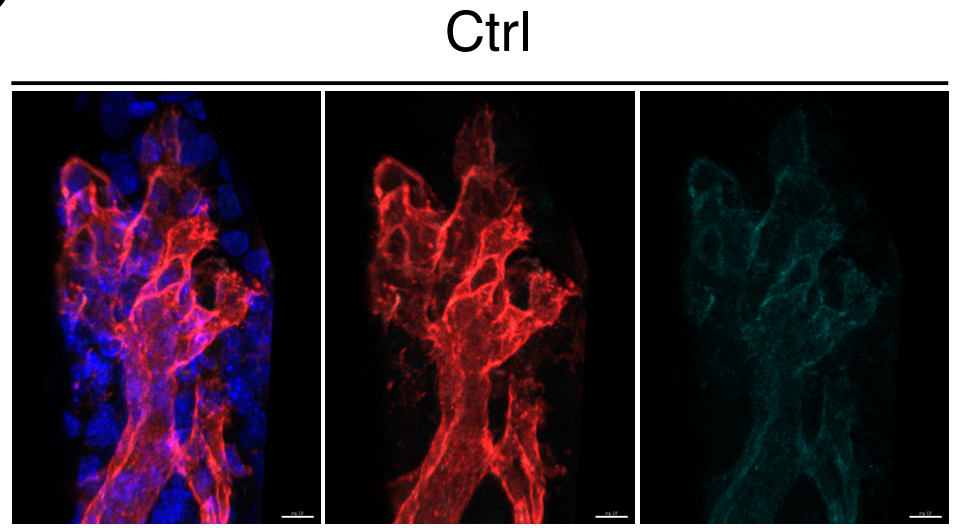

DAPI Emcn D\|l4
DII4-Asp $_{8 \mathrm{x}}$

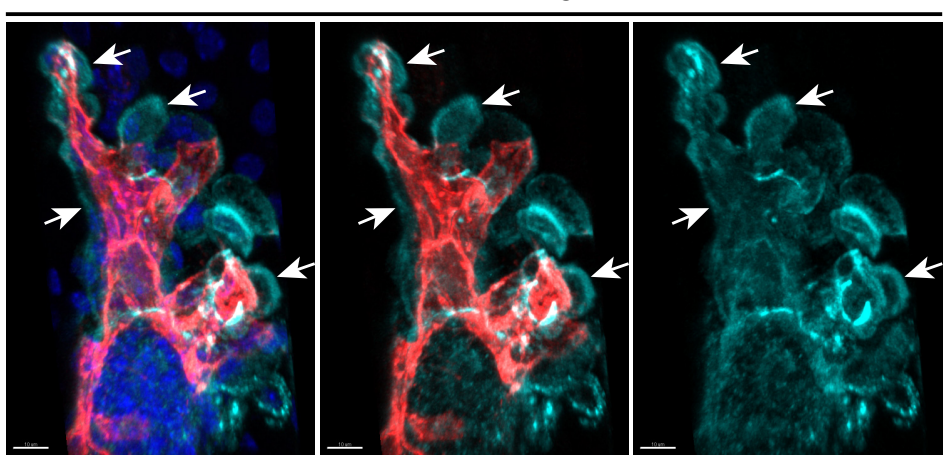

DAPI Emcn D\|l4

Xu, Dinh et al., Figure 1-figure supplement 2_R1 

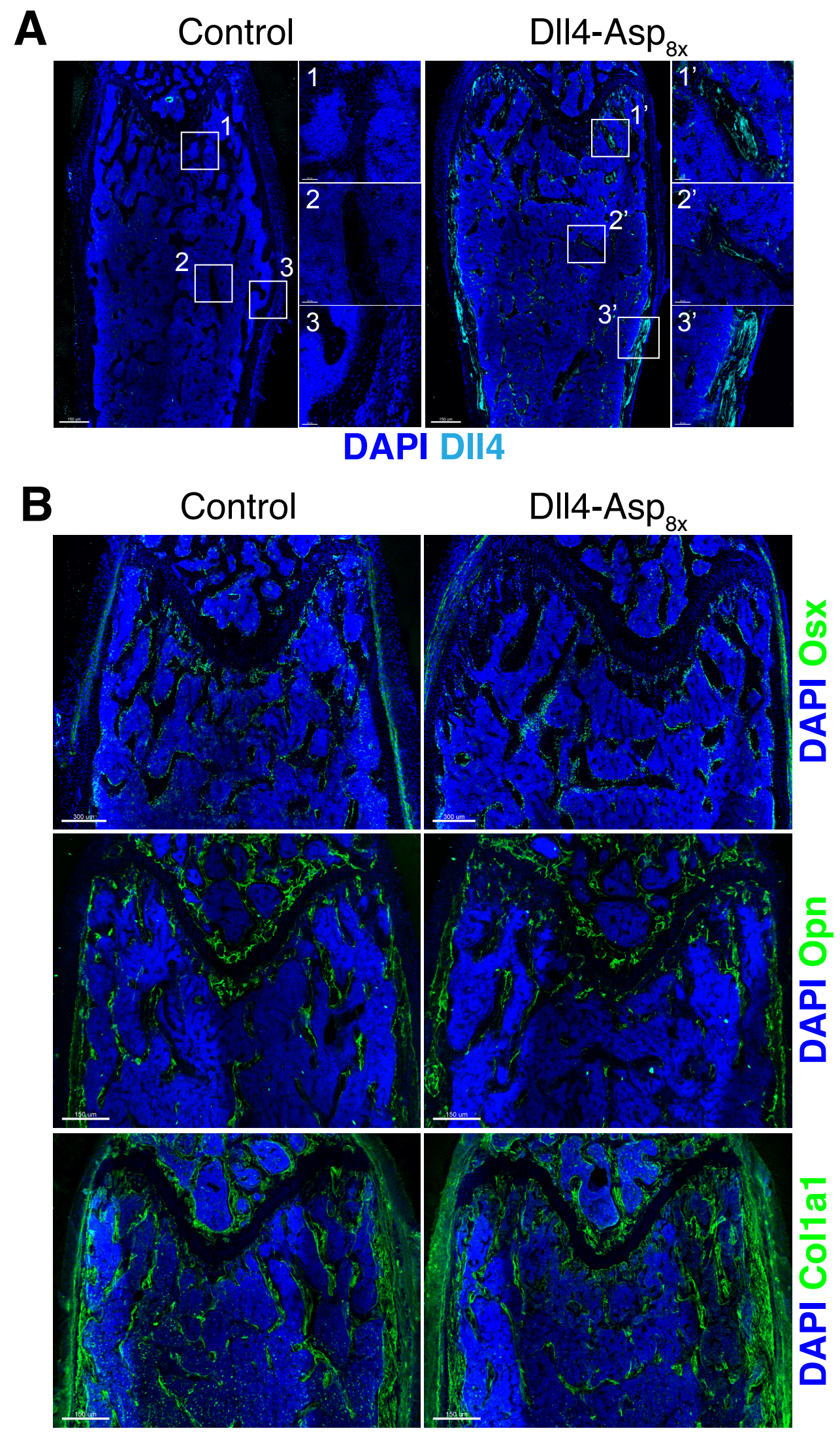

Xu, Dinh et al., Figure 1-figure supplement 3_R1 


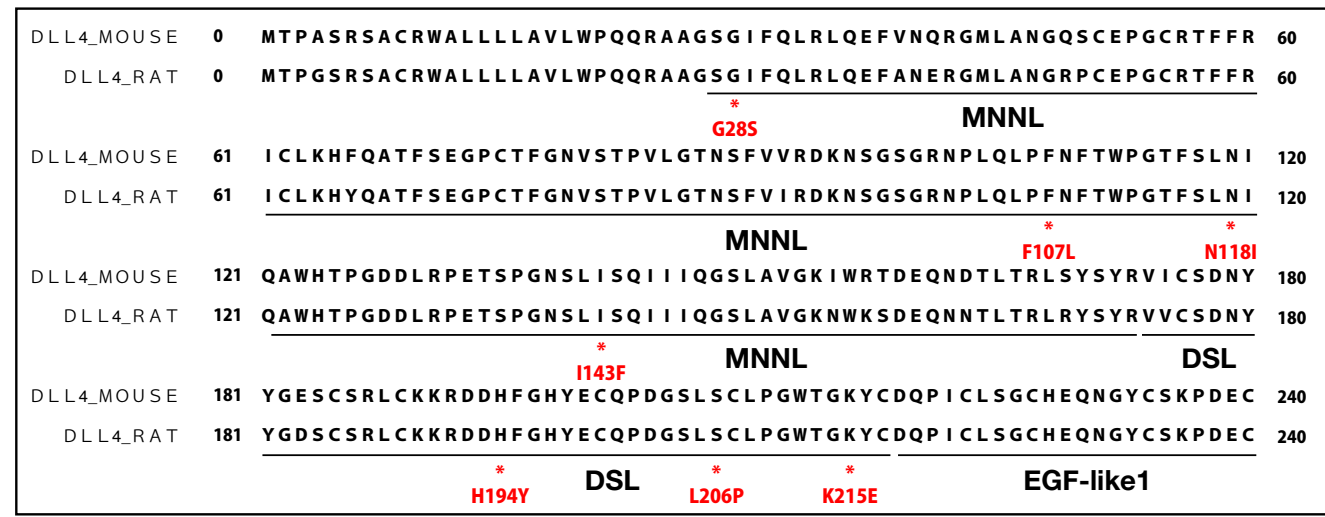
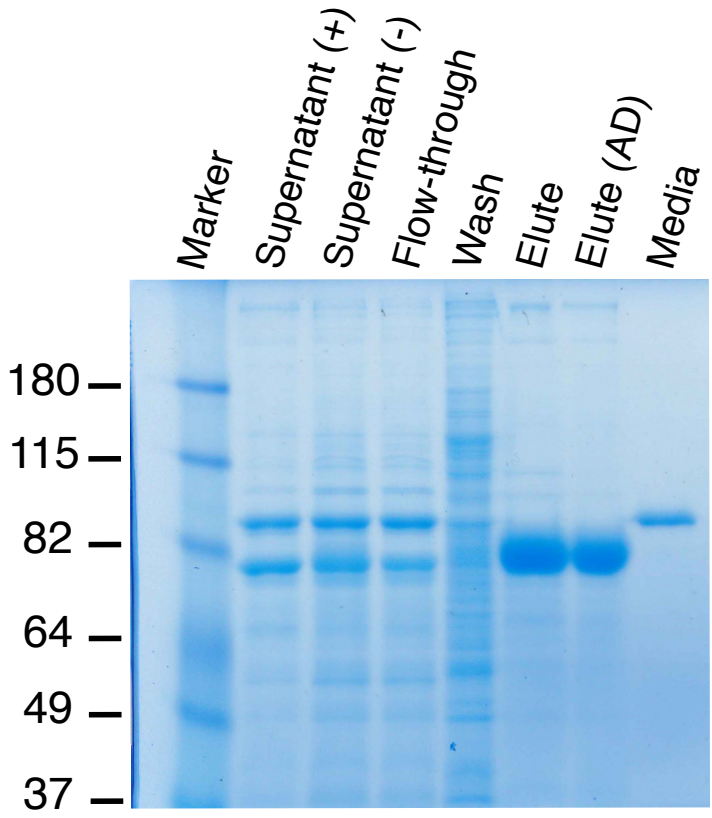

D Immobilized DII4-Asp ${ }_{8 x}$ and D\|l| ${ }_{(E 12)}$

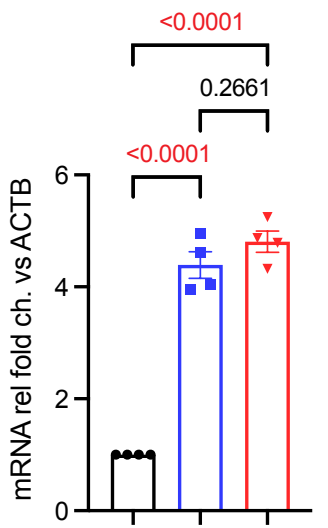

Hs DLL4

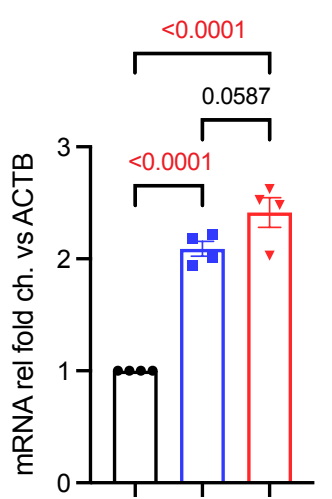

Hs HES1

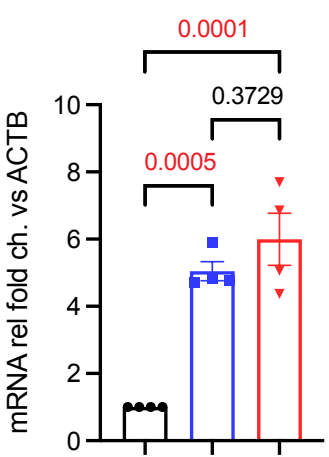

Hs HEY1

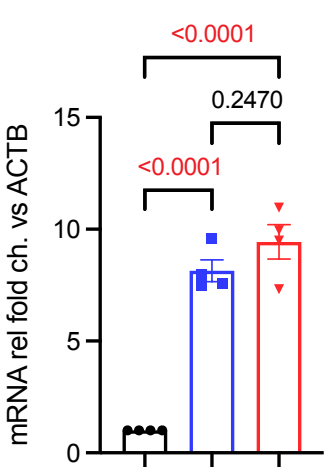

Hs EFNB2

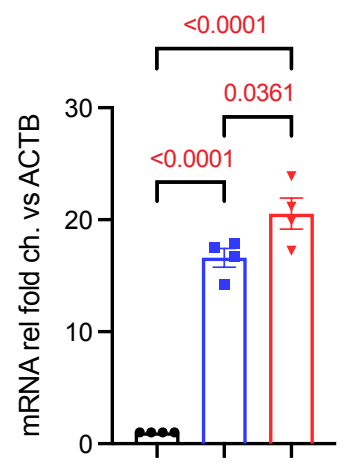

Hs HEY2

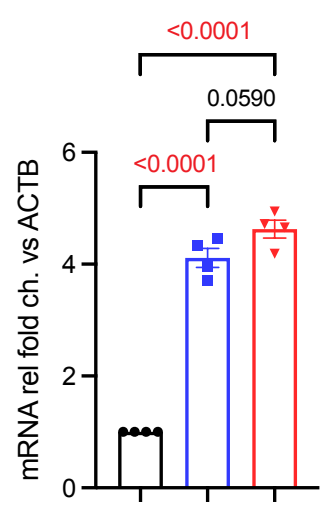

Hs NRARP

Soluble DII4-Asp ${ }_{8 x}$ and D\|l| ${ }_{(E 12)}$

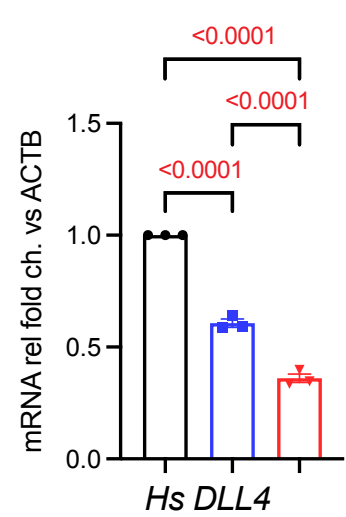

Hs DLL4

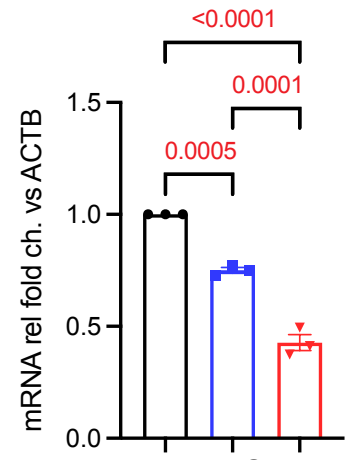

Hs HES1

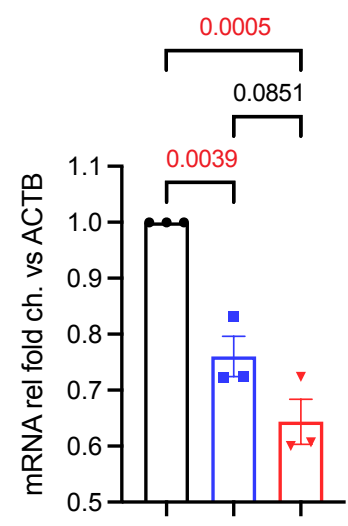

Hs HEY1

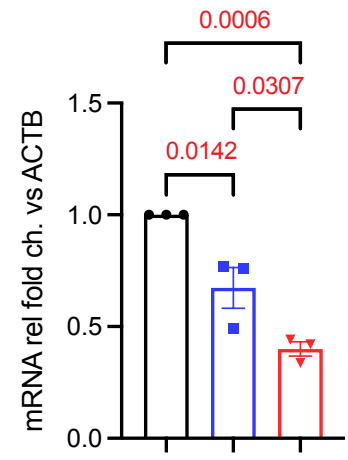

Hs EFNB2

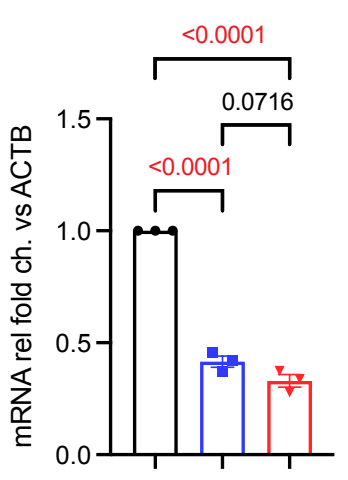

Hs HEY2

0.7682

0.6807

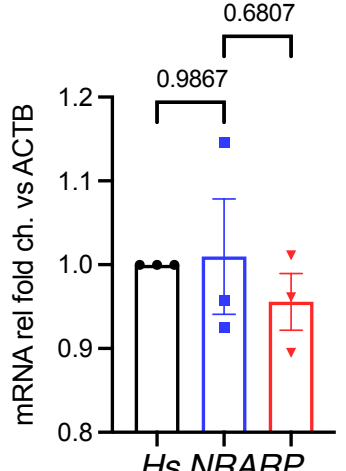

Xu, Dinh et al., Figure 1-figure supplement 4_R1 
A

Ctrl

$\mathrm{DII4}_{(\mathrm{E} 12)}$
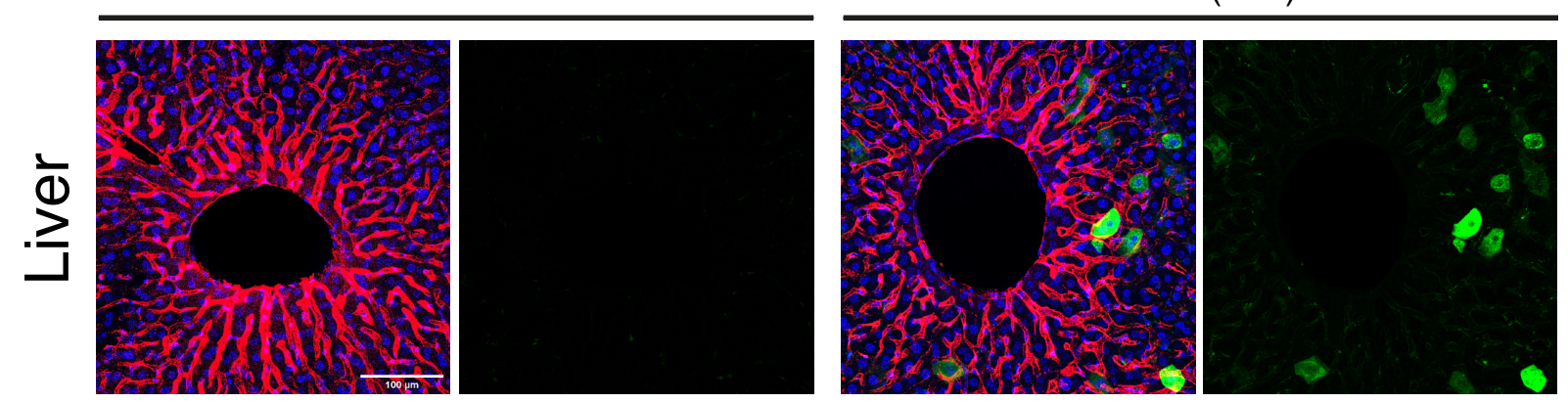

DAPI Emcn DII4

B

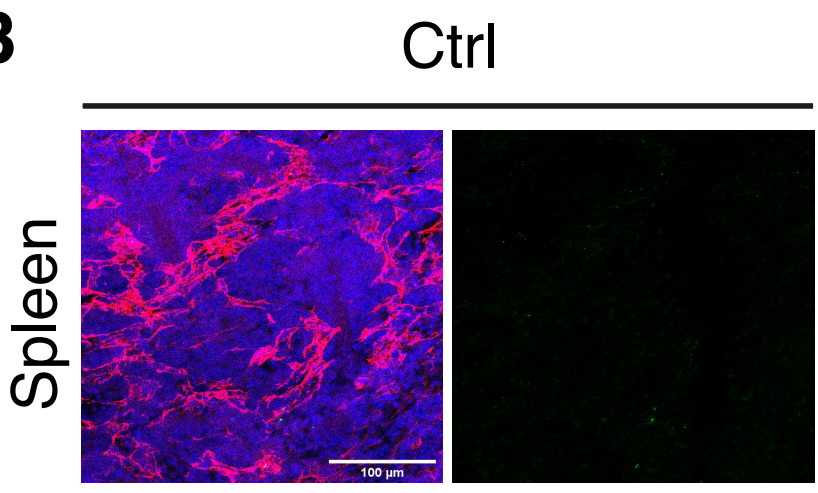

DAPI Emcn DII4

C

Ctrl
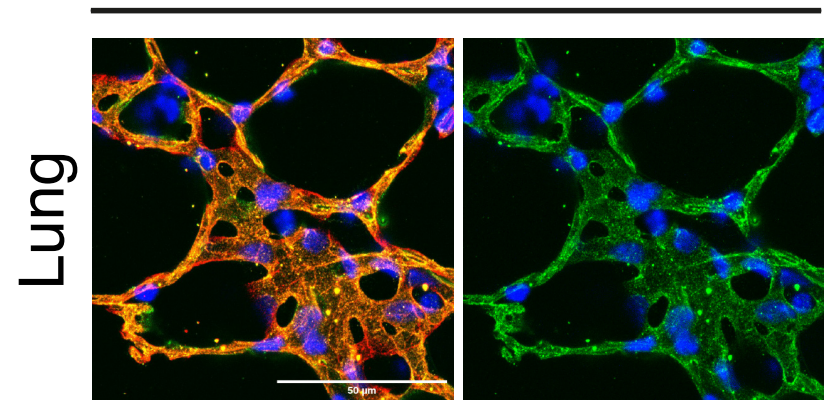

$\operatorname{Dll}_{(\mathrm{E} 12)}$

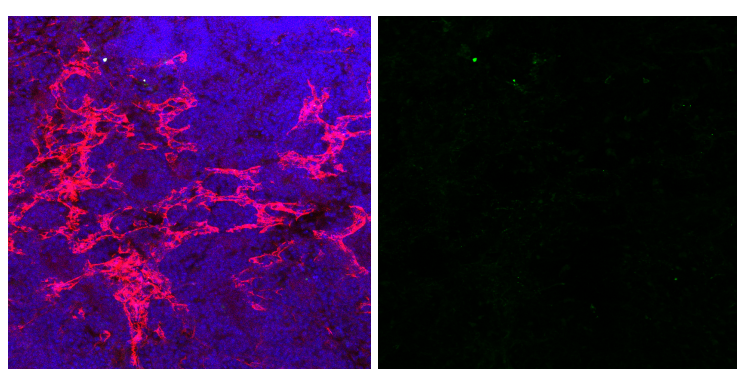

DAPI CD31 DII4

Xu, Dinh et al., Figure 1- figure supplement 5_R1 
A

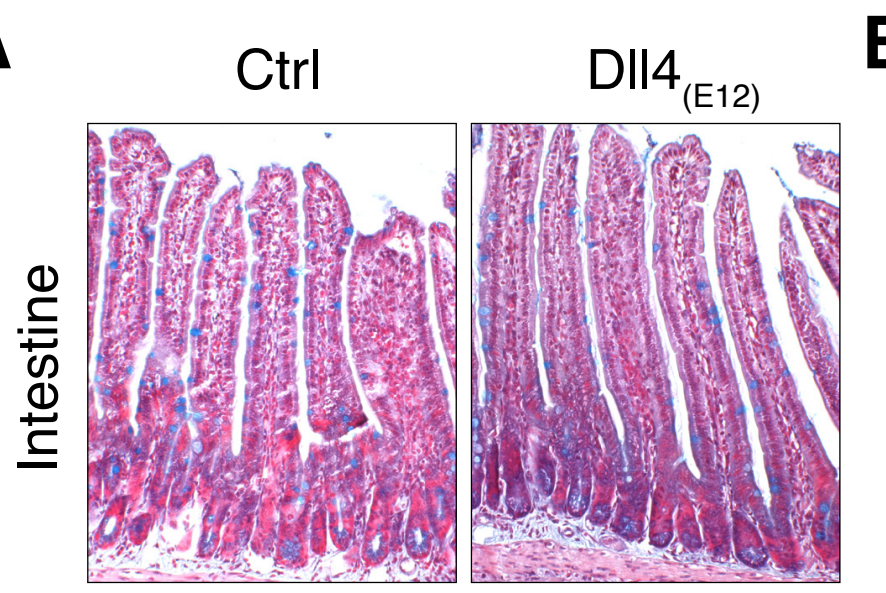

B

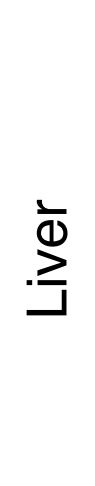

Ctrl

$\operatorname{Dll}_{(\mathrm{E} 12)}$

C

Ctrl

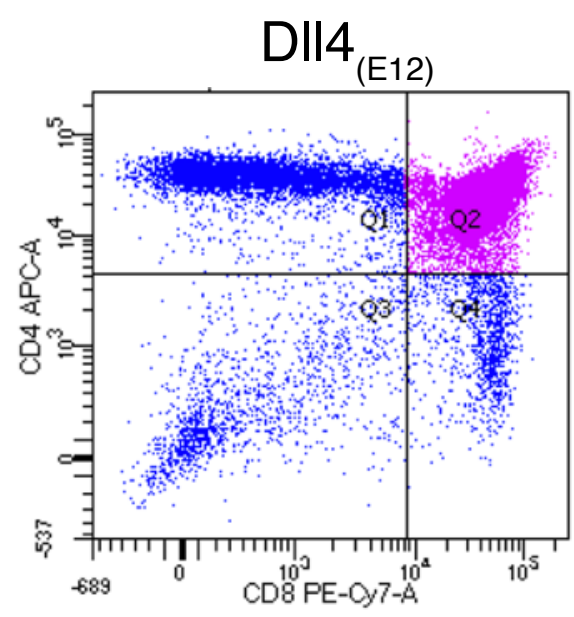

D

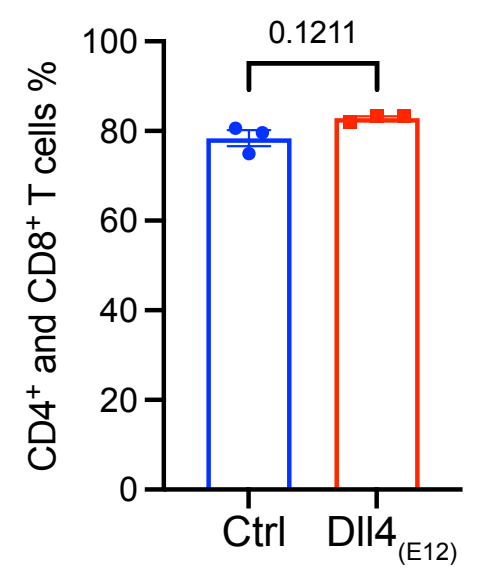

E

Ctrl

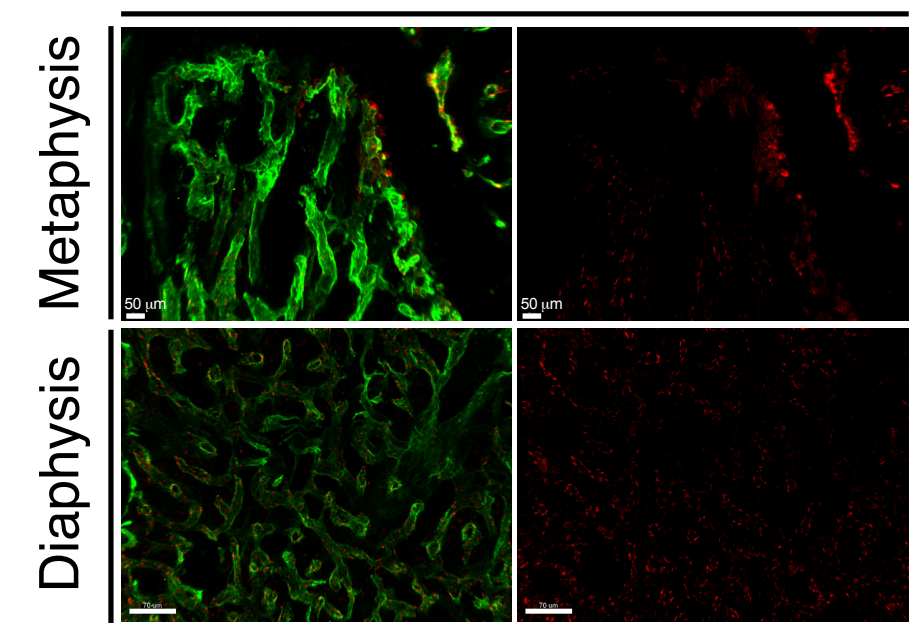

DII4
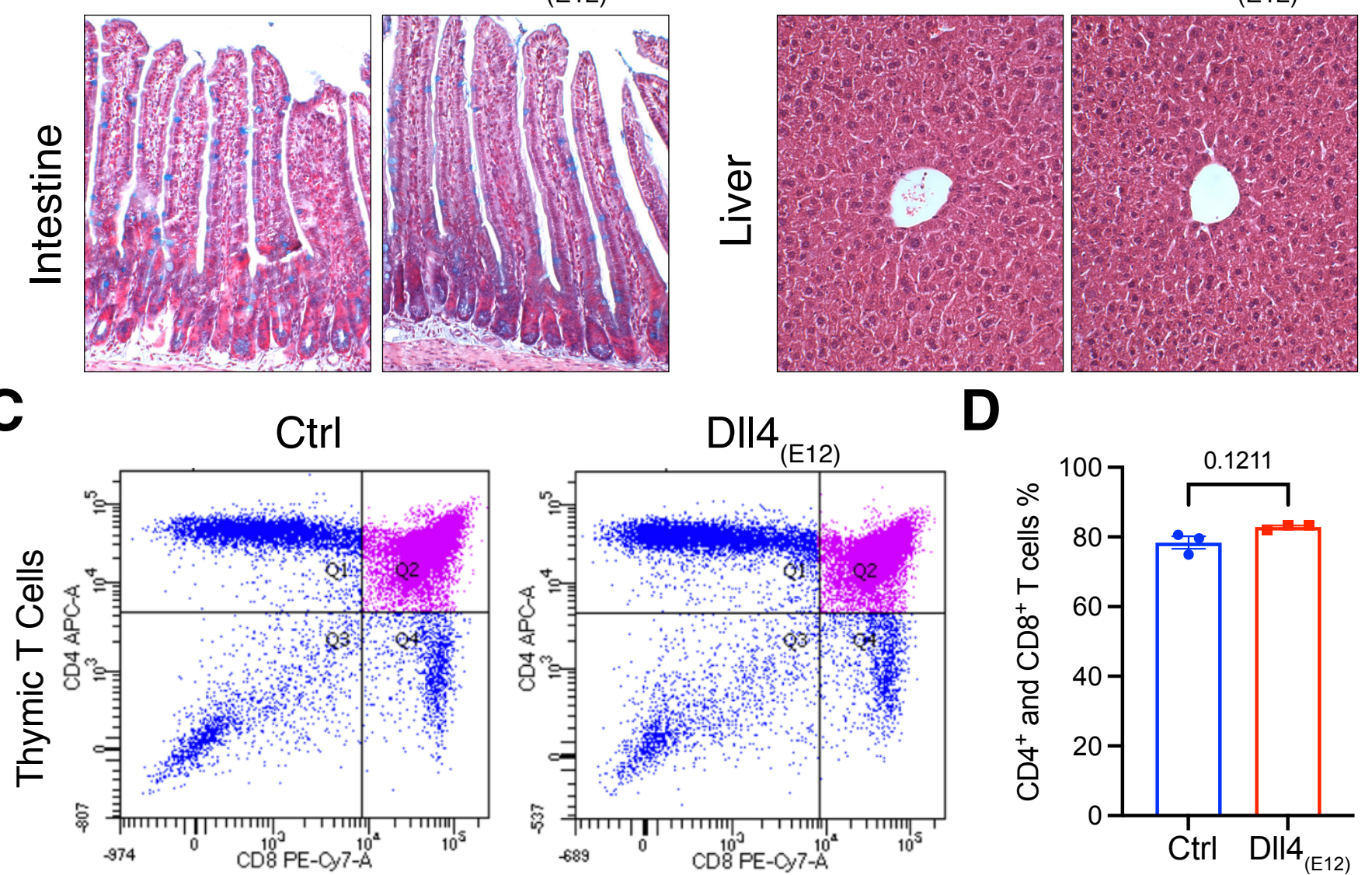
(E12)

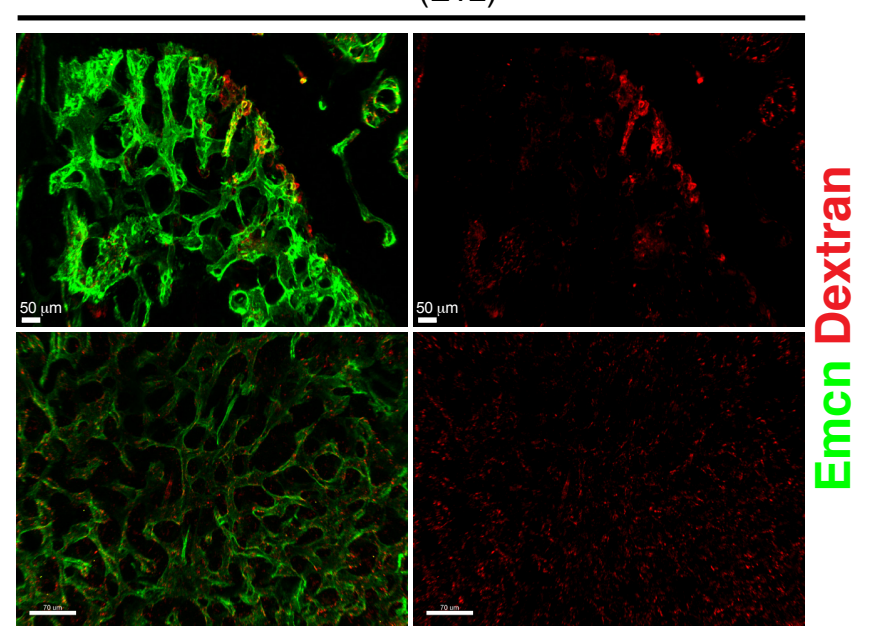

$\mathbf{F}$

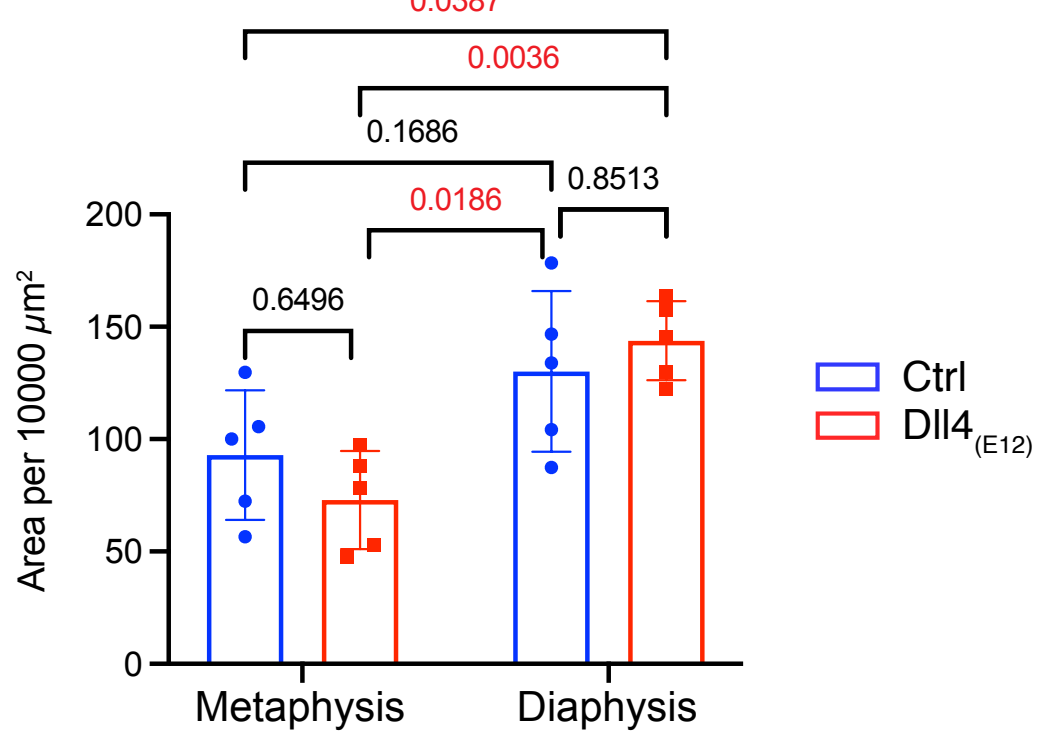

Xu, Dinh et al., Figure 2_R1 


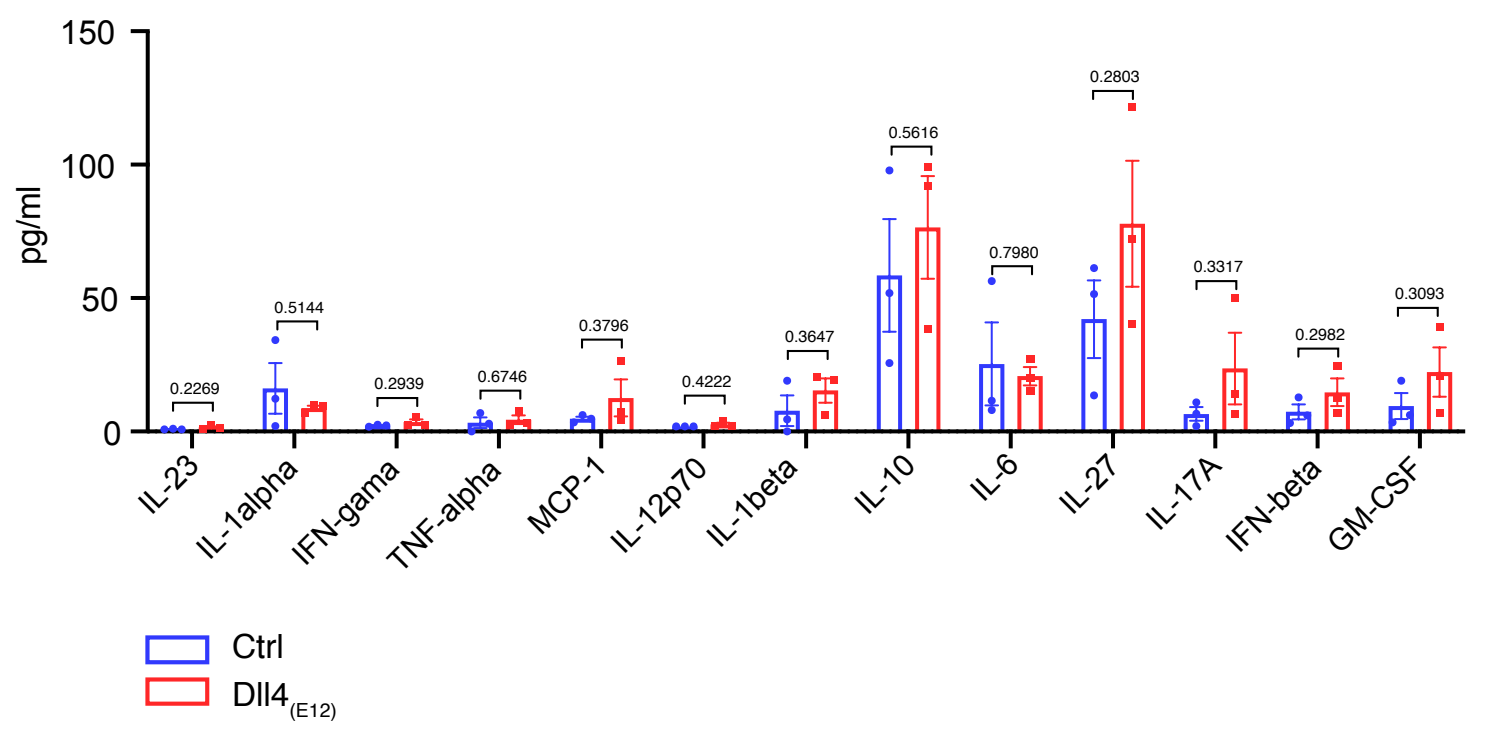

Xu, Dinh et al., Figure 2-figure supplement 1_R1 


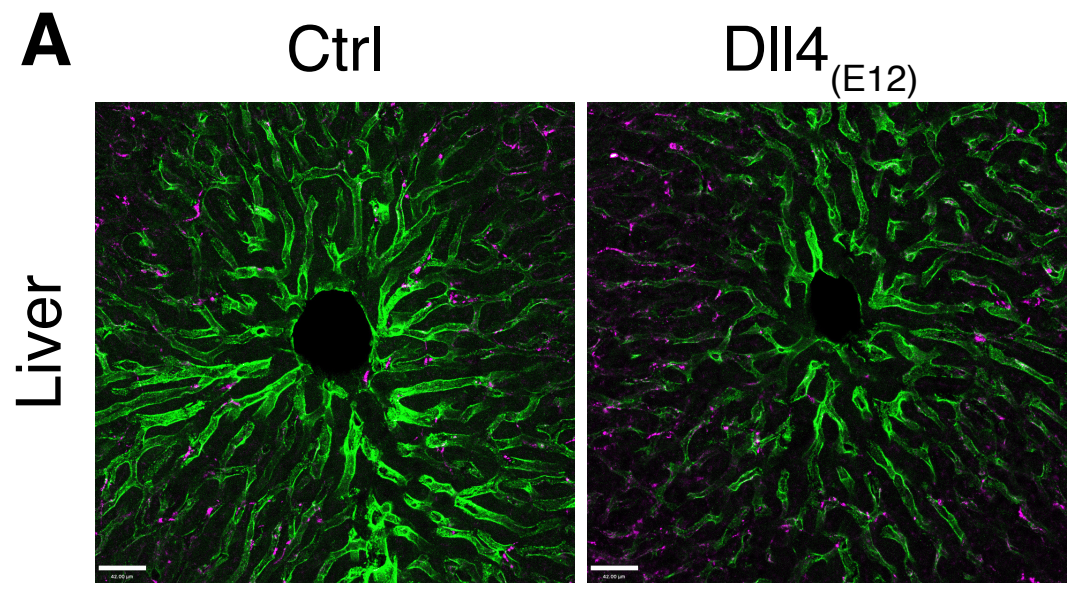

Emcn Dextran

B

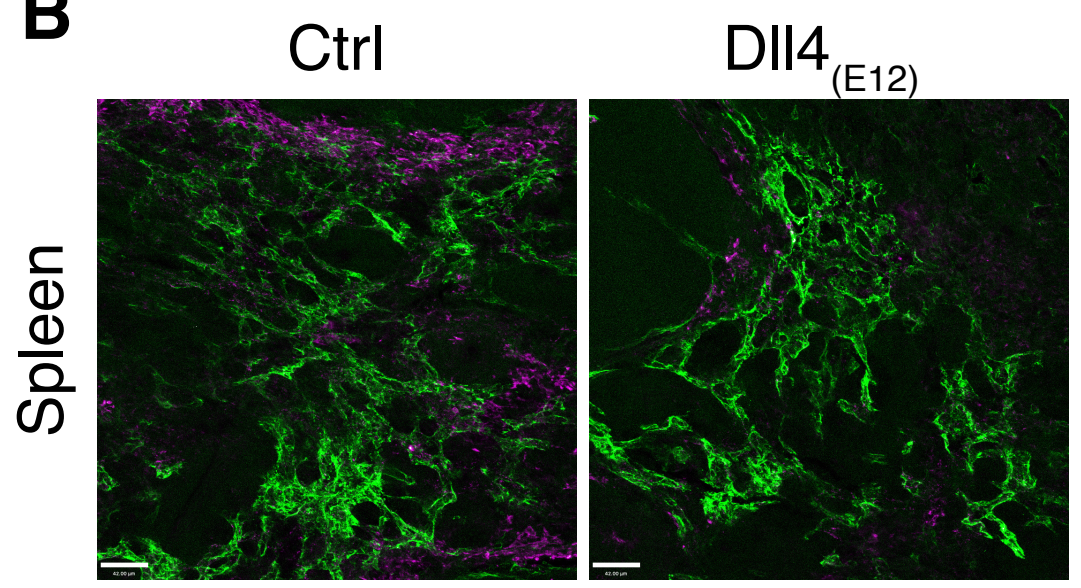

Emcn Dextran

C

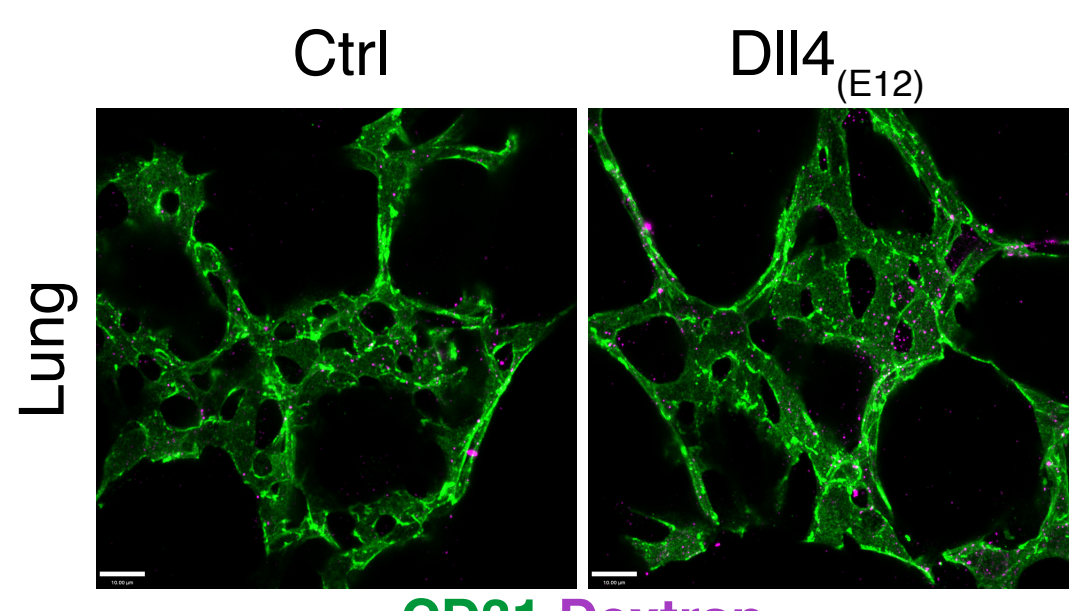

CD31 Dextran
Liver Dextran

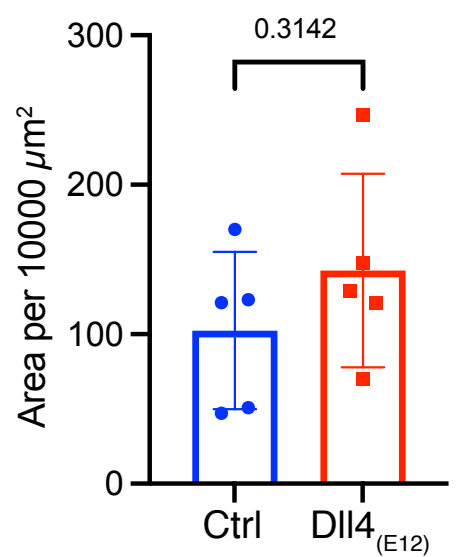

Spleen Dextran

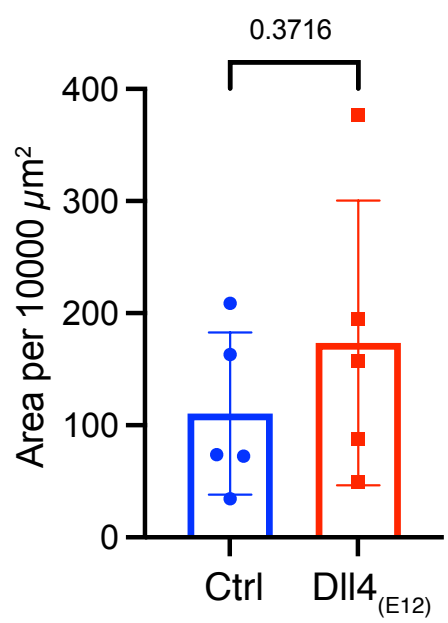

Xu, Dinh et al., Figure 2- figure supplement 2_R1 
$\mathbf{A}$

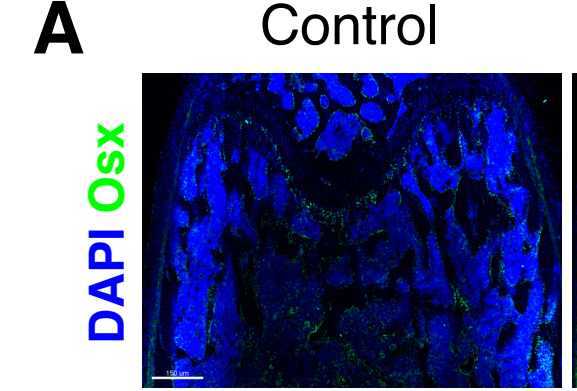

\section{B}

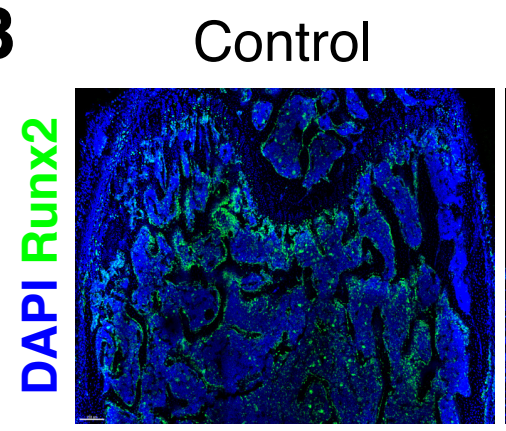

C
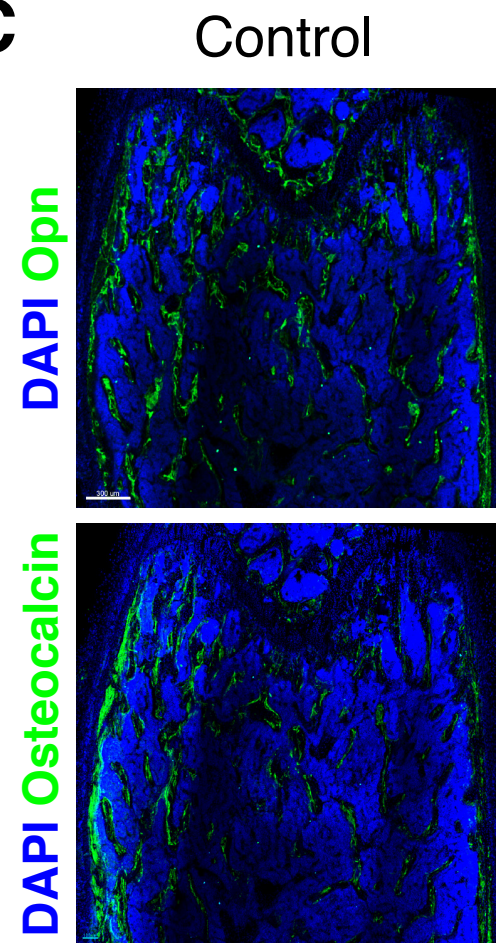

D

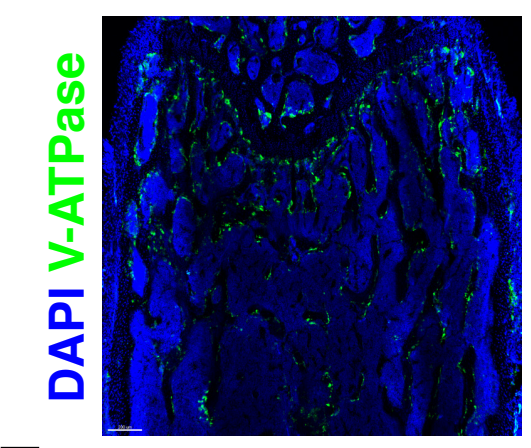

E

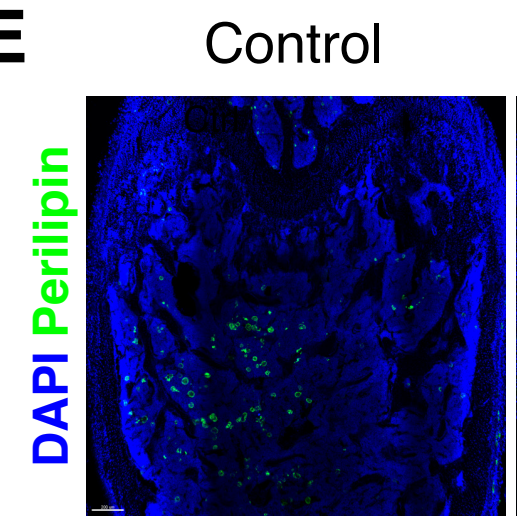

DII4 $_{(\mathrm{E} 12)}$

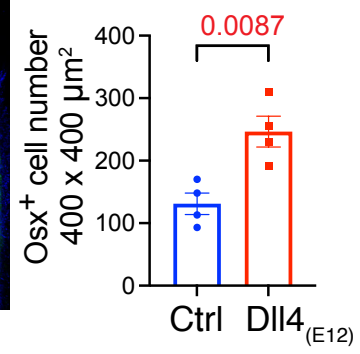

DII4

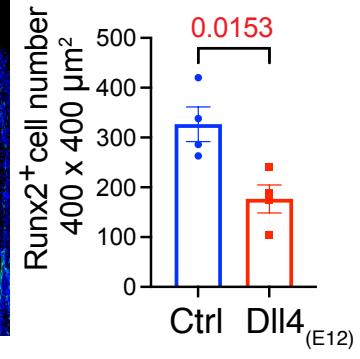

$\mathrm{DII4}_{(\mathrm{E} 12)}$
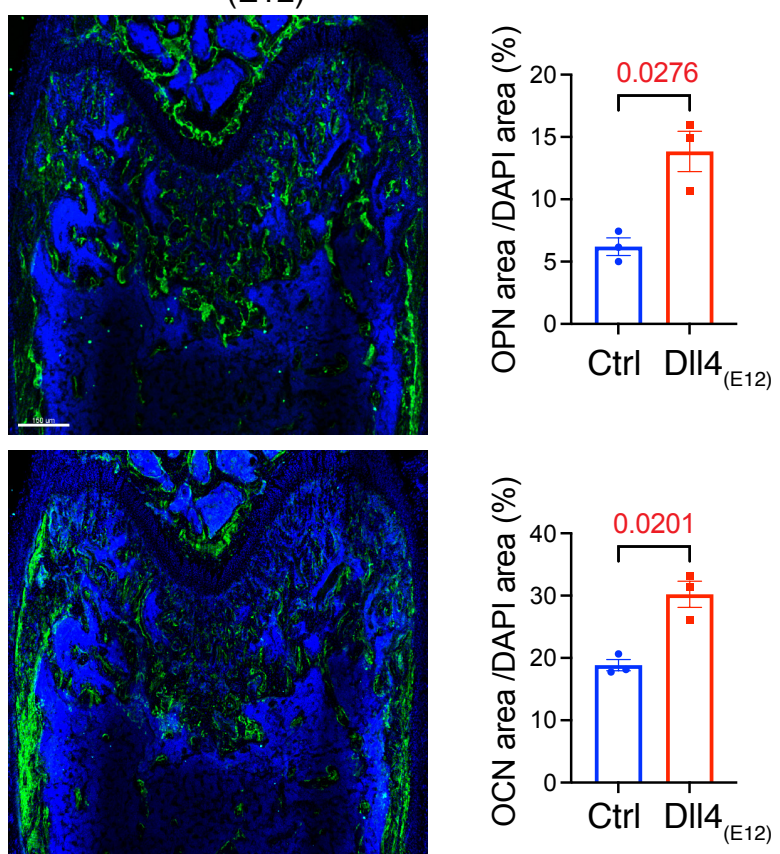

$\mathrm{DII4}_{(\mathrm{E} 12)}$
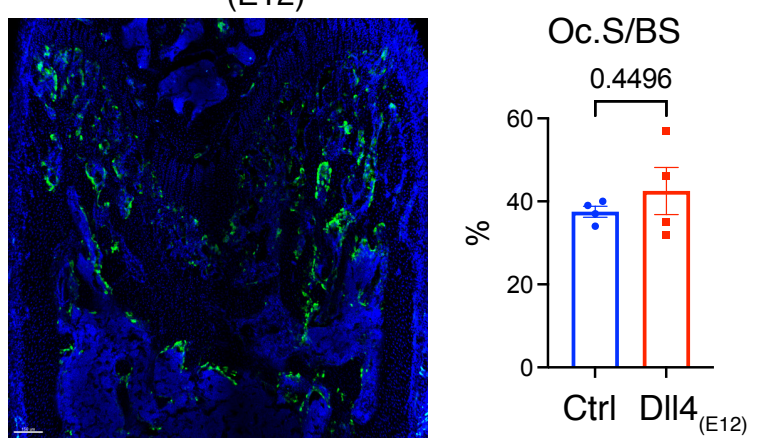

N.Oc/B.Pm

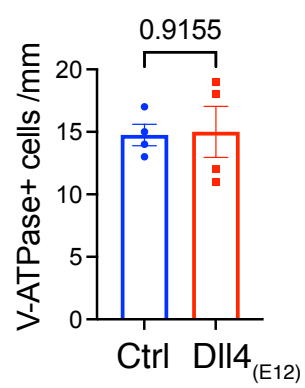

$\mathrm{DII4}_{(\mathrm{E} 12)}$
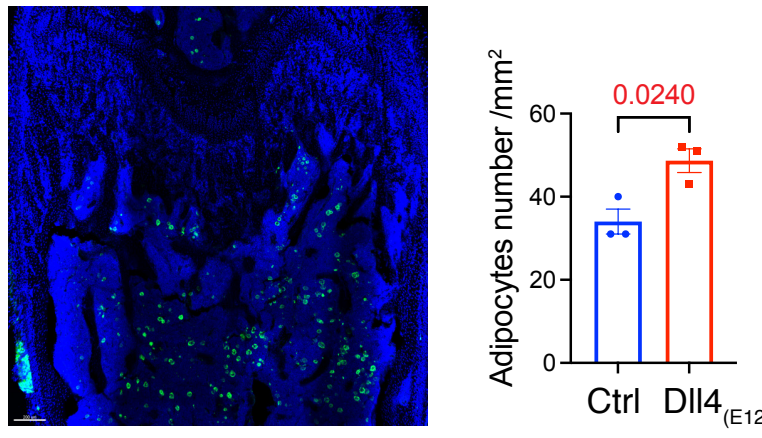

Xu, Dinh et al., Figure 3_R1 


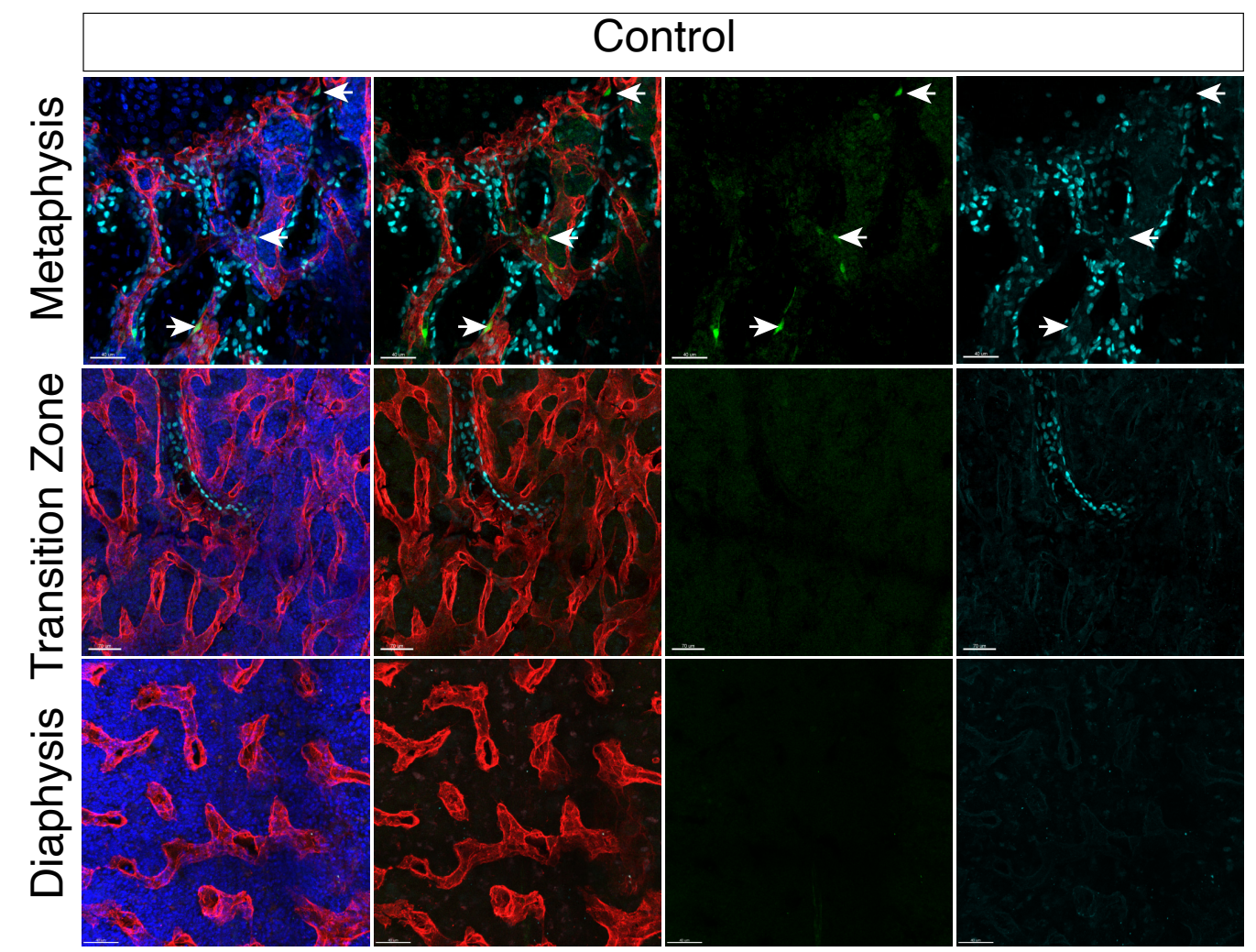

DAPI Emcn Osx Hey1-GFP

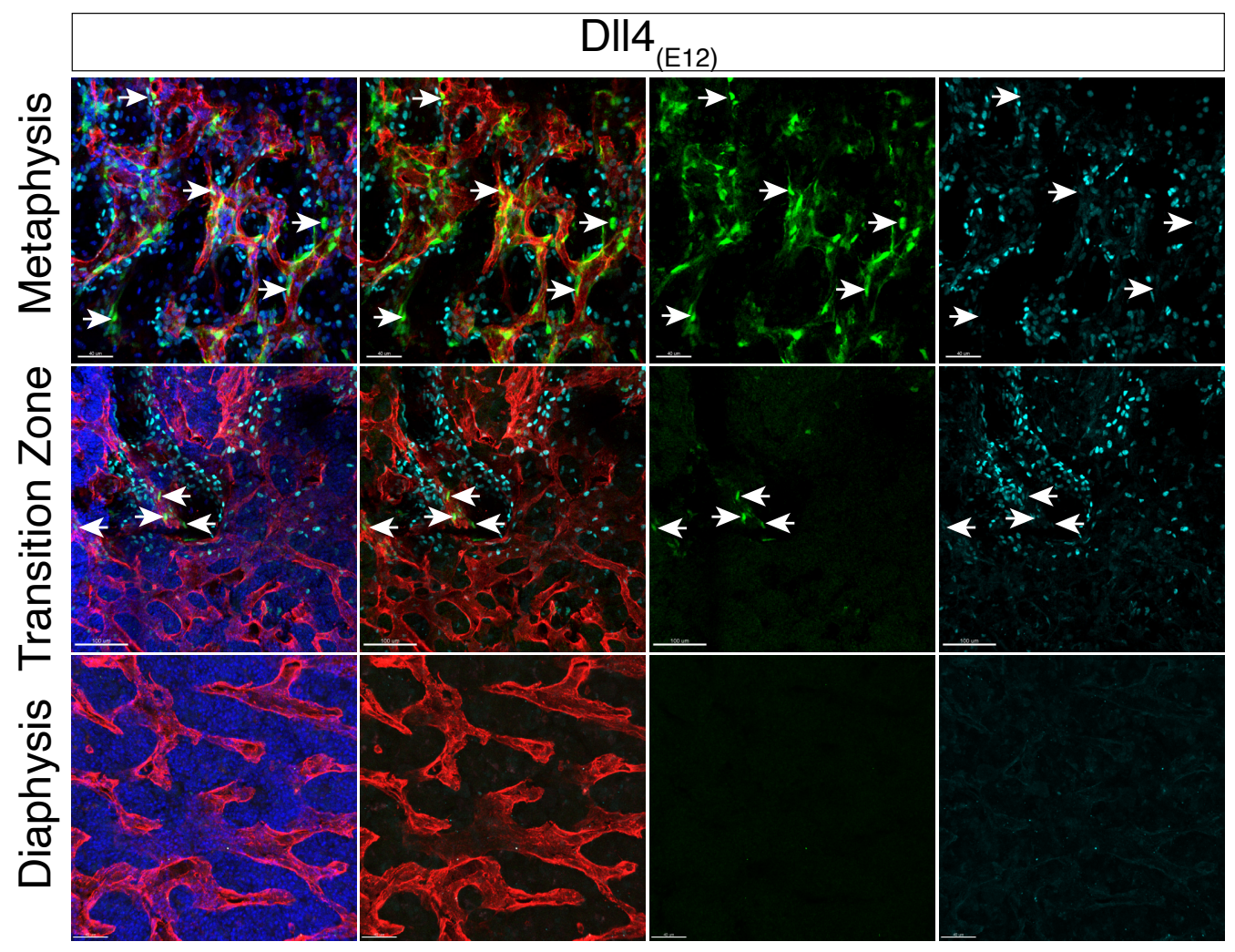

DAPI Emcn Osx Hey1-GFP

Xu, Dinh et al., Figure 3-figure supplement 1_R1 
A

Control

$\operatorname{DII4}_{(\mathrm{E} 12)}$

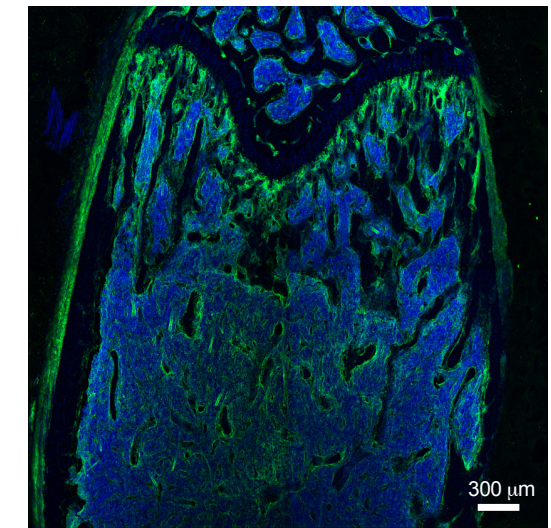

DAPI PDGFR $\beta$

B

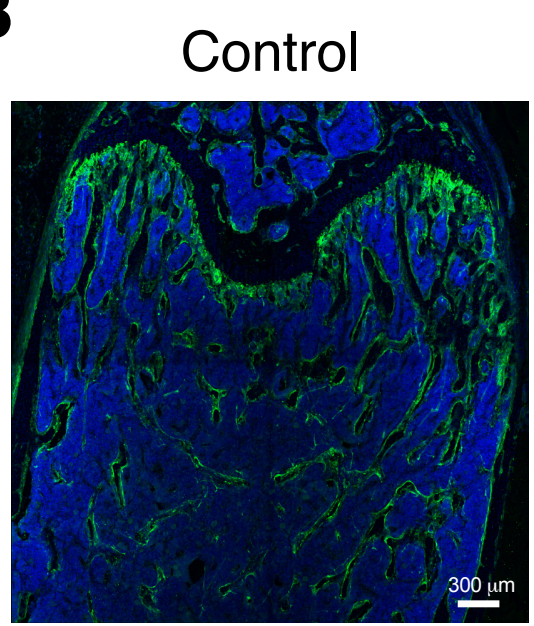

DAPI NG2

C

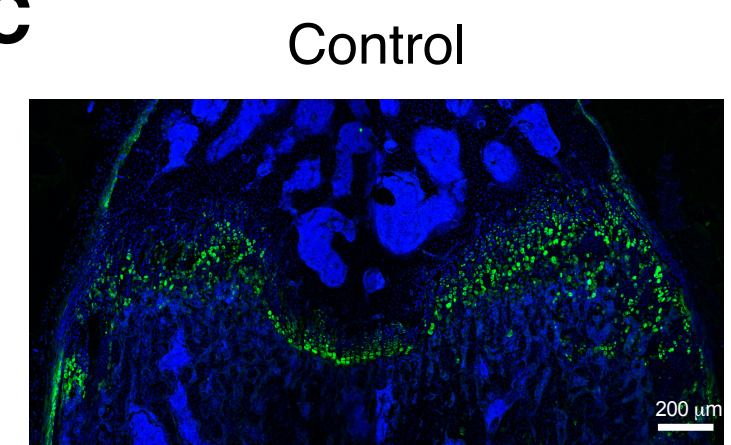

DAPI ACAN

D

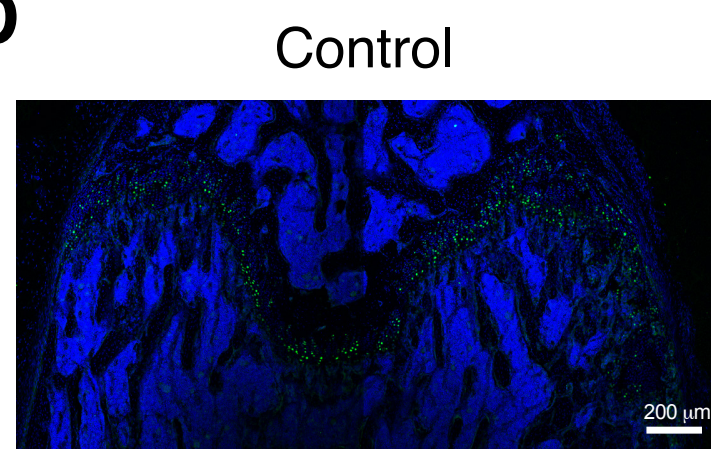

DAPI SOX9

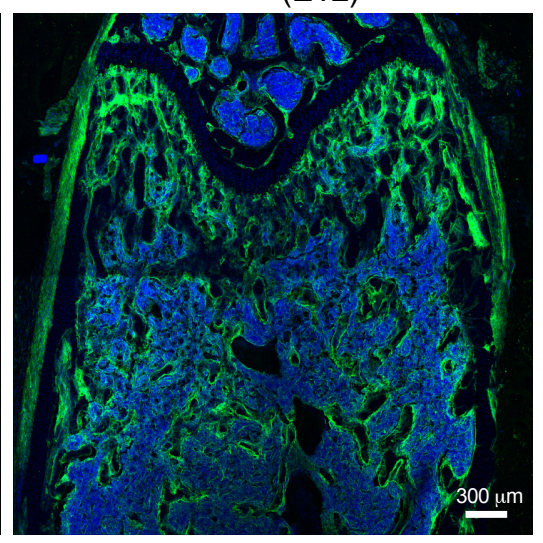

DAPI PDGFR $\beta$

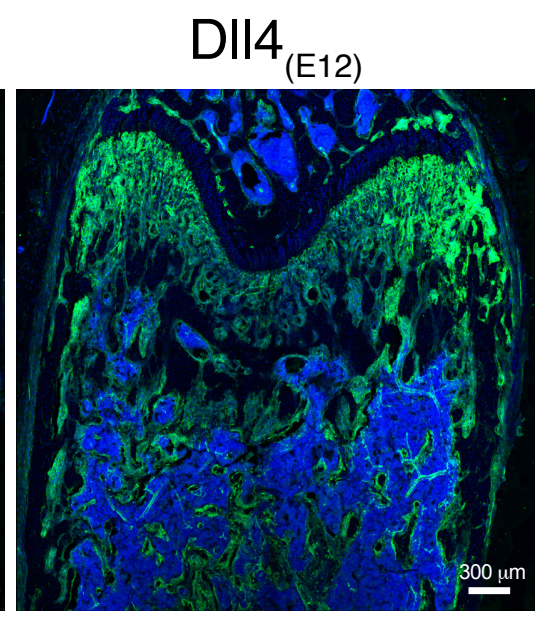

DAPI NG2
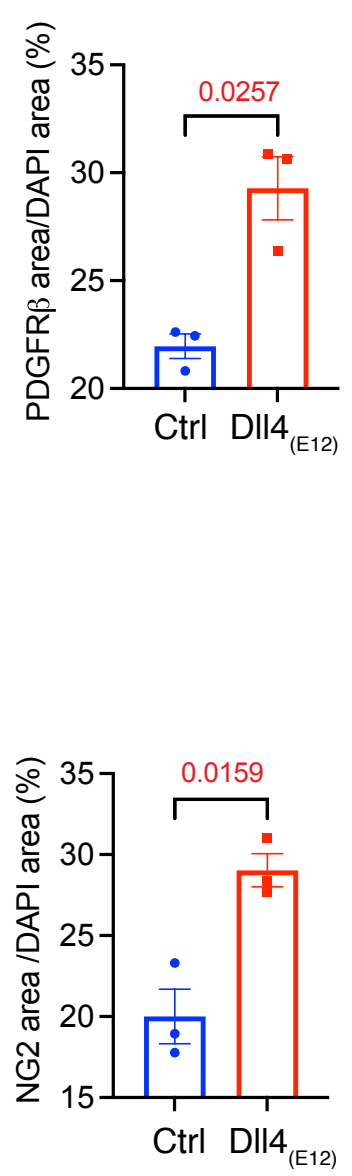

$\mathrm{DIl4}_{(\mathrm{E} 12)}$

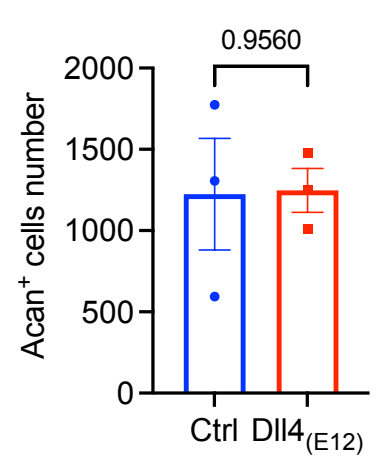

DAPI ACAN

$\mathrm{DII4}_{(\mathrm{E} 12)}$

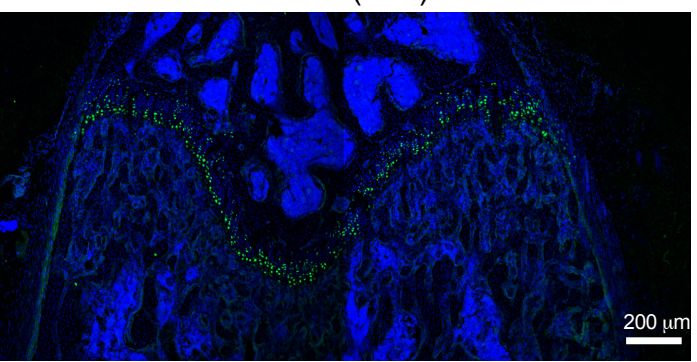

DAPI SOX9

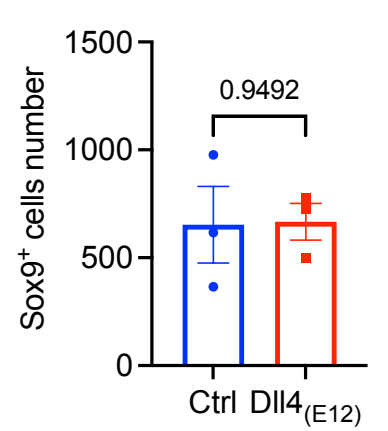

Xu, Dinh et al., Figure 3-figure supplement 2_R1 
A

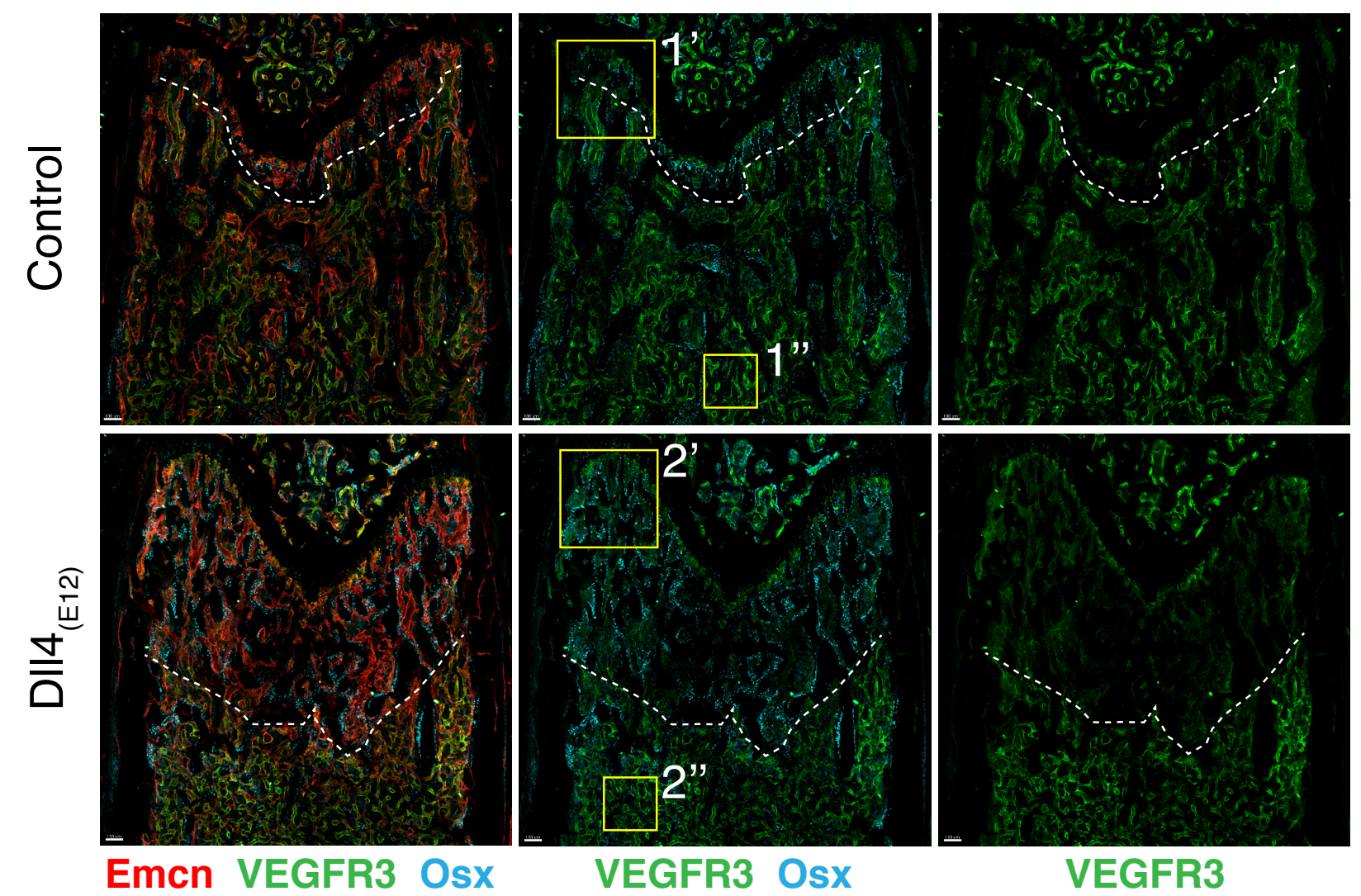

B

Control

DII4

Control

$D^{D I 14}{ }_{(E 12)}$

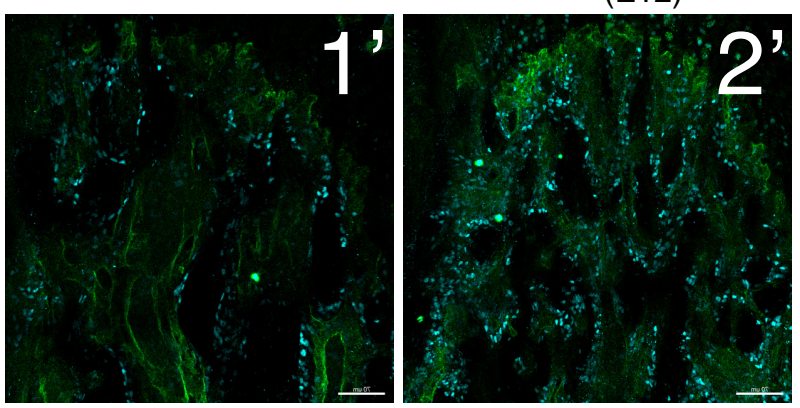

VEGFR3 Osx

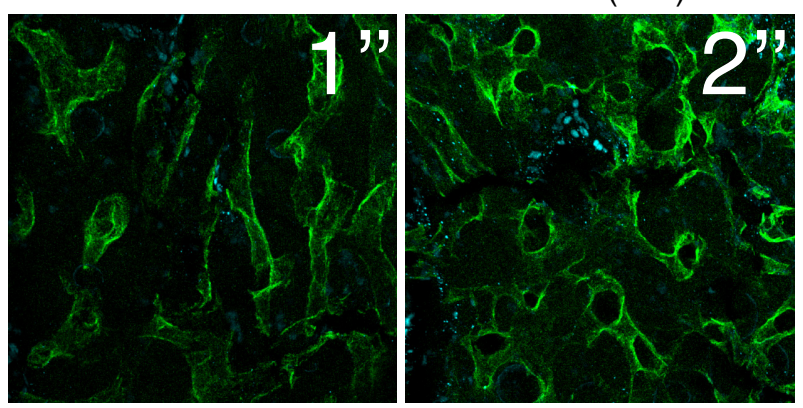

VEGFR3 OsX

C

D Control

DII4 ${ }_{(E 12)}$

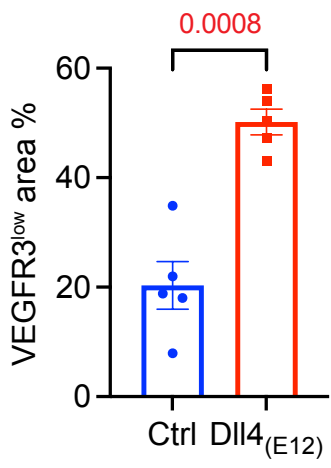

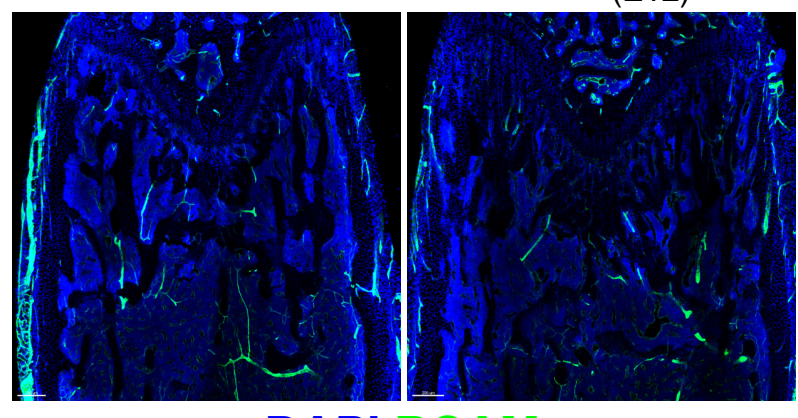

DAPI BCAM

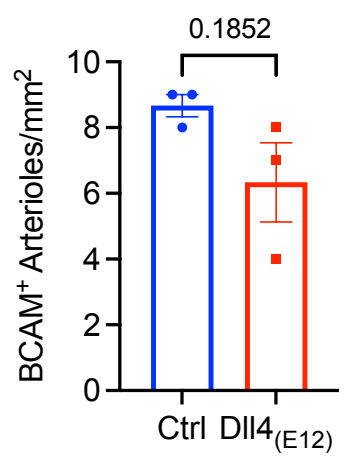

Xu, Dinh et al., Figure 4_R1 
A

Extracellular Domain (ECD)

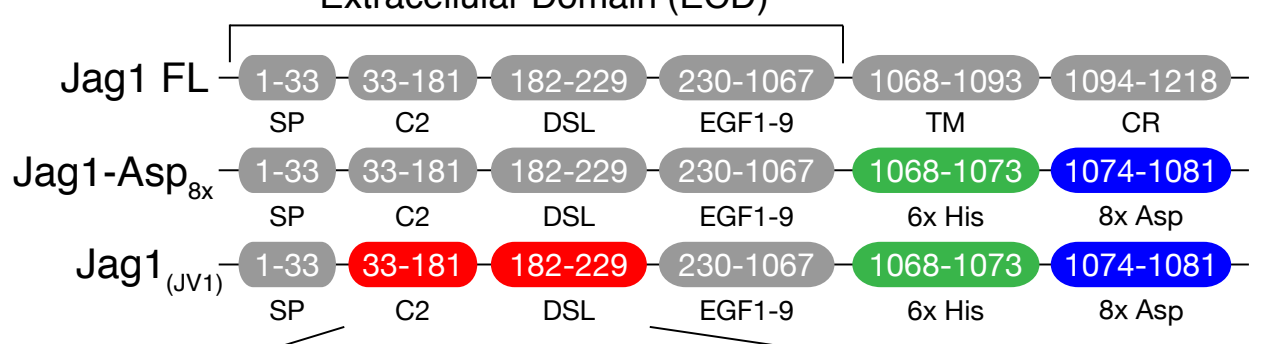

S32L, R68G, D72N, T87R, Q182R

B

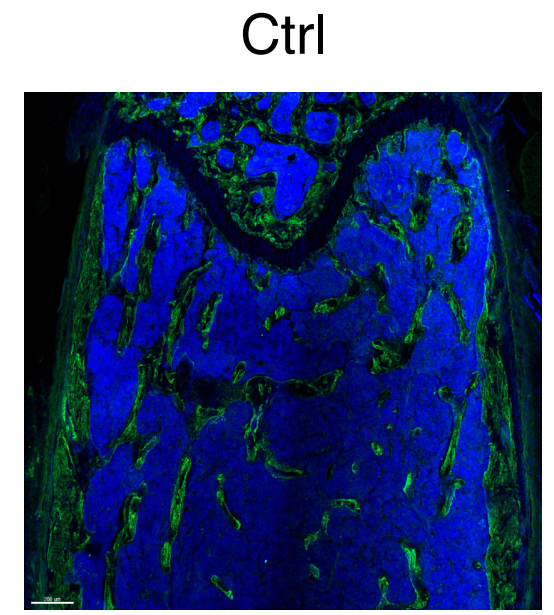

Jag1-Asp $8 x$

$\operatorname{Jag}_{(\mathrm{JV} 1)}$
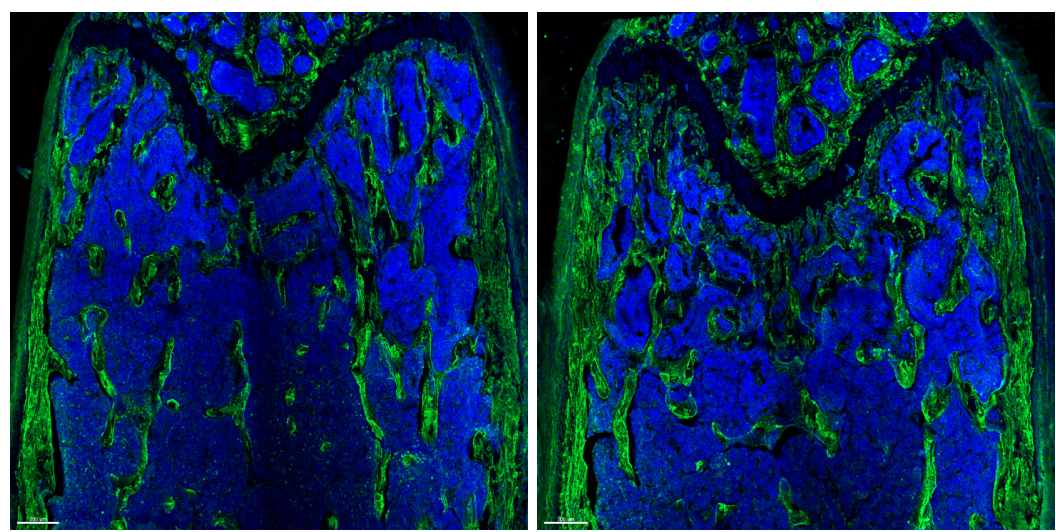

DAPI Col1a1

C

Ctrl

Jag1 $1_{(J V 1)}$
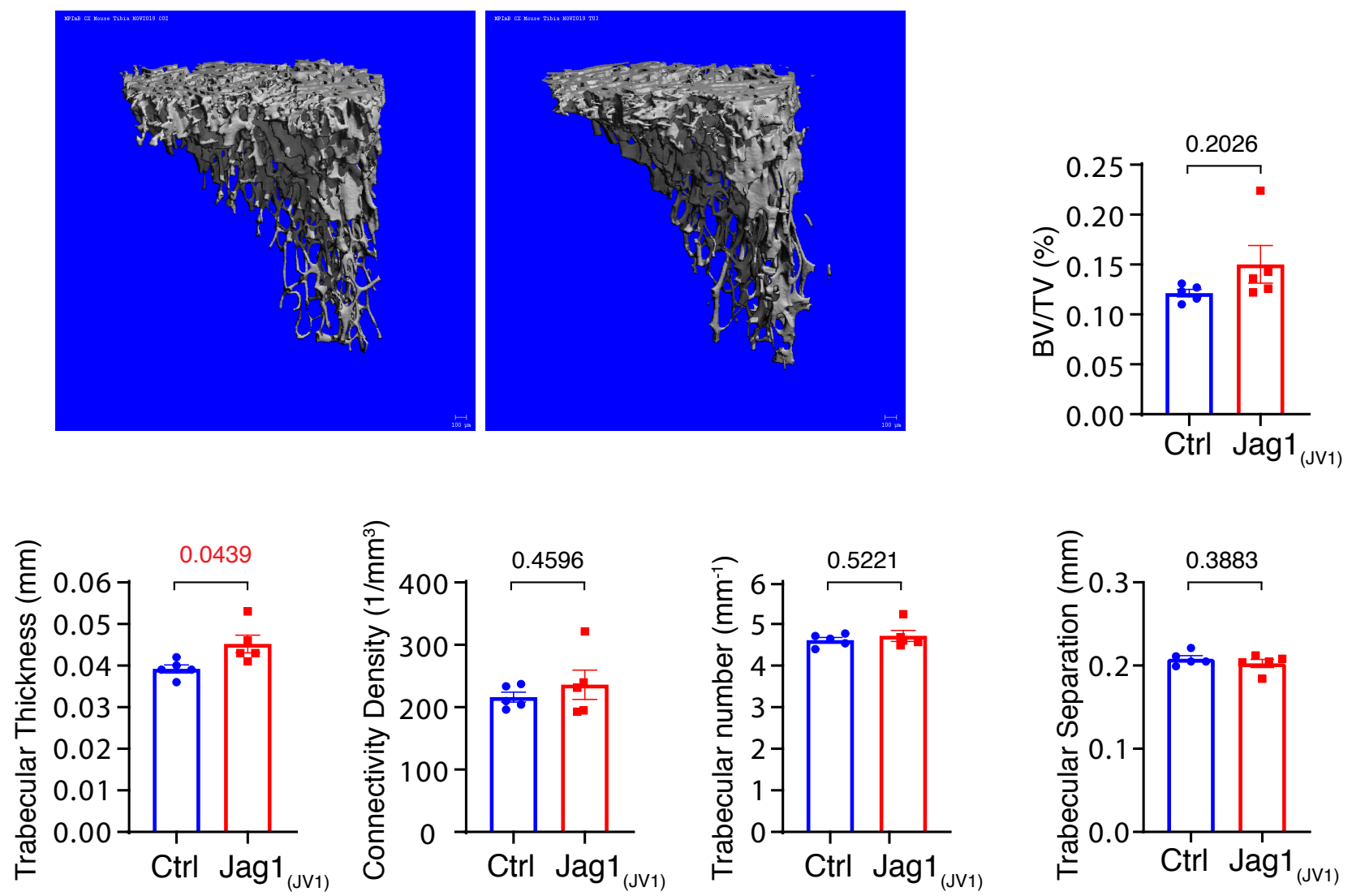

Xu, Dinh et al., Figure 5_R1 
A
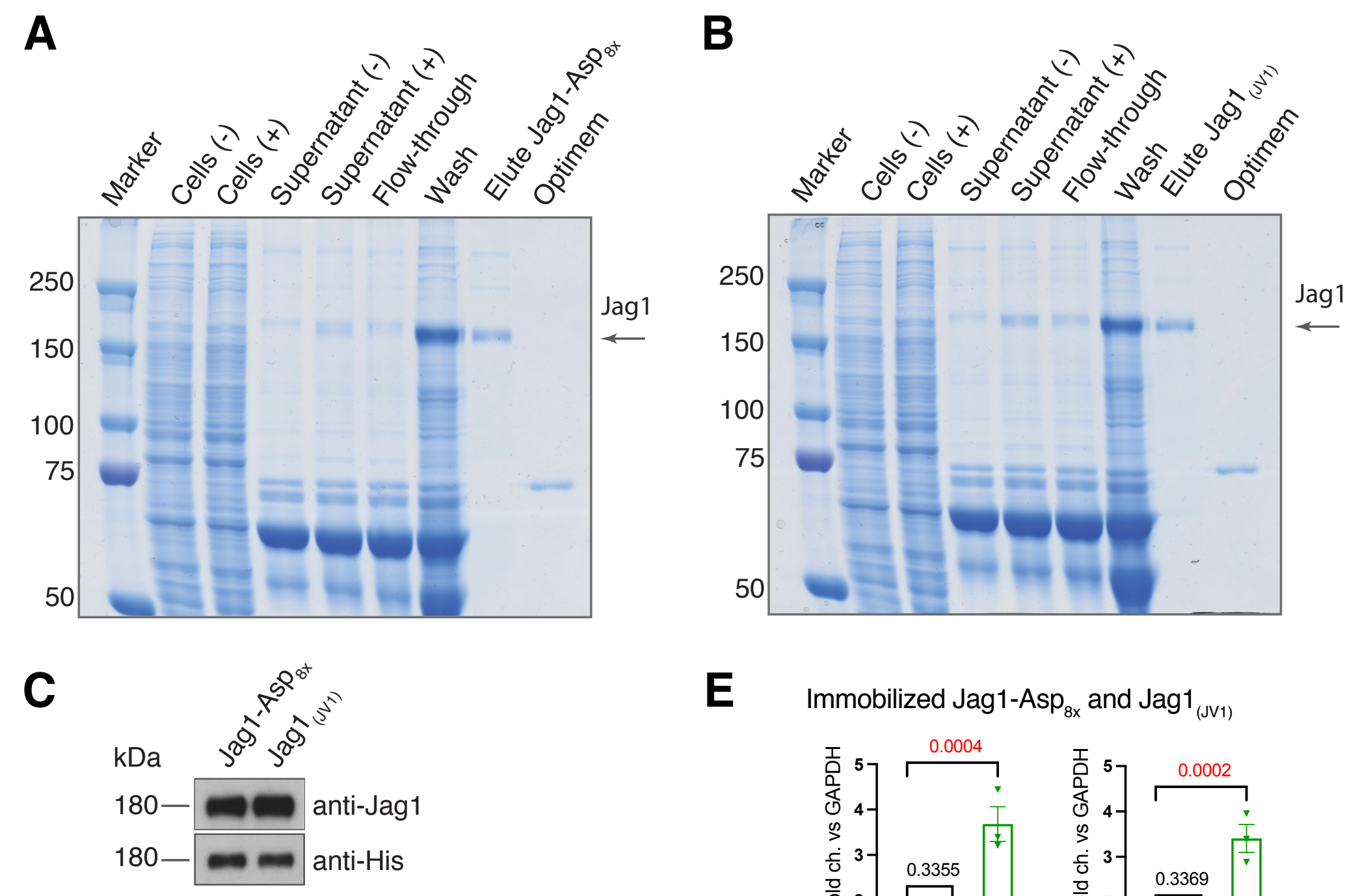

E Immobilized Jag1-Asp $P_{8 x}$ and Jag1 $1_{(J V 1)}$
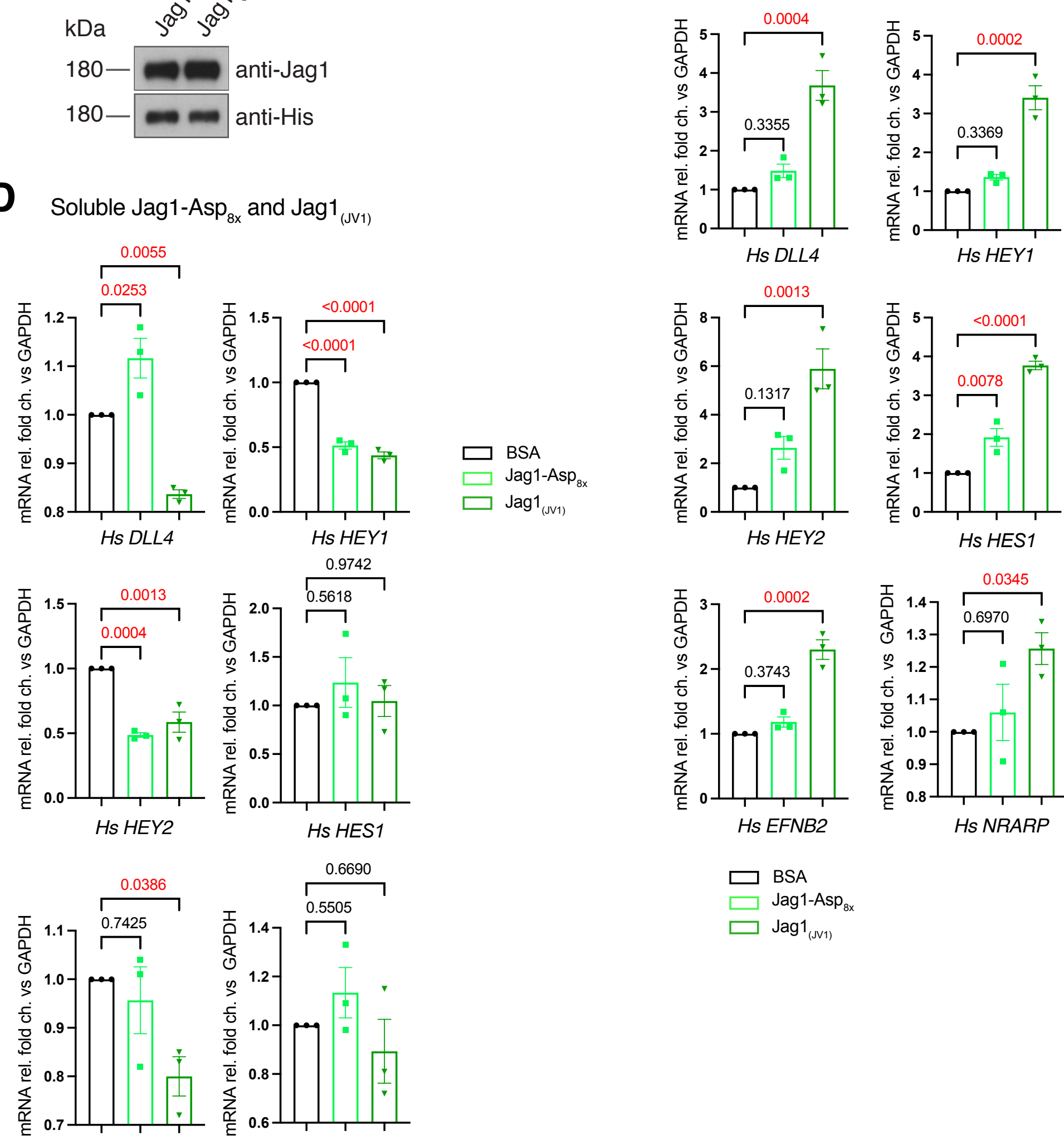

Hs EFNB2
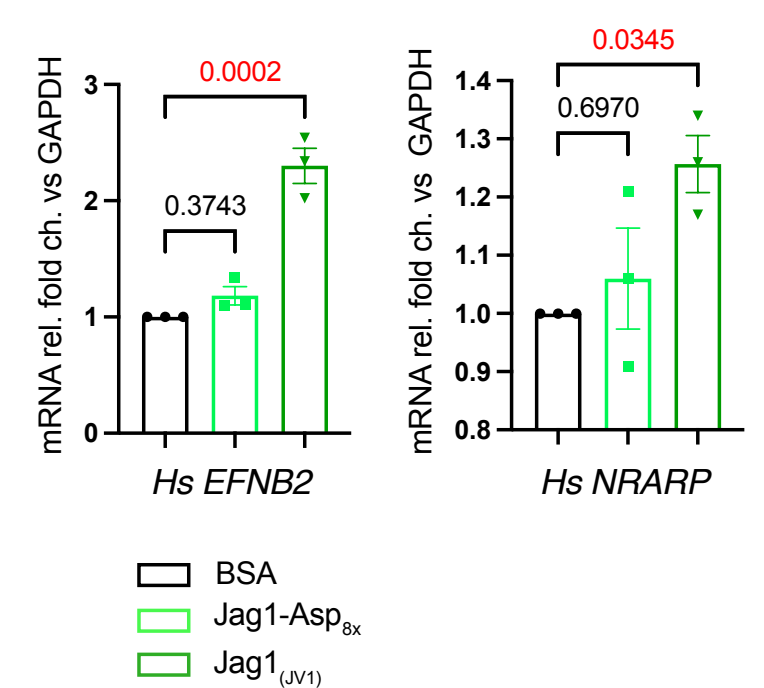


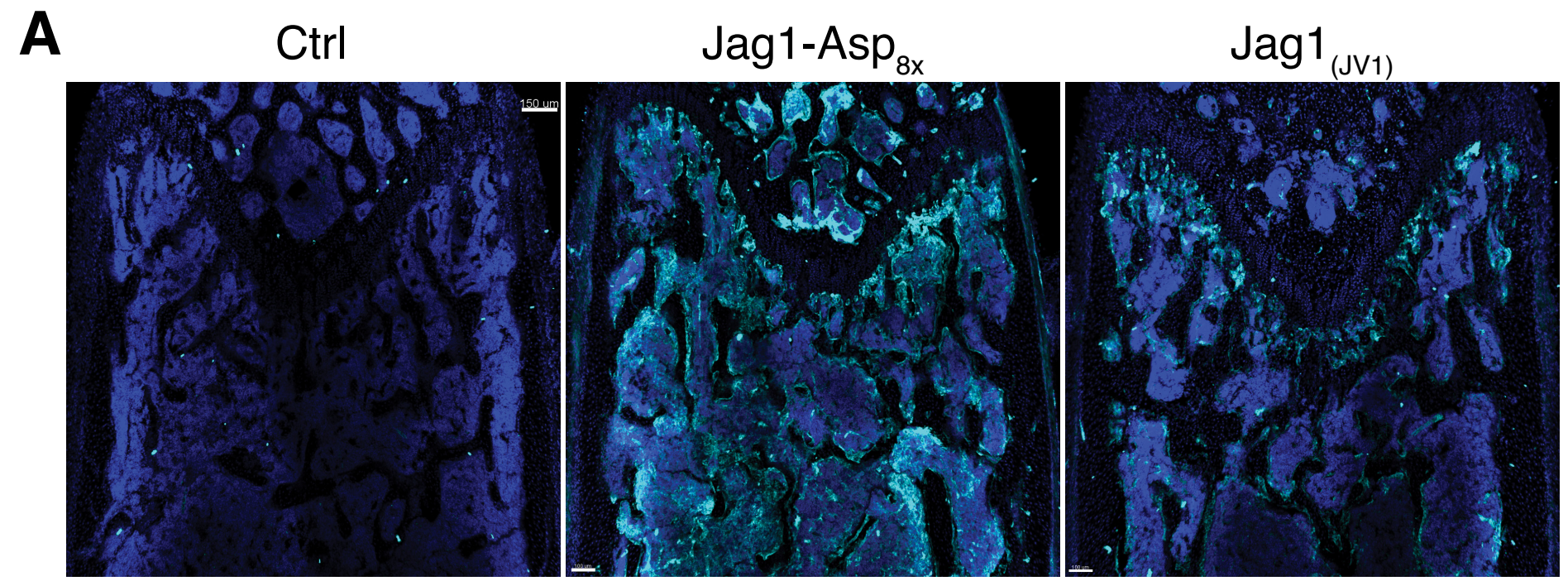

\section{DAPI Jag1}

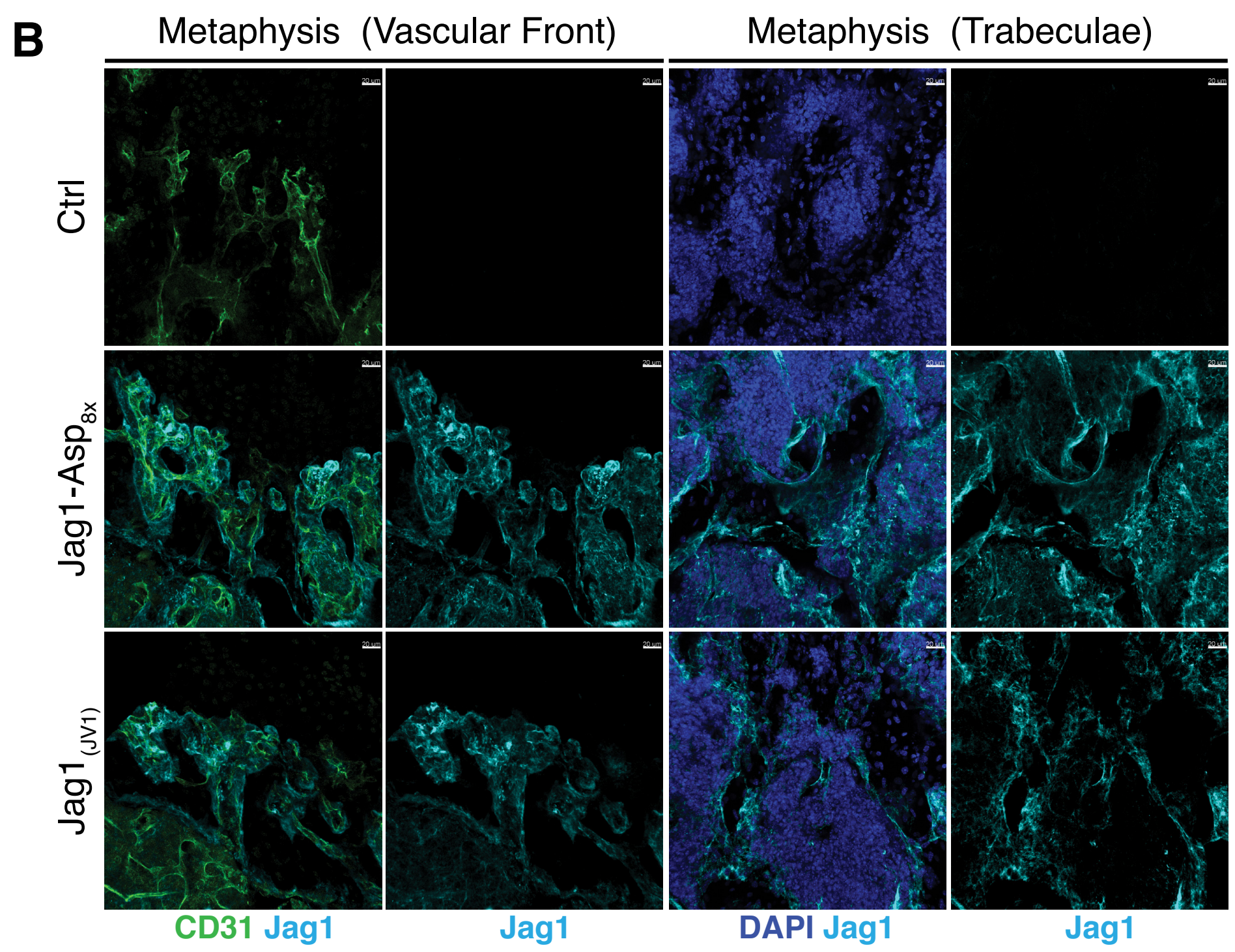

Xu, Dinh et al., Figure 5-figure supplement 2_R1 
A

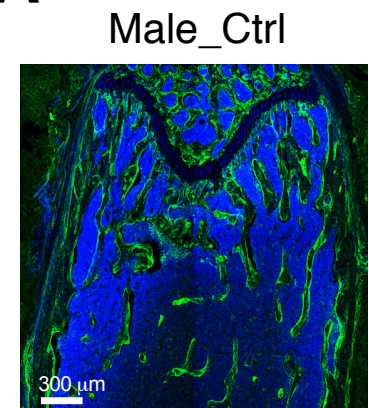

DAPI Col1a1

B

Male_DII4 ${ }_{(E 12)}$

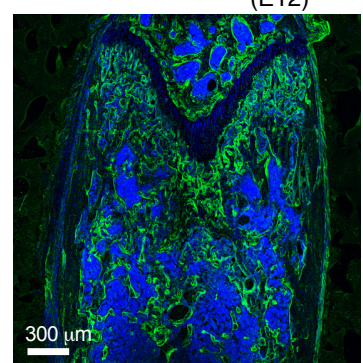

DAPI Col1a1

C

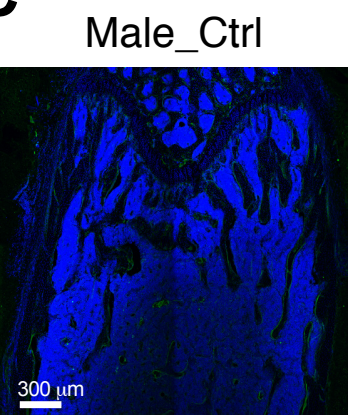

DAPI DII4

D

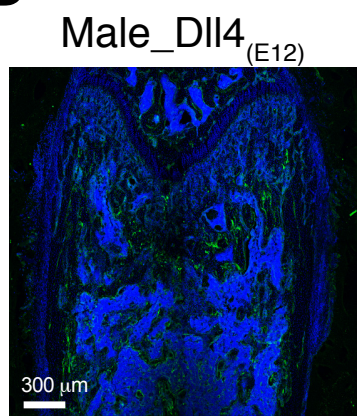

DAPI DII4
Female_Ctrl

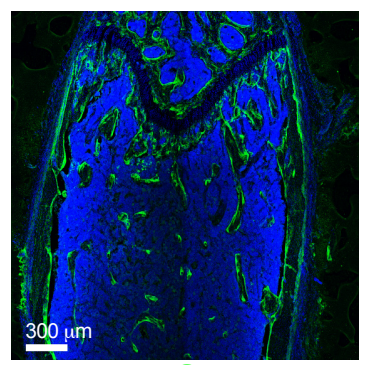

DAPI Col1a1

Female_DII4 ${ }_{(\mathrm{E} 12)}$

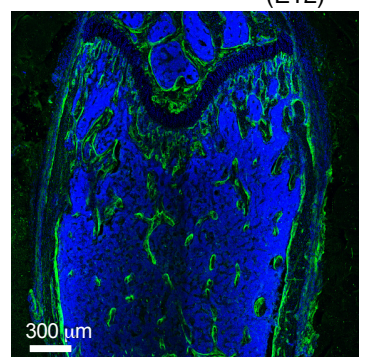

DAPI Col1a1

Female_Ctrl

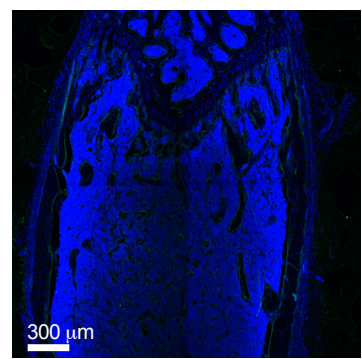

DAPI DII4

Female_Dll4 ${ }_{(\mathrm{E} 12)}$

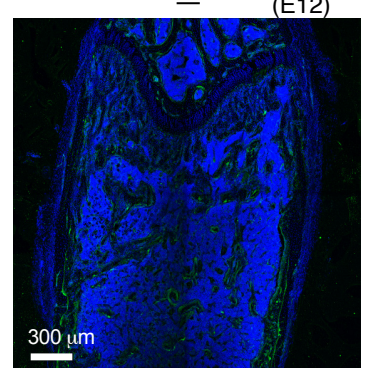

DAPI DII4
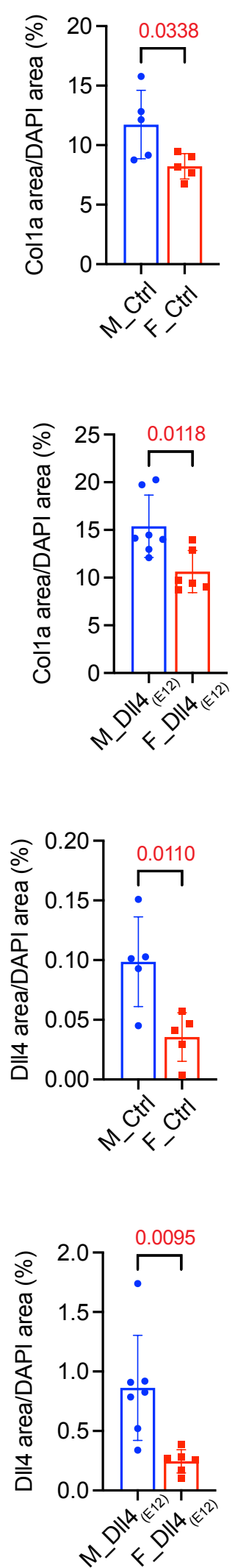

Xu, Dinh et al., Figure 6-figure supplement 1_R1 
A
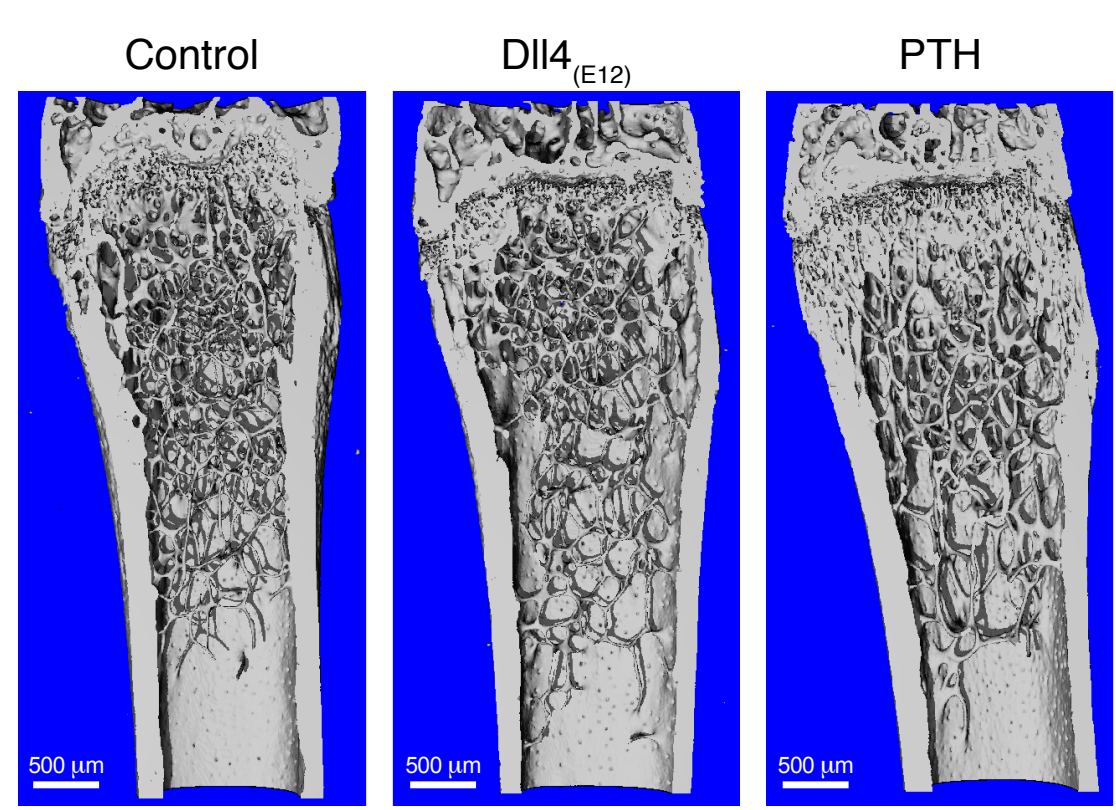

$\mathrm{PTH}+\mathrm{Dll4}$
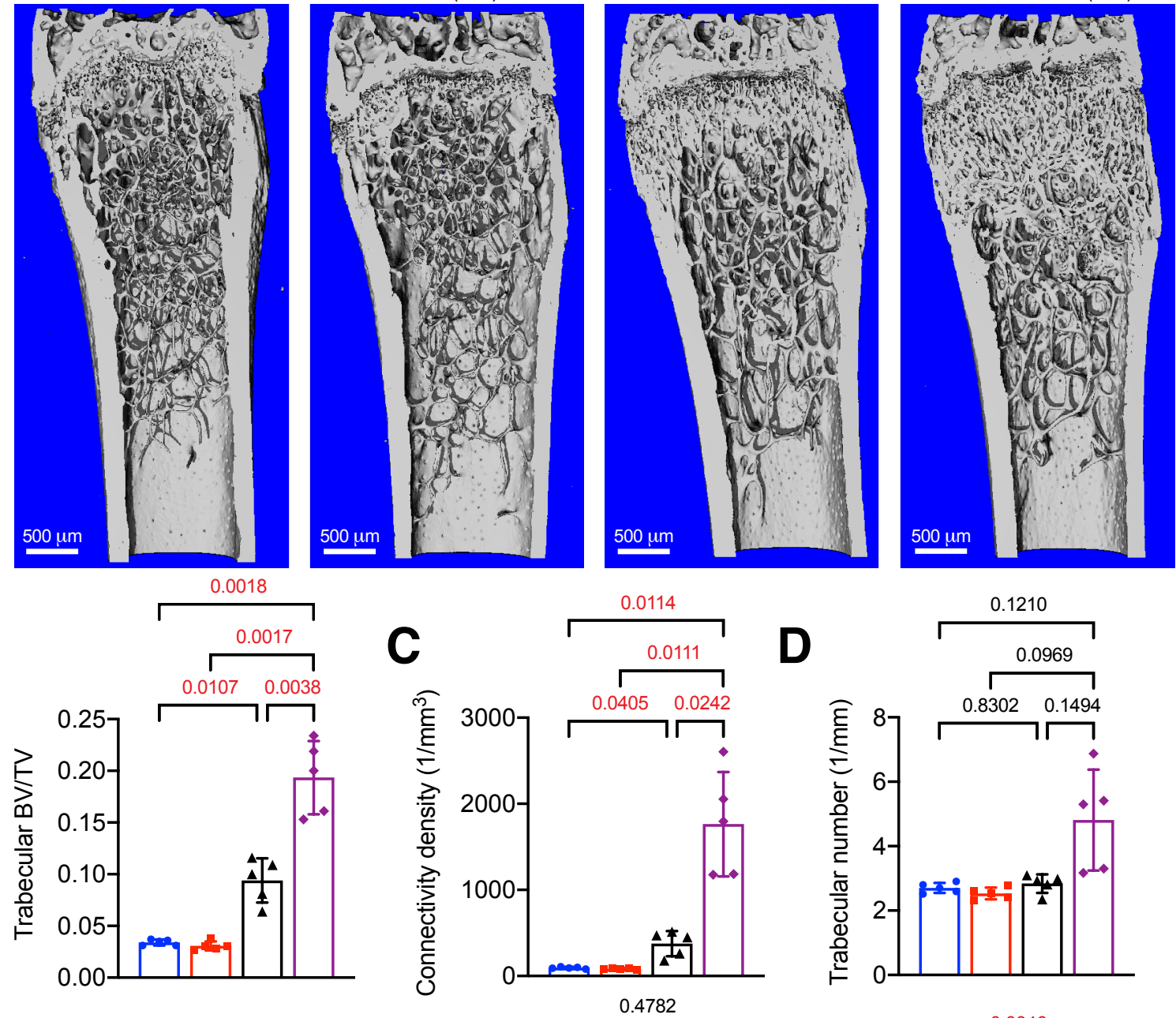

B
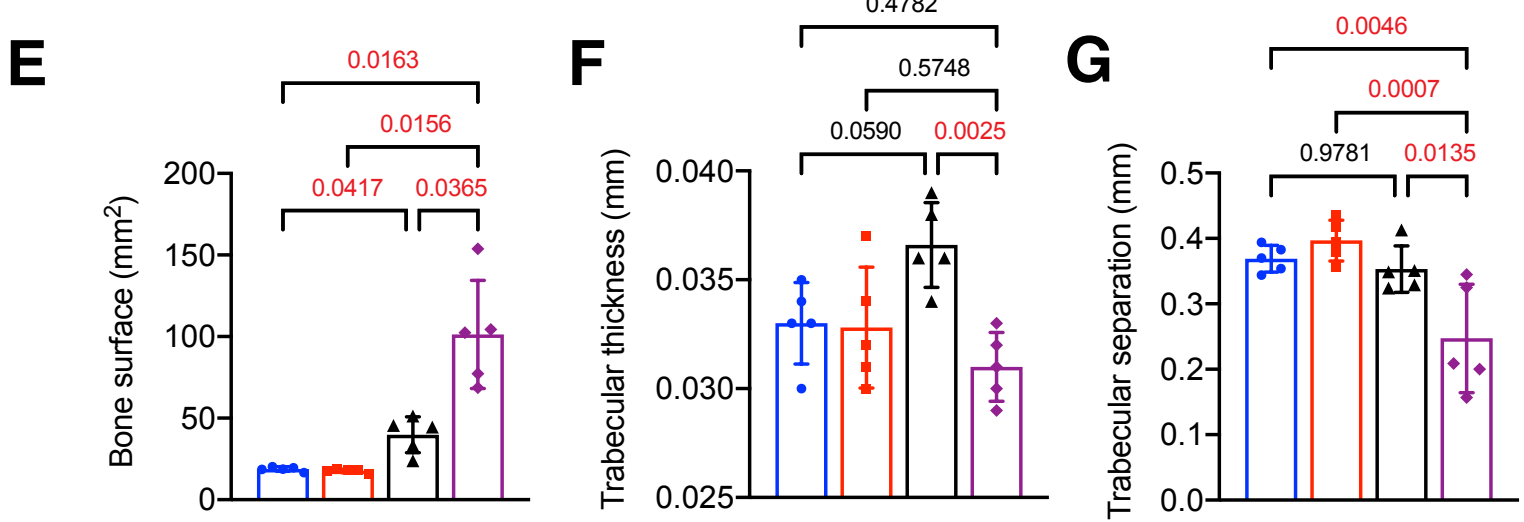

- Control

- DII4 ${ }_{(E 12)}$

A $\mathrm{PTH}$

H Control $\mathrm{DII4}_{(\mathrm{E} 12)}$
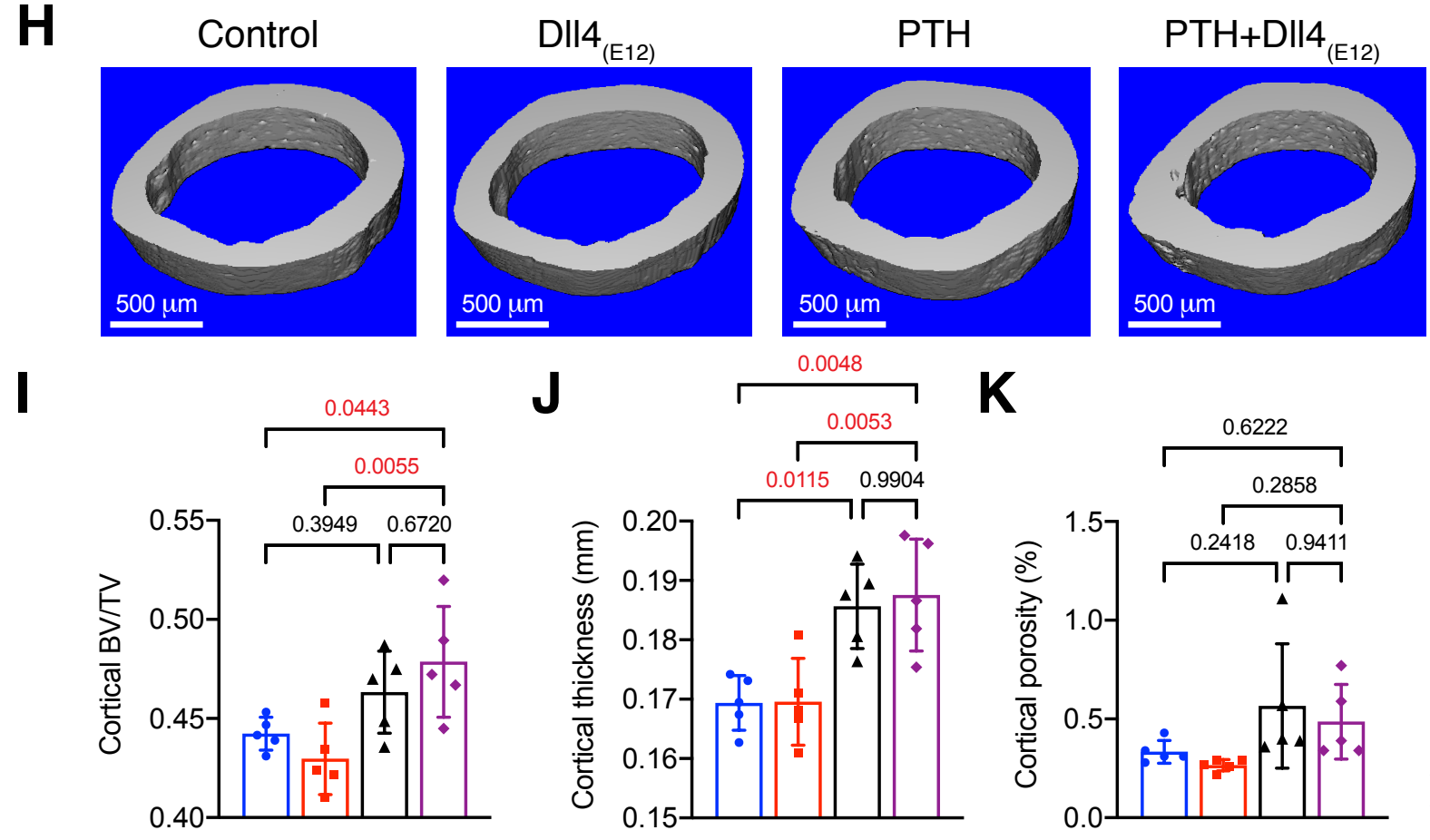

- Control

- DII4 ${ }_{(\mathrm{E} 12)}$

$\triangle \mathrm{PTH}$

- PTH+DII4 ${ }_{(\mathrm{E} 12)}$

Xu, Dinh et al., Figure 7_R1 
A

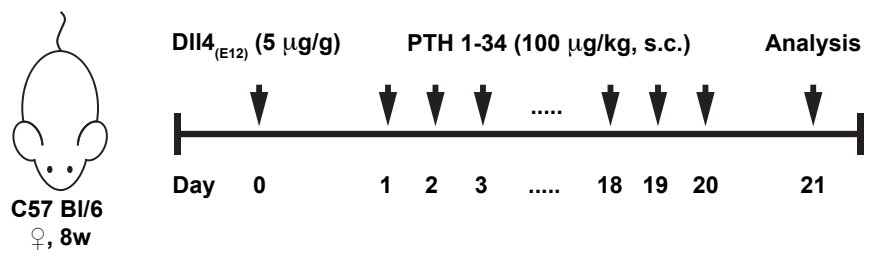

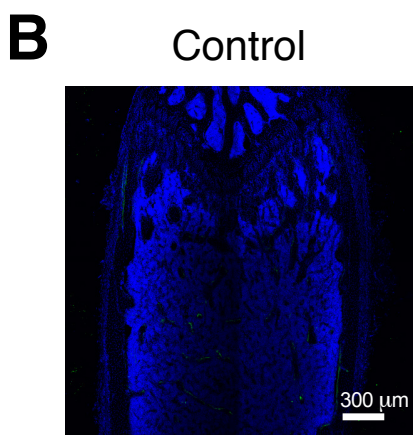

DAPI D\|I4
DII4

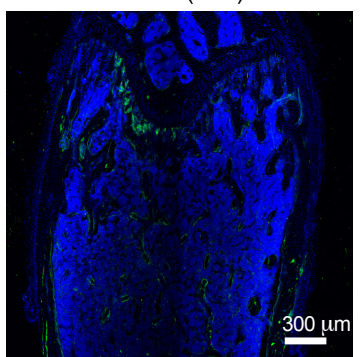

DAPI DII4
PTH

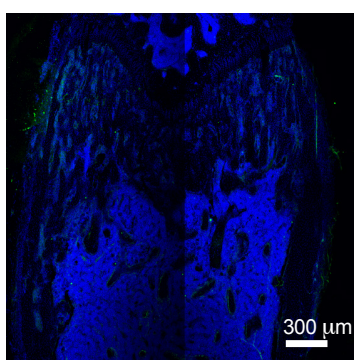

DAPI DII4

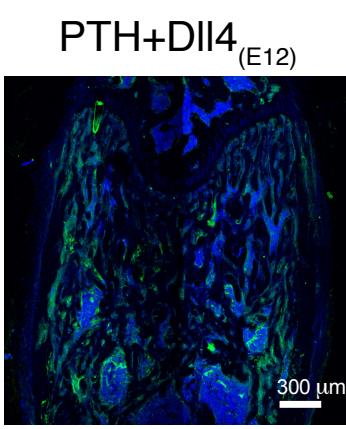

DAPI DII4

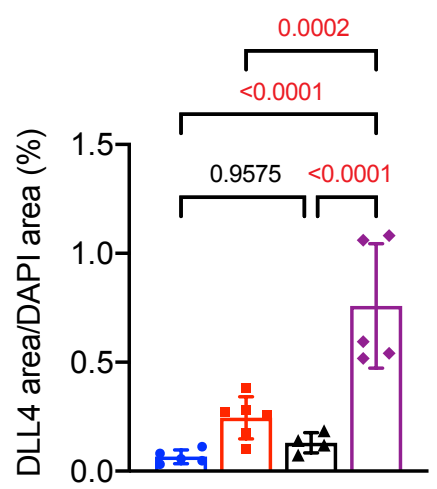

C

Control

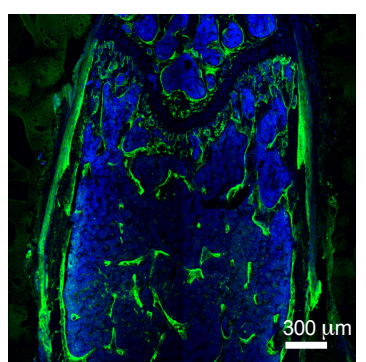

DAPI Col1a
$\mathrm{DII4}_{(\mathrm{E} 12)}$

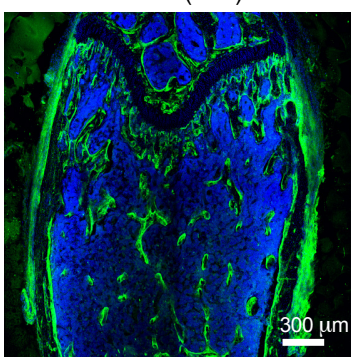

DAPI Col1a

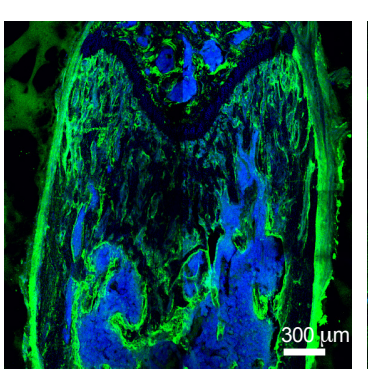

DAPI Col1a

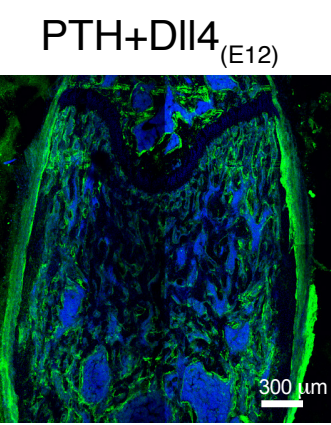

DAPI Col1a

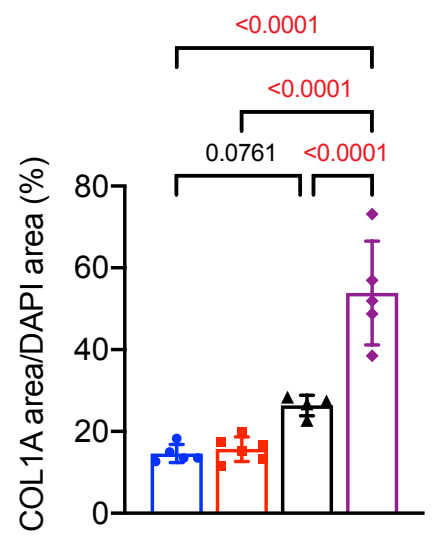

D

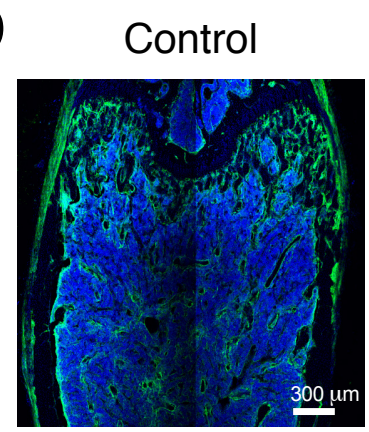

DAPI PDGFR $\beta$

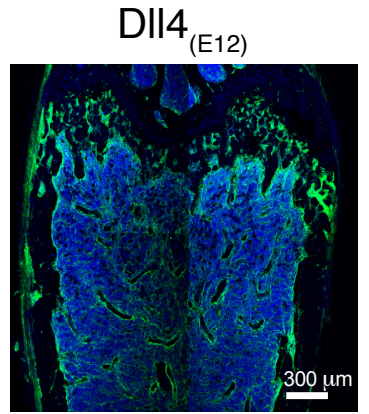

DAPI PDGFR $\beta$

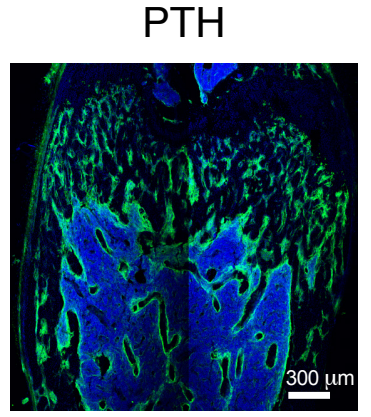

DAPI PDGFR $\beta$

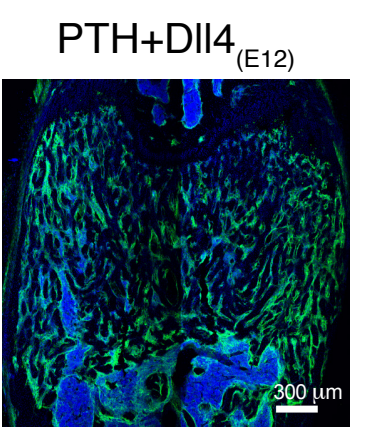

DAPI PDGFR $\beta$

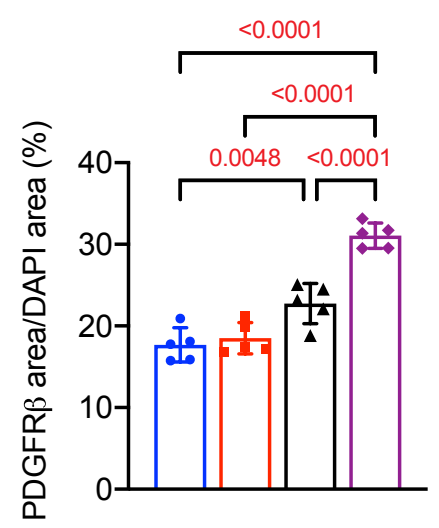

E

Control

DII4

PTH

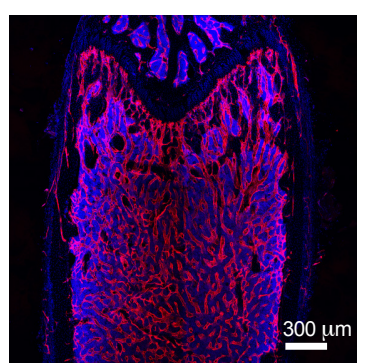

DAPI EMCN

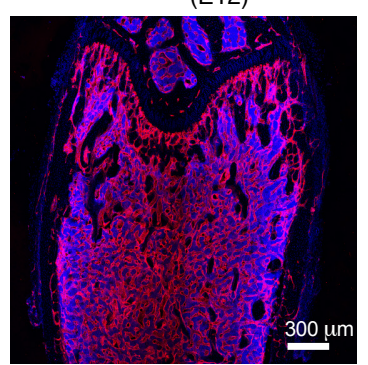

DAPI EMCN

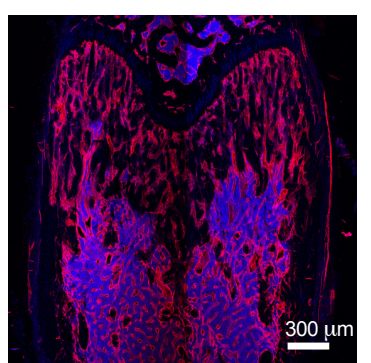

DAPI EMCN

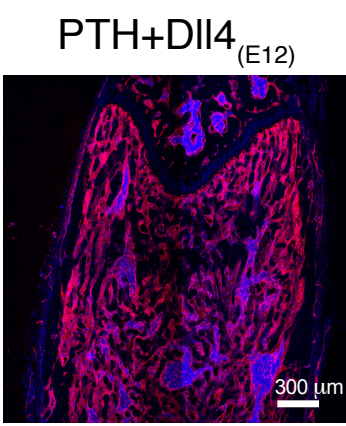

DAPI EMCN

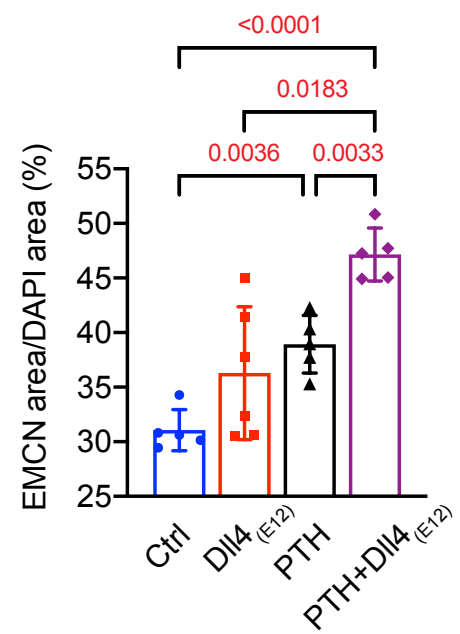

Xu, Dinh et al., Figure 7-figure supplement 1_R1 

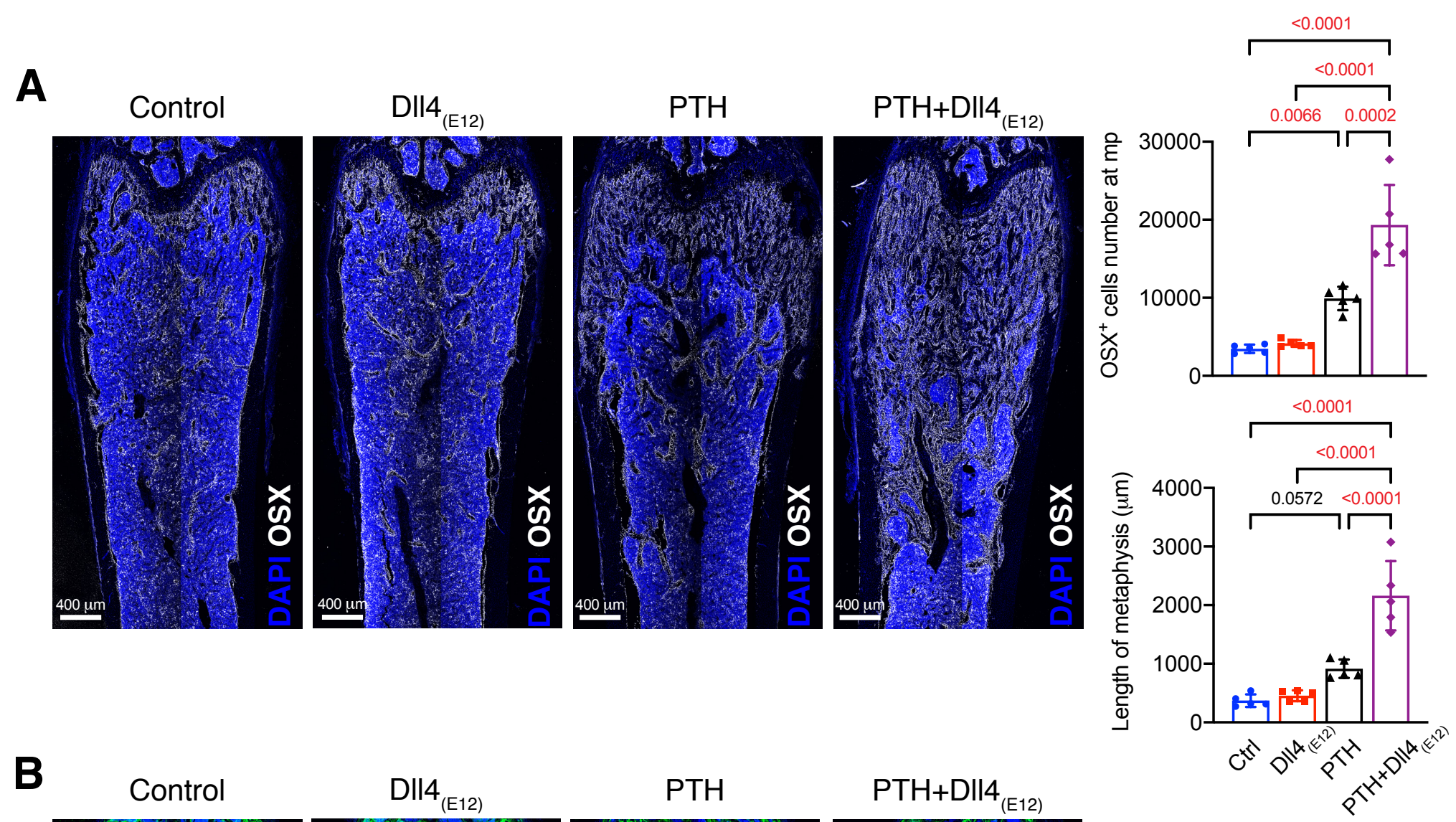

B
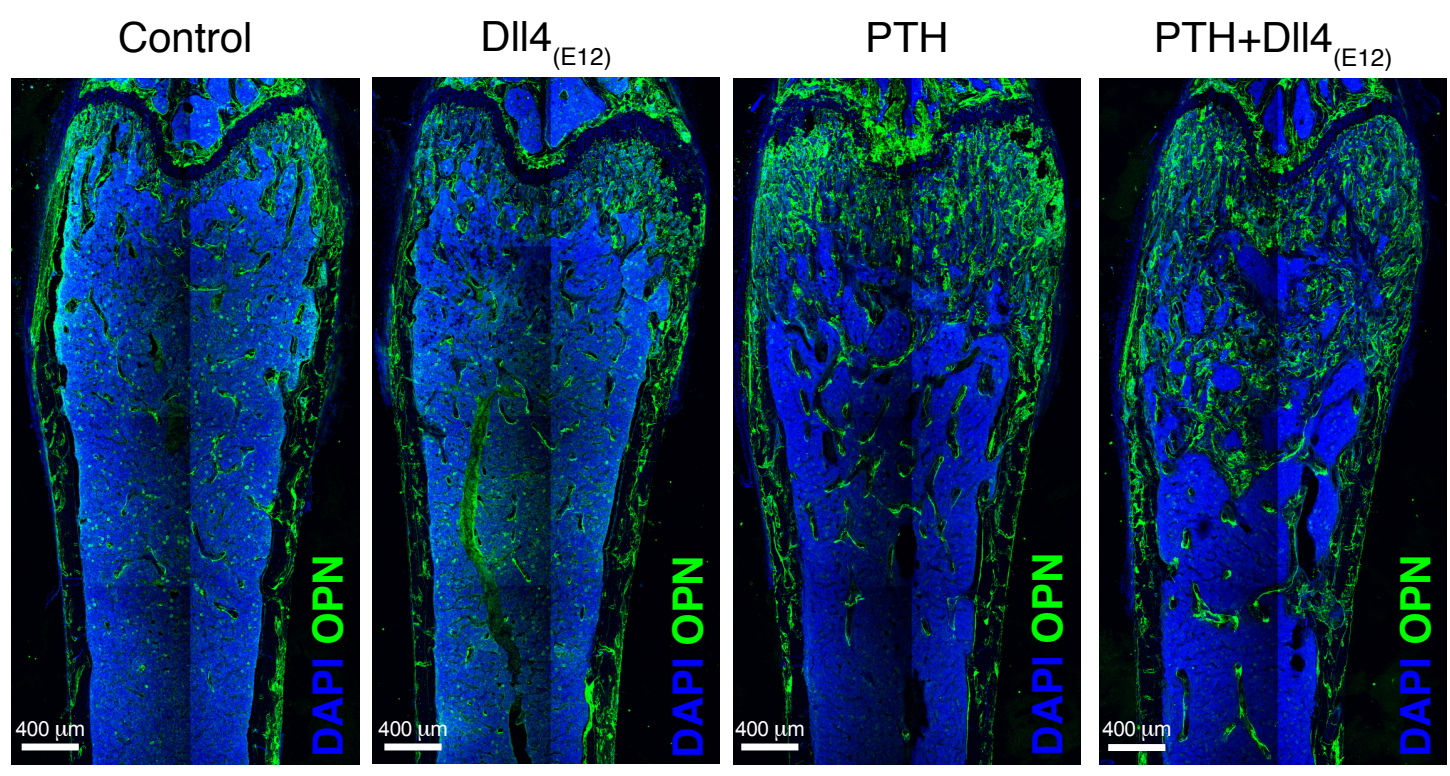

Xu, Dinh et al., Figure 7-figure supplement 2_R1

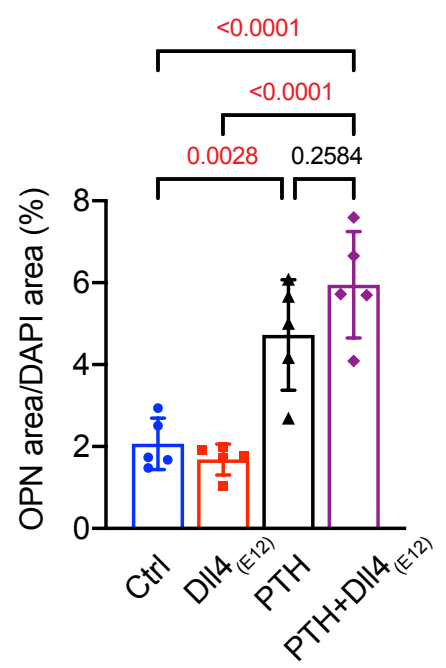


A

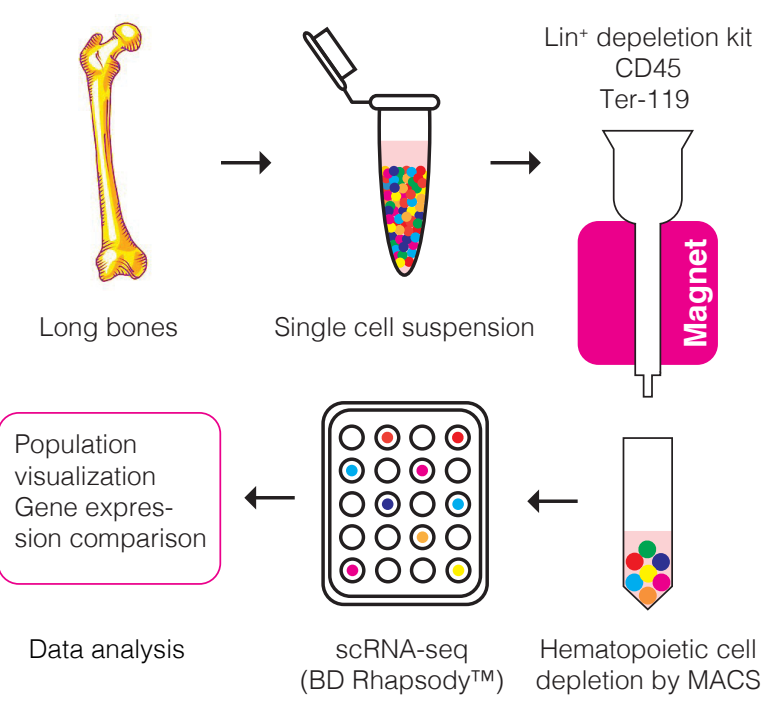

B

C Control DII4

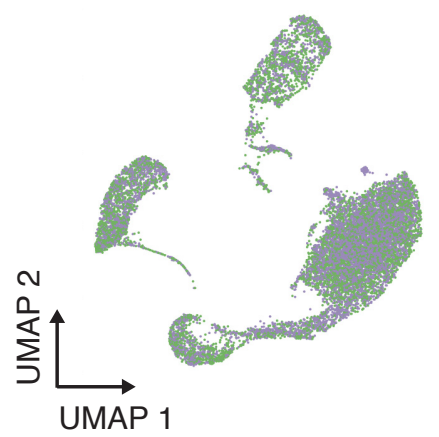

F

ECs

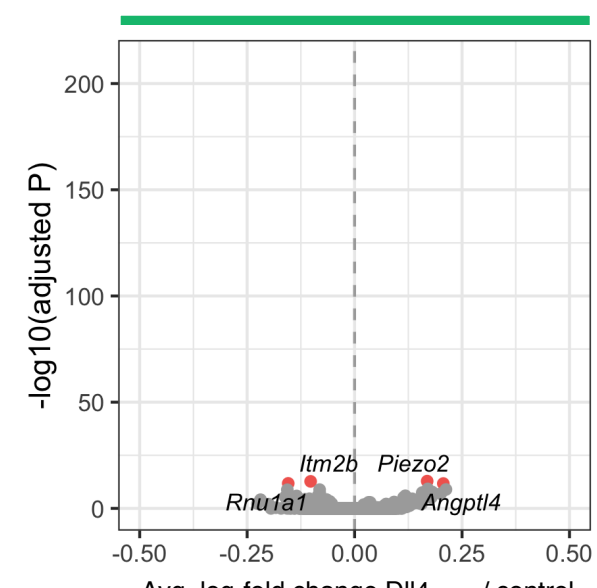

I
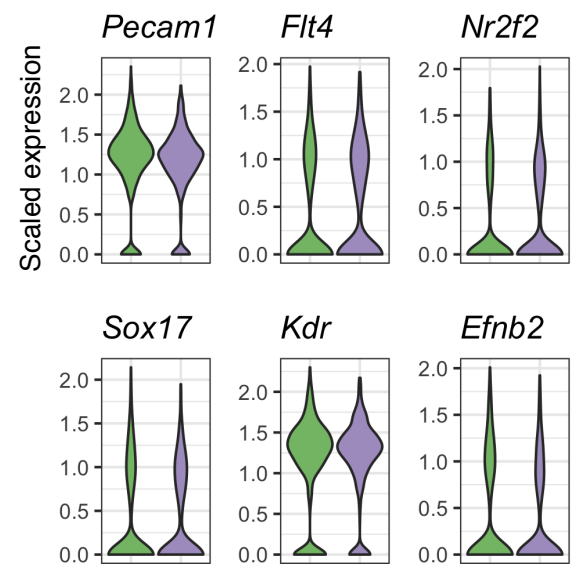
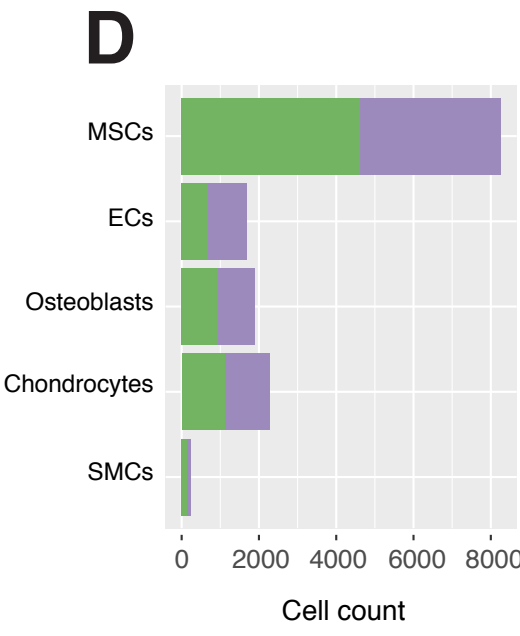

G

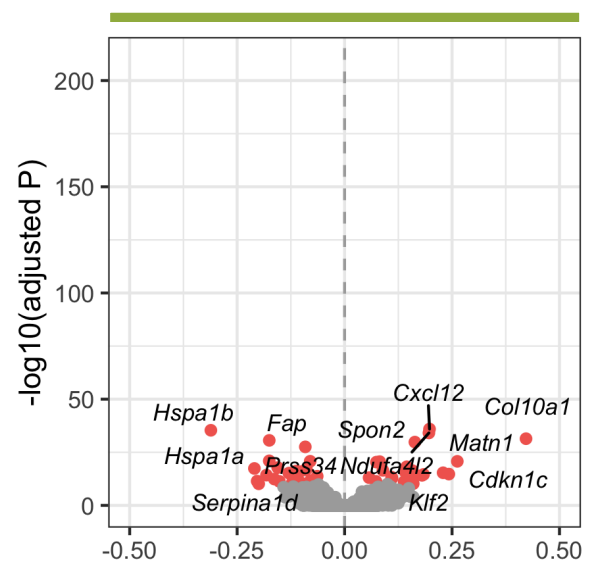

J
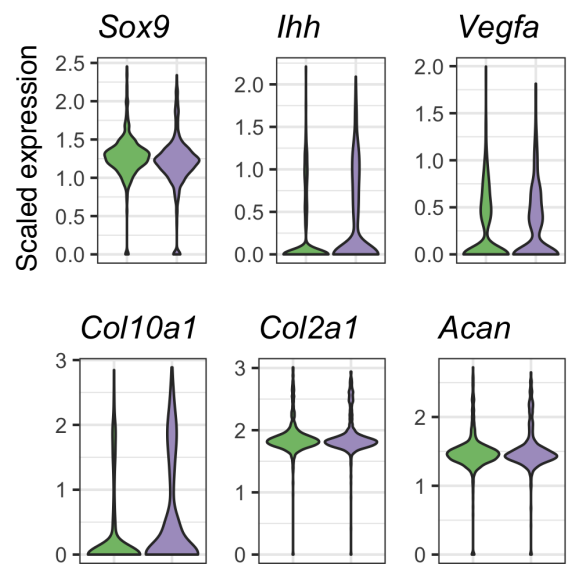
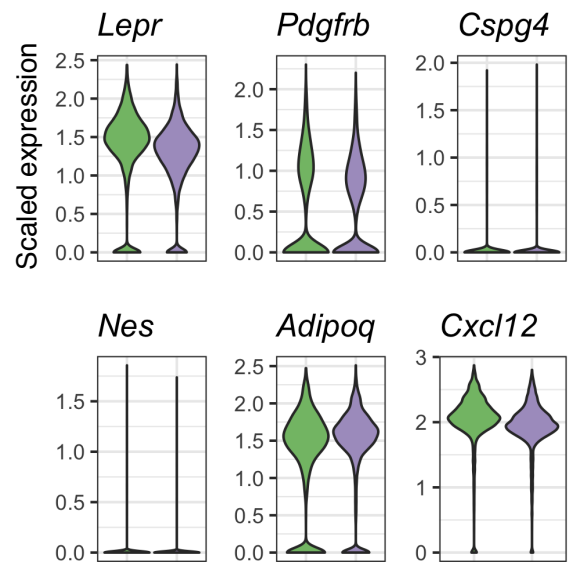

Expression
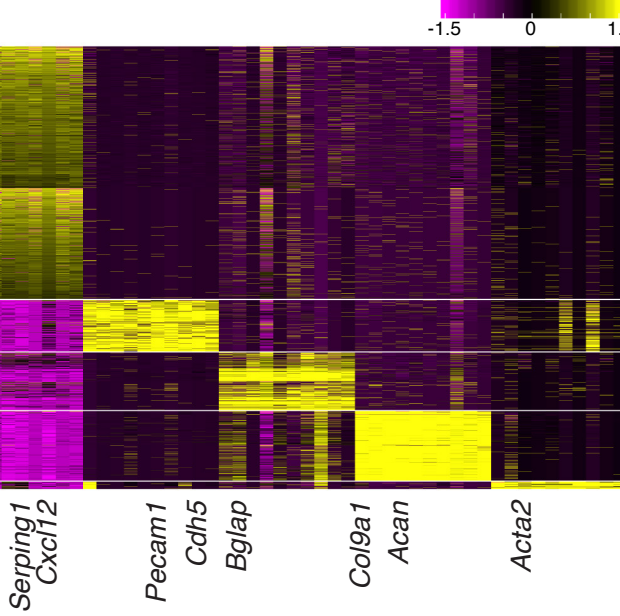

H MSCs
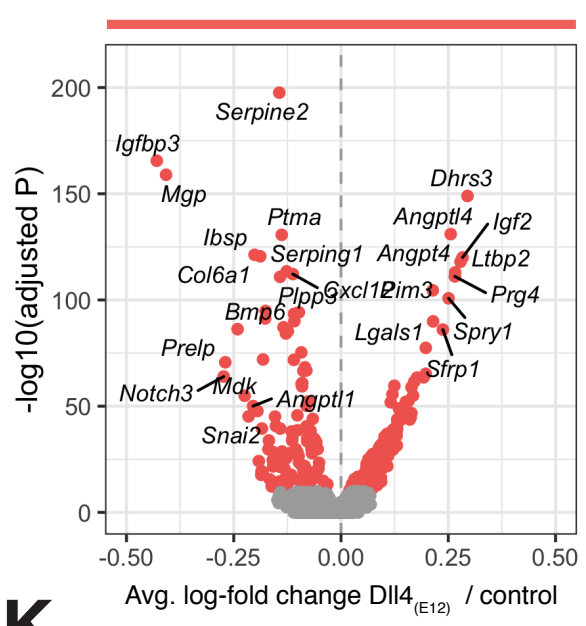

Control DII4 


\section{Control (unfiltered)}
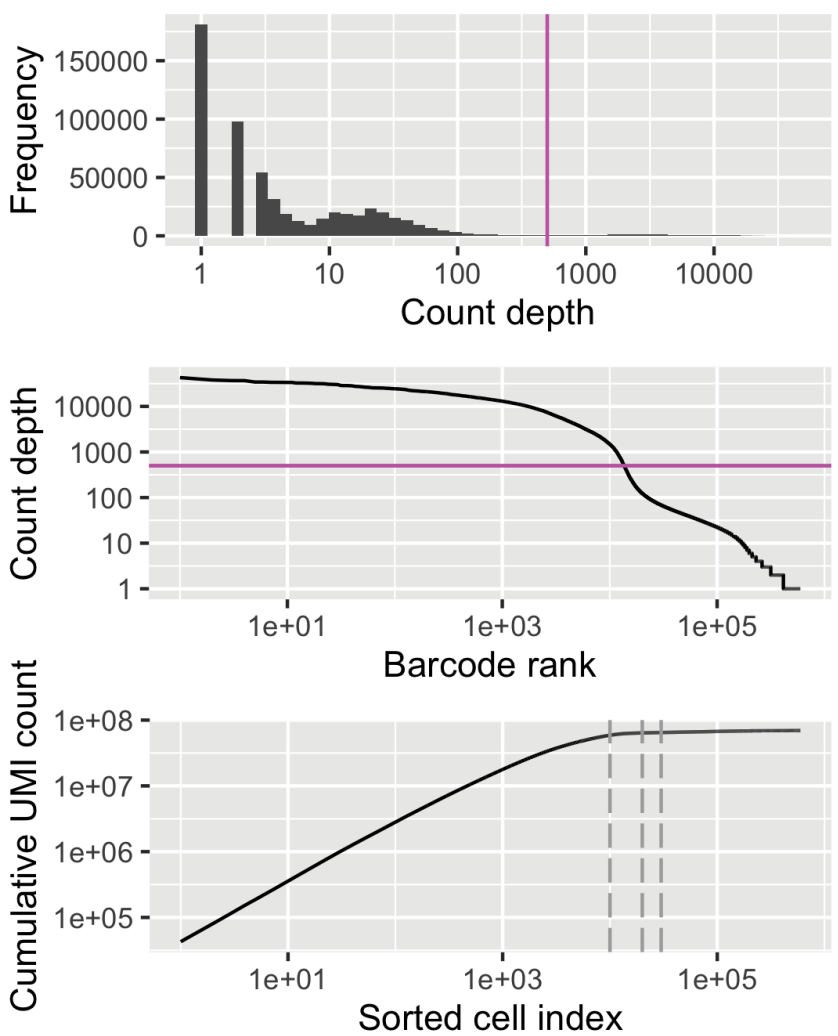

$D \| 4_{(E 12)}$ (unfiltered)
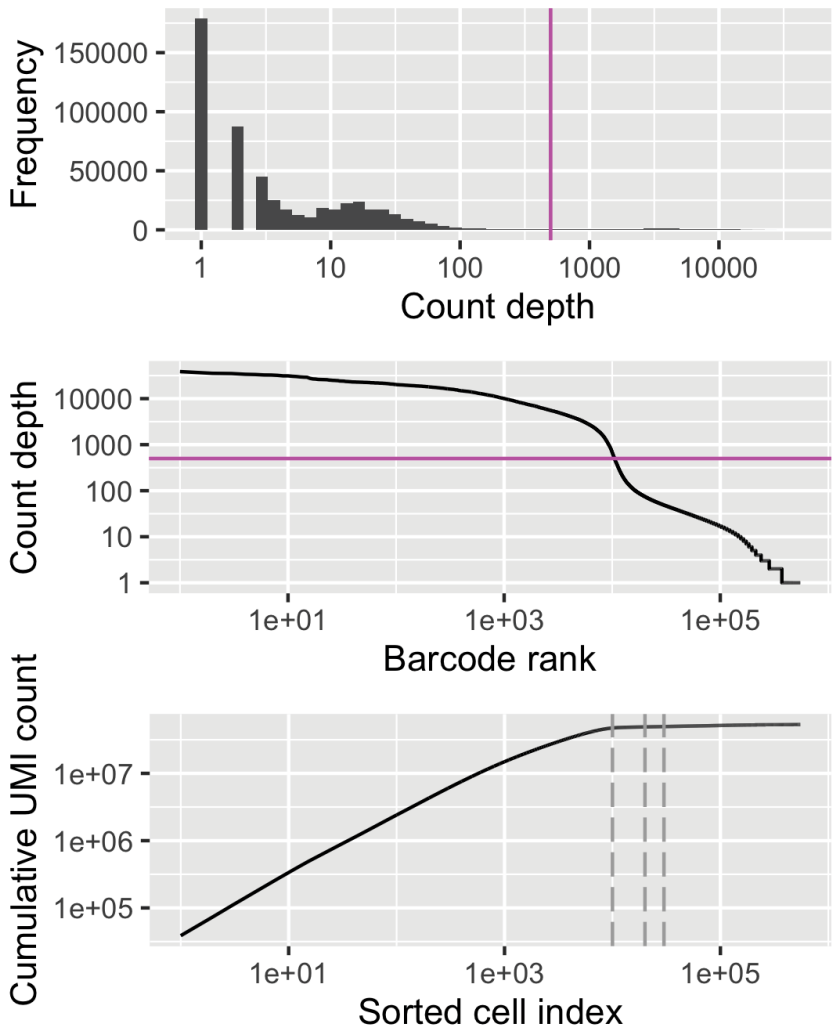

\section{Control (filtered)}
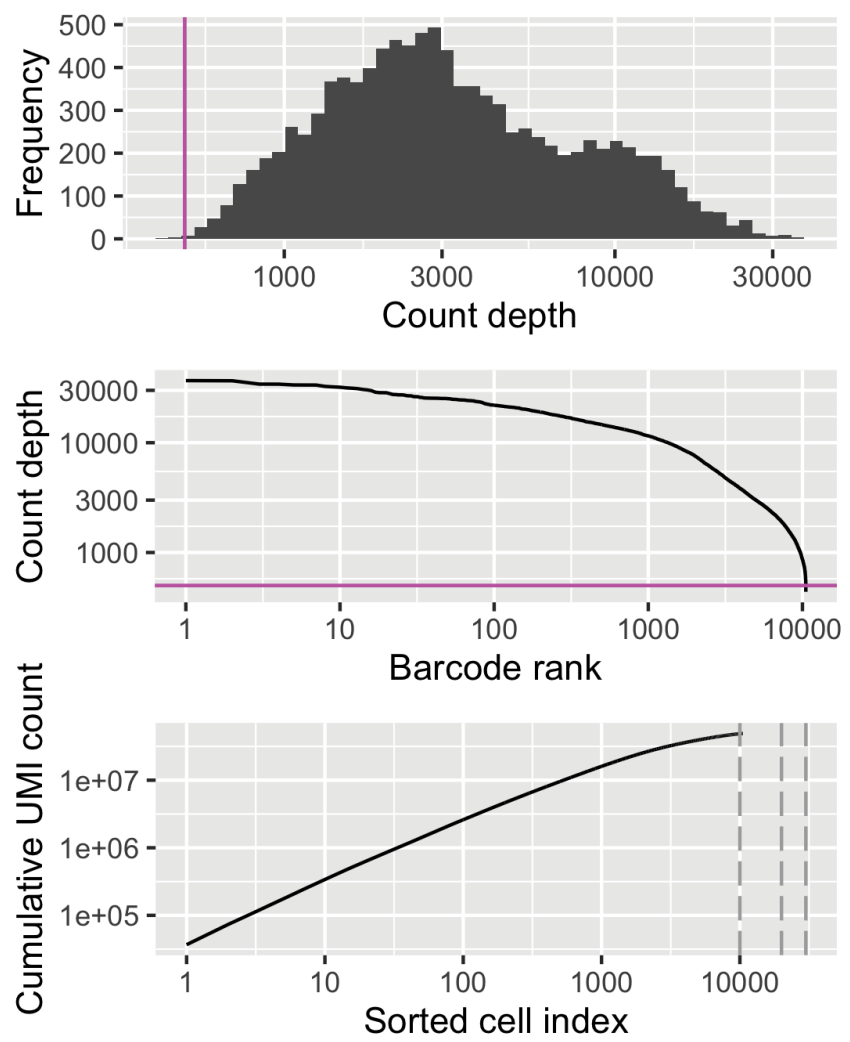

D

DII4 ${ }_{(E 12)}($ filtered)
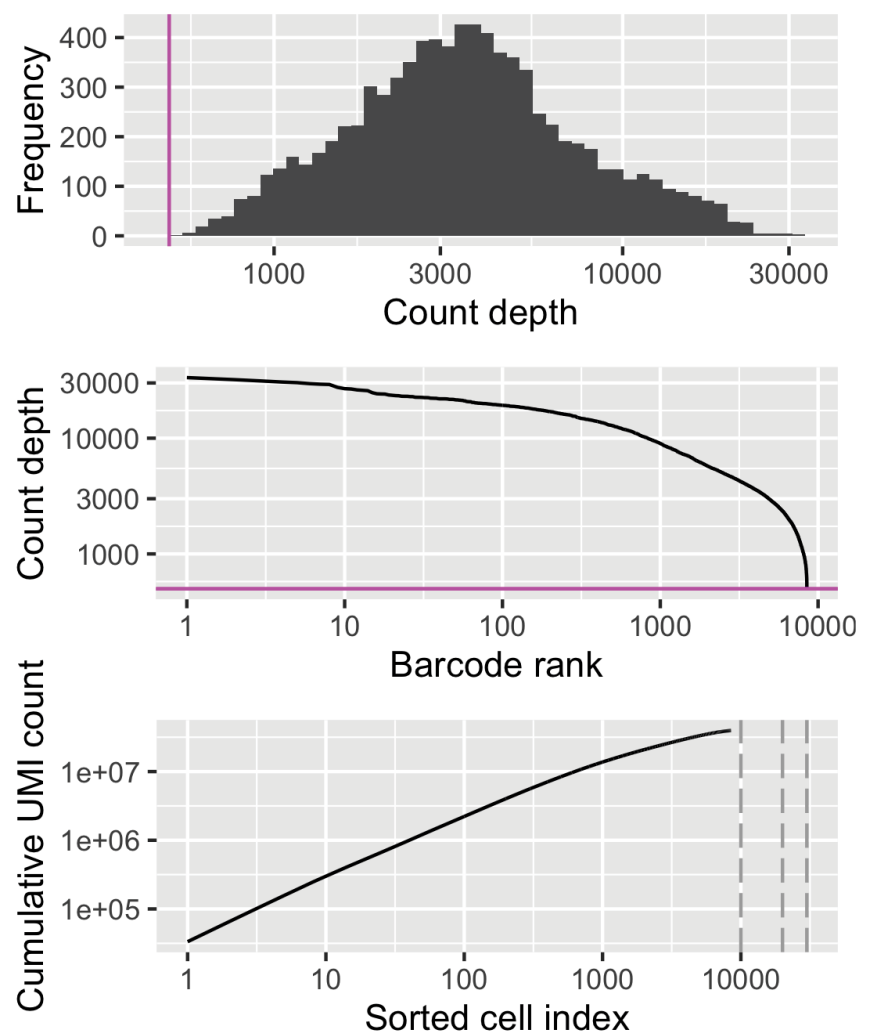
A
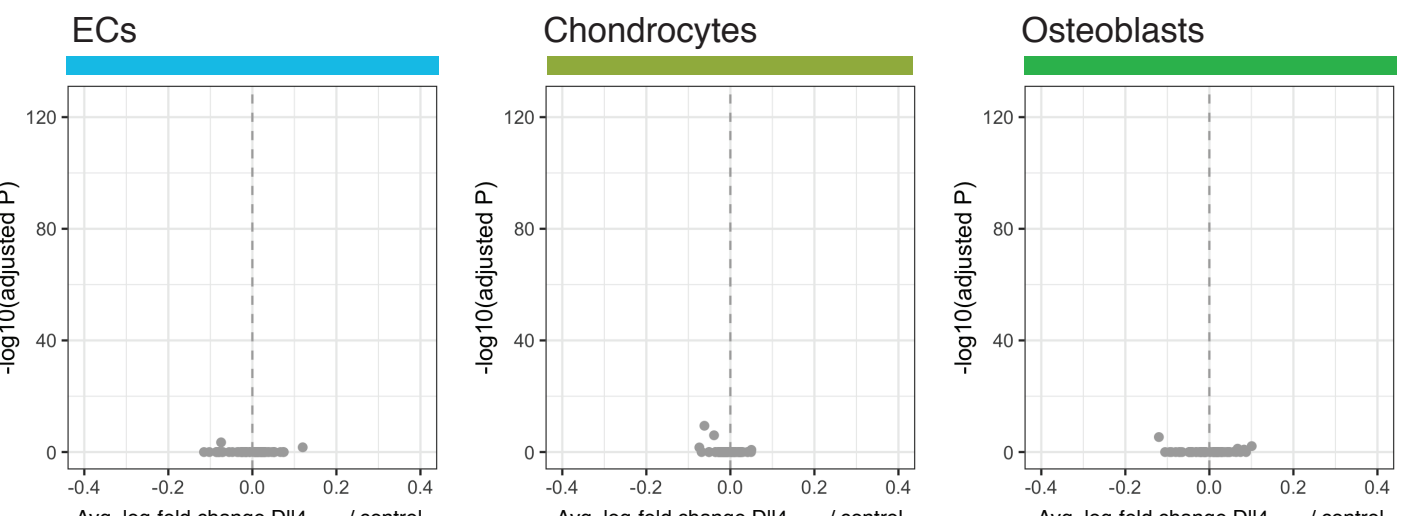

MSCs

Avg. log-fold change DII4 $4_{(E 12)} /$ contro

Avg. log-fold change DII4 $4_{(E 12)} /$ control

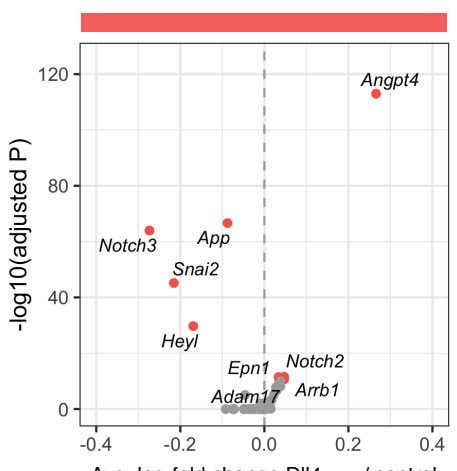

B
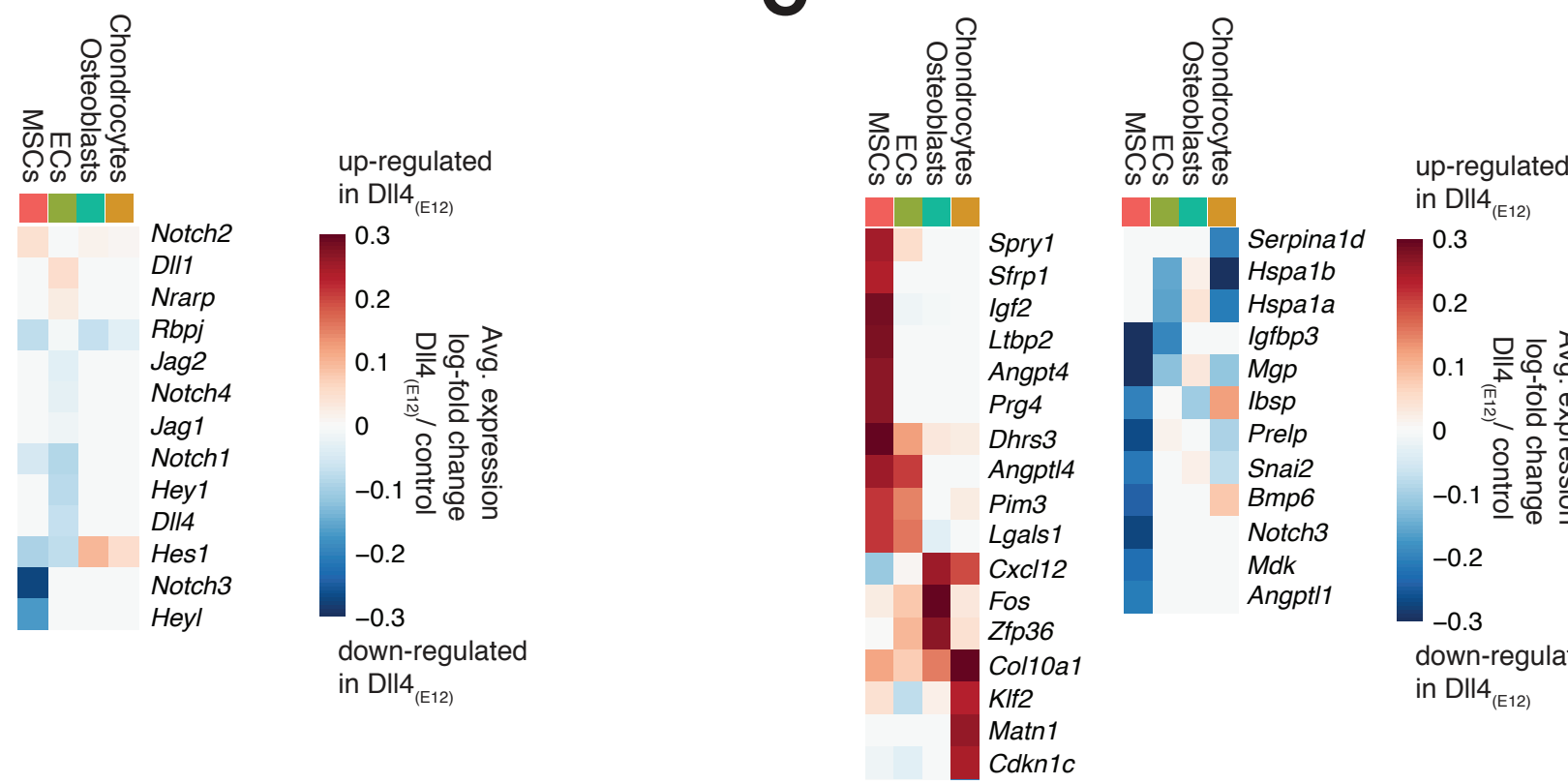

in DII4

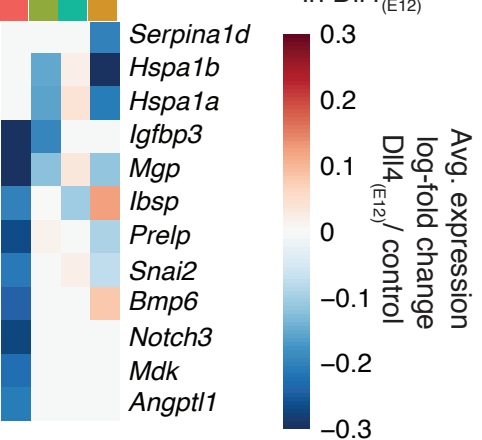

down-regulated in DII4

D
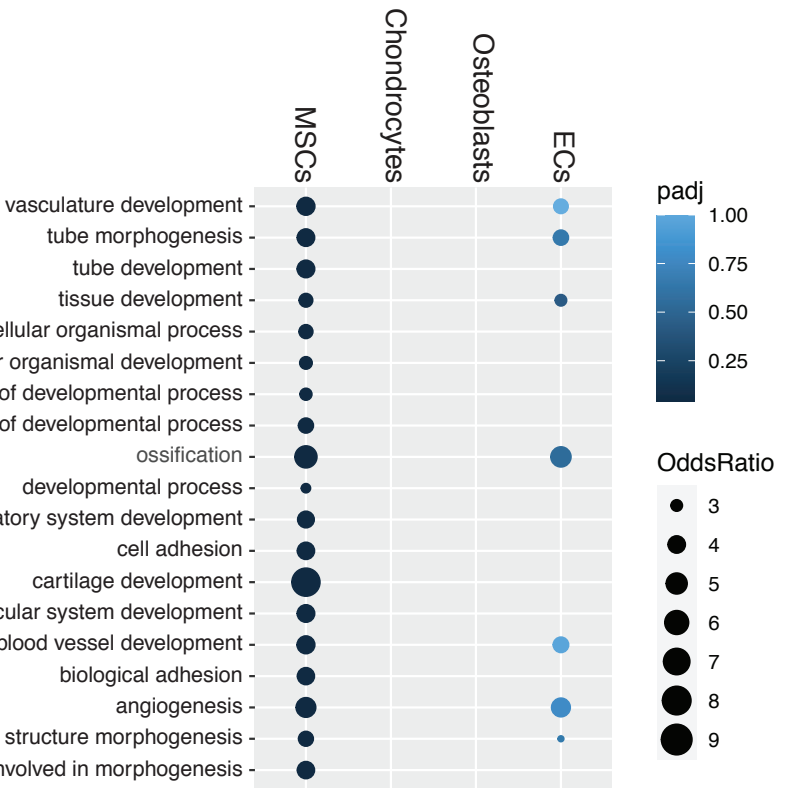

E

regulation of multicellular ord

regulation of developmental process

positive regulation of developmental process circulatory system development -

vessel development

angiogenesis

anatomical structure morphogenesis -

anatomical structure formation involved in morphogenesis -

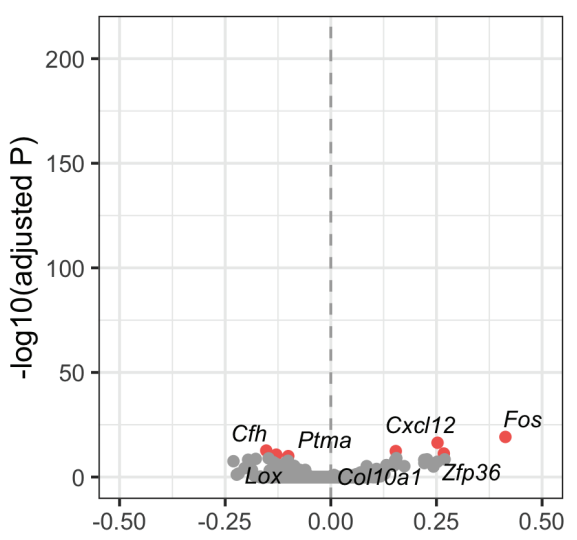

Avg. log-fold change DII4 ${ }_{(E 12)} /$ control

\section{Xu, Dinh et al., Figure 8-figure supplement 2_R1}


A

B
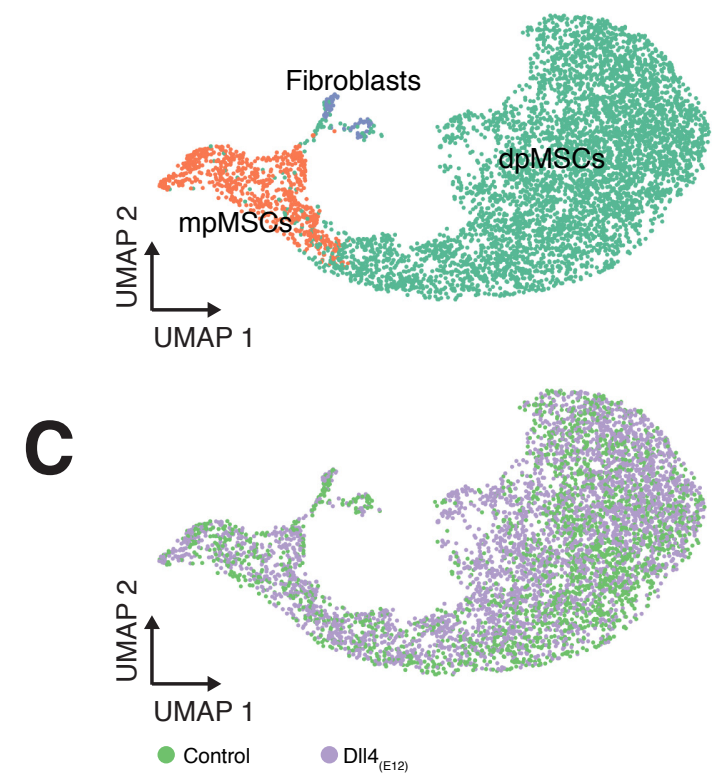

D

E
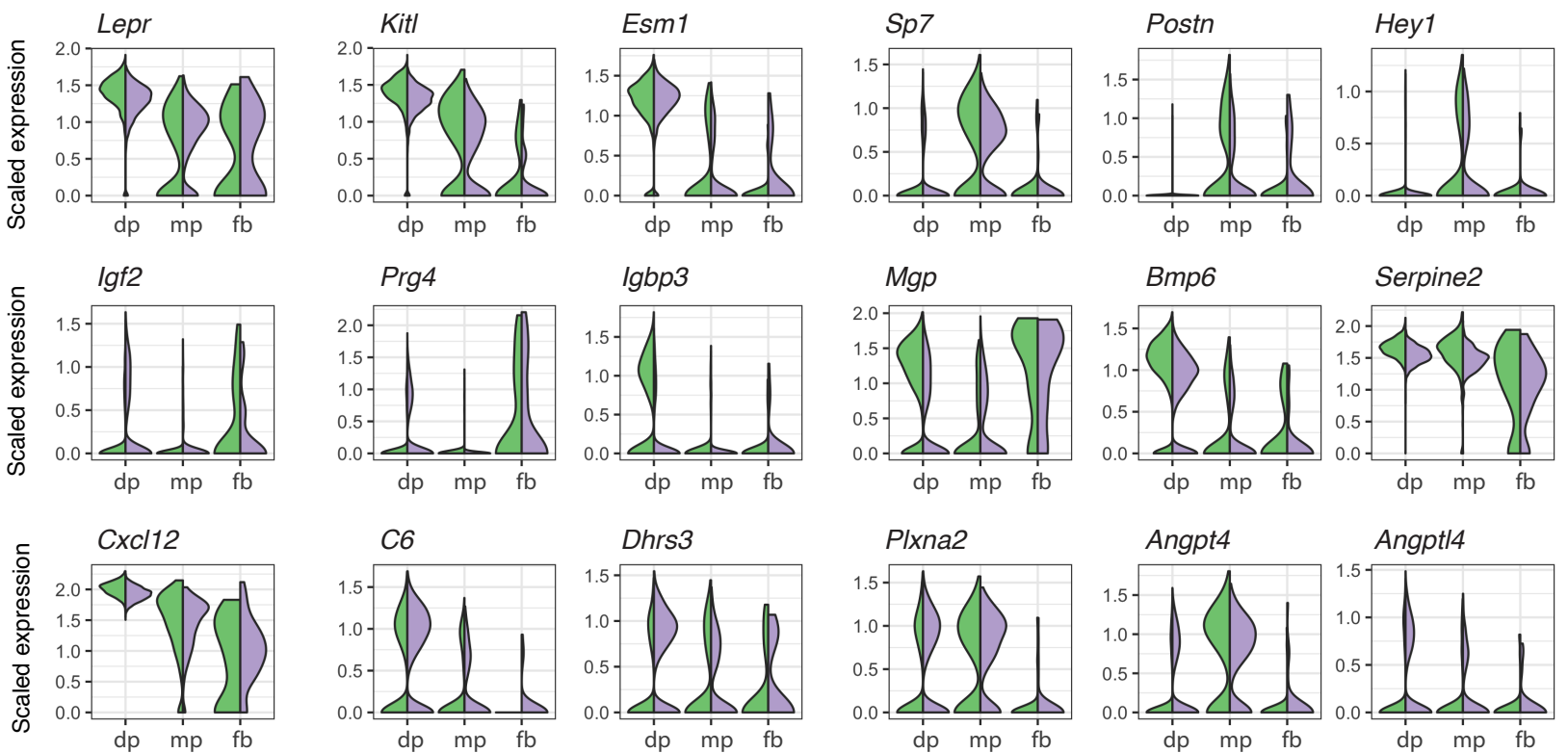

$\mathbf{F}$

$S p 7$

Control
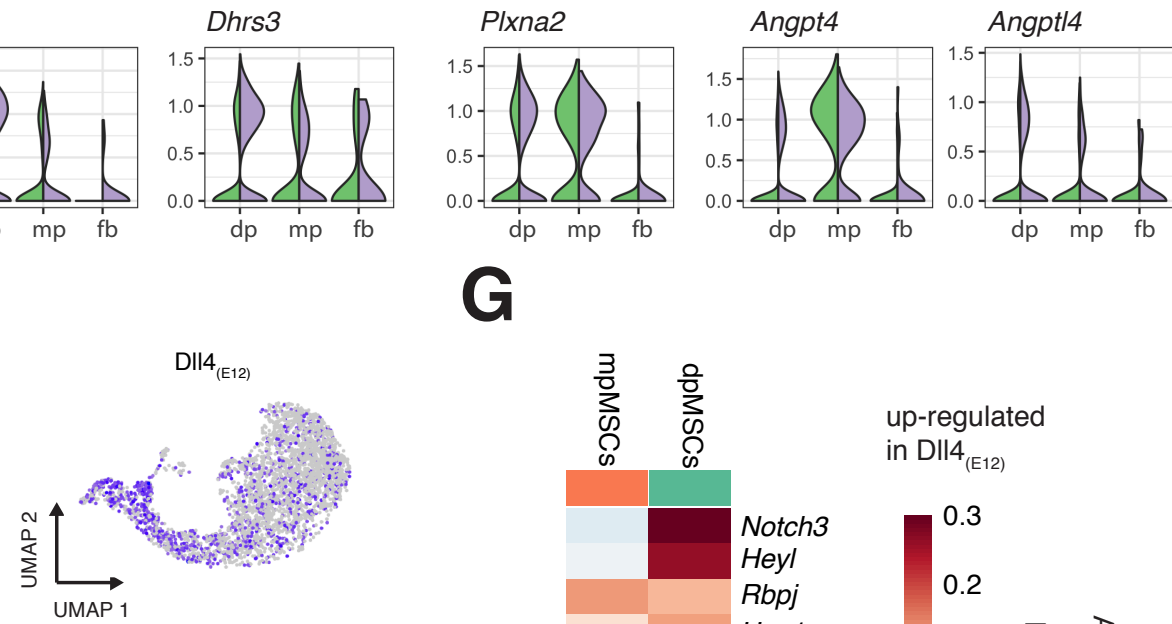

\section{$\mathbf{G}$}
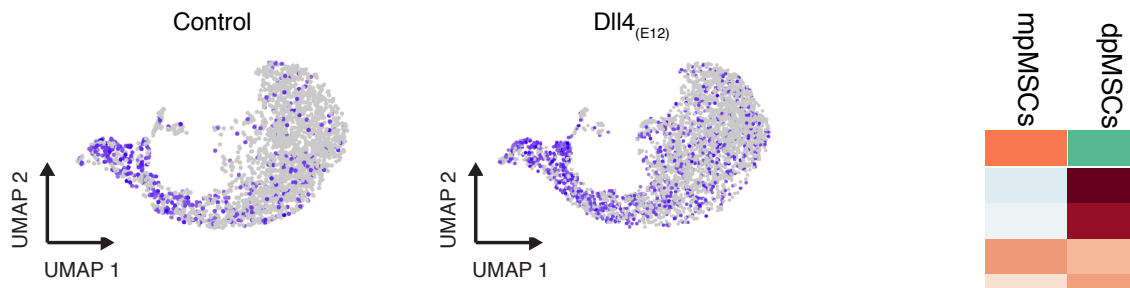

up-regulated in DII4

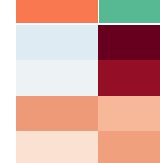

Hey1
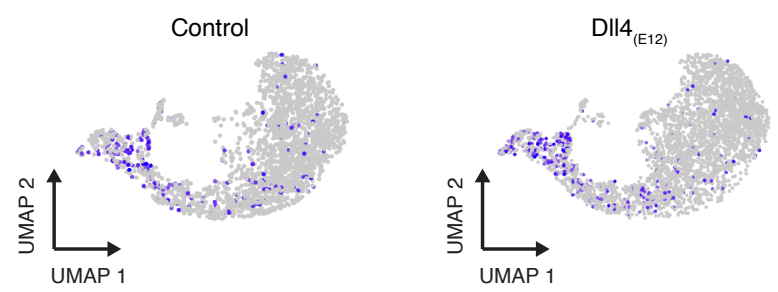